
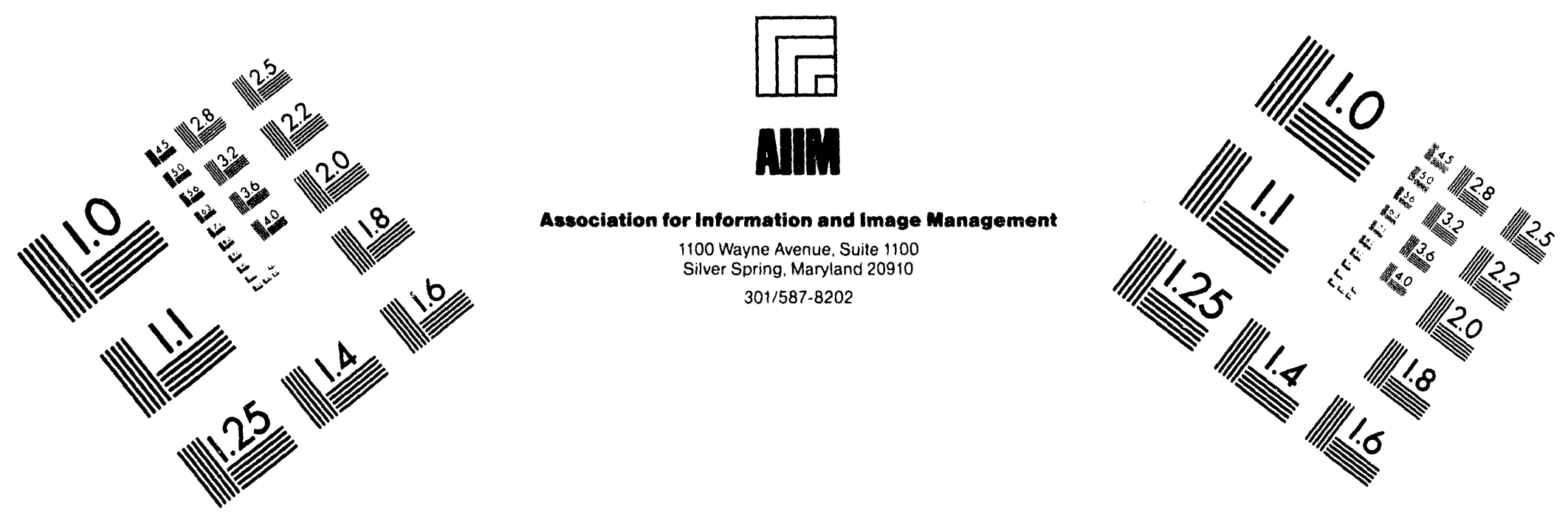

\title{
Centimeter
}

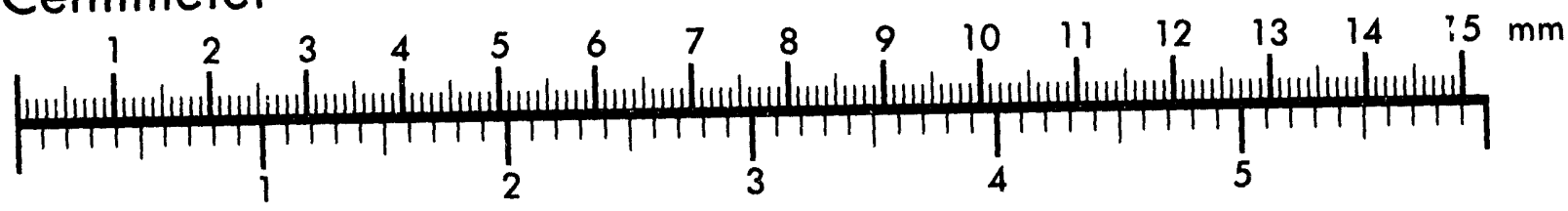
Inches
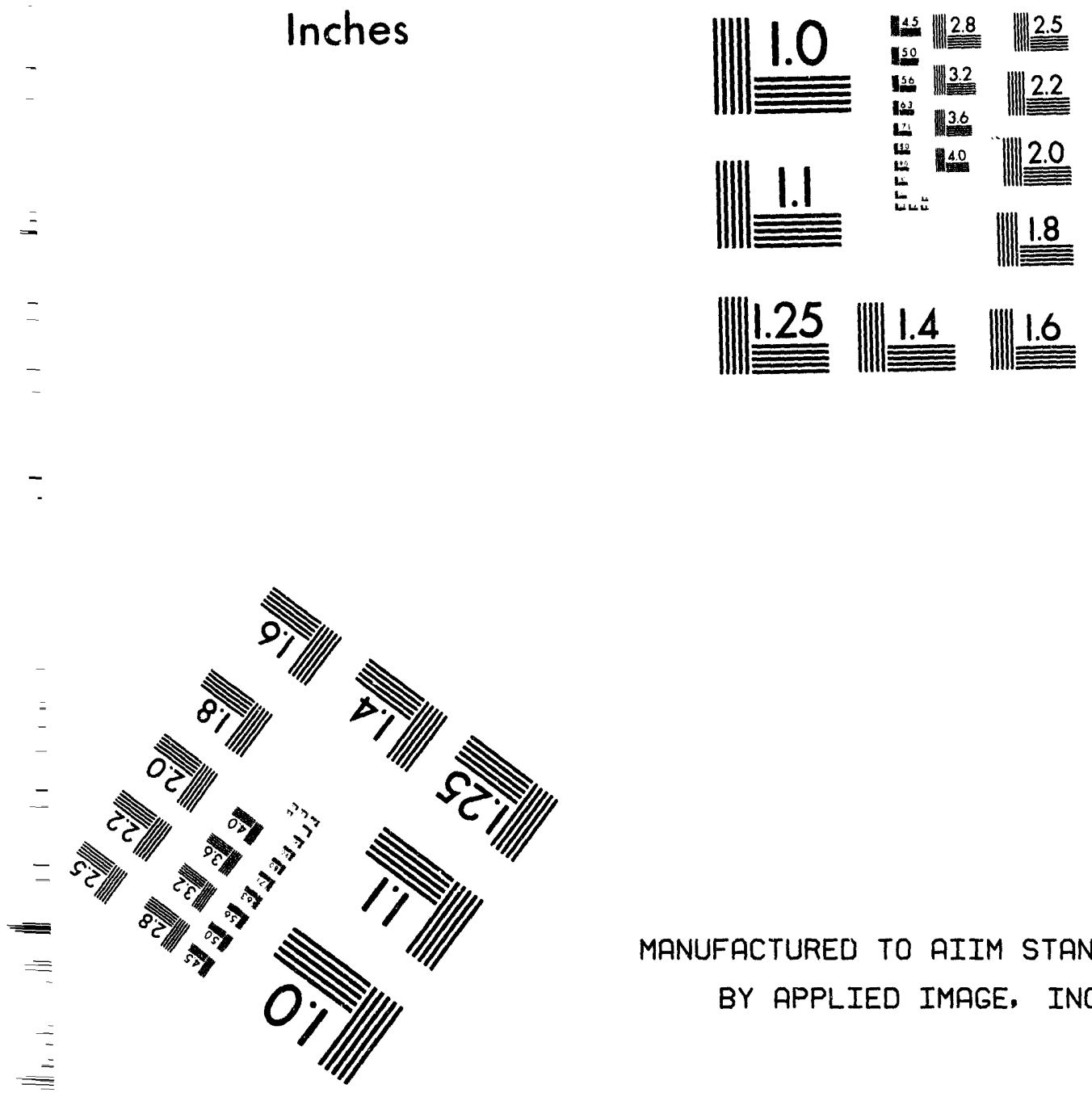

MANUFACTURED TO AIIM STANDARDS

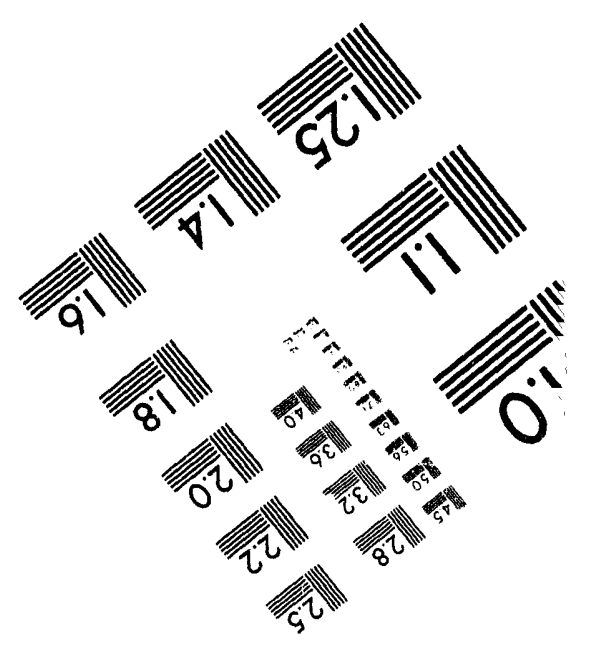



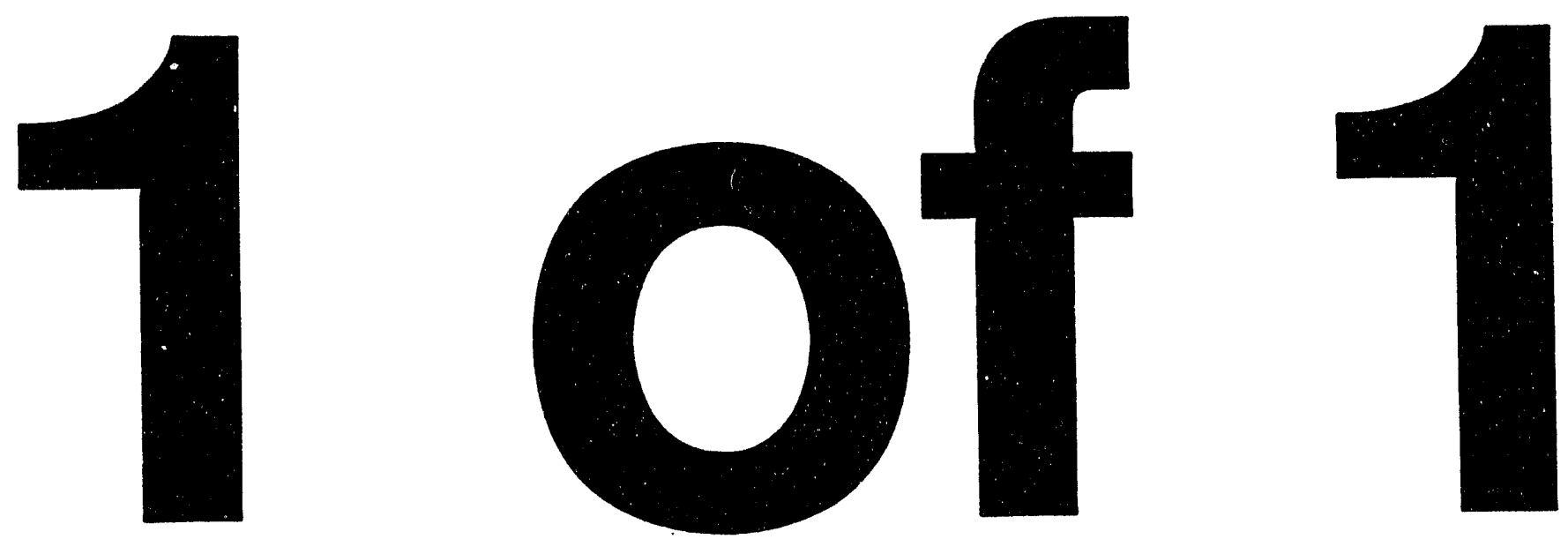


\section{Chemical Safety Vulnerability Working Group Report}

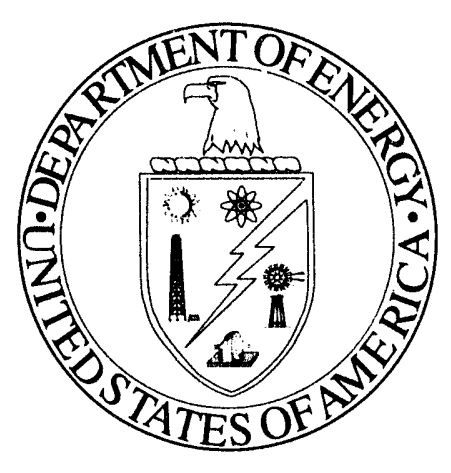

Volume 1 of 3

September 1994

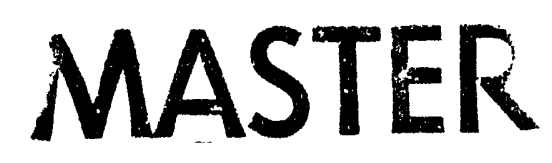

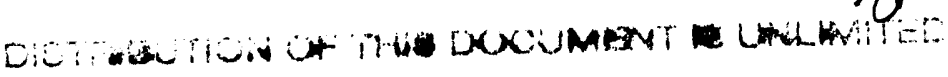

U. S. Department of Energy 


\section{Foreword}

Issuance of this report marks the culmination of an intensive 4-month review conducted to identify chemical safety vulnerabilities existing at Department of Energy (DOE) facilities. These vulnerabilities represent circumstances or conditions with the potential to affect workers, the public, and the environment as a result of the manner in which hazardous chemicals have been, are being, $c r$ will be handled, used, treated, stored, or dispositioned. The Chemical Safety Vulnerability Review was authorized by Secretary Hazel R. O'Leary as a cooperative effort between the Office of Environment, Safety and Health (EH) and line management representatives from DOE Headquarters and field organizations.

Despite the presence of significant chemical hazards at DOE facilities, the potential risks associated with hazardous chemicals have historically received less attention than those involving radioactive materials. This imbalance resulted from a misperception that chemicals present an acceptable risk and that the hazards identified with ionizing radiation are greater than those of most chemicals. A number of large-scale incidents occurring at private-sector industrial chemical facilities have demonstrated the potentially catastrophic nature of chemical accidents. Such events, coupled with the Department's considerable inventory of hazardous chemicals, plus a number of operational mishaps at DOE facilities, illustrated the need for this review. The review is an integral part of the Department's efforts to raise its commitment to chemical safety to the same level as that for nuclear safety, to understand and manage hazardous chemicals more effectively, to prevent the continuation of existing vulnerabilities, and to improve the quality and comprehensiveness of all safety programs.

Conducting the review at this time is particularly relevant because the Department's shift in focus away from nuclear weapons production and toward environmental restoration will require cleanup of numerous chemically contaminated facilities. Cleanup of these facilities will present significant hazards, particularly to workers, due to the extensive, diverse, and (all too often) uncharacterized nature of their chemical inventories and the limited experience with many of the technologies that may be used for decontamination and decommissioning. To eliminate these chemical hazards, the work force is being asked to take an aggressive role in implementing chemical safety programs for which they have not historically been responsible. Management must ensure that adequate systems and programs are in place to anticipate, prevent, and rnitigate hazards that might result in worker exposures or environmental releases.

This review represents a continuation of the problem-solving approach used last year to examine the condition of spent fuel stored at DOE facilities. As with the Spent Fuel Initiative, the review was coordinated by a Working Group of line management personnel from DOE and contractor field organizations in partnership with the Office of Environment, Safety and Health. This collaboration is in keeping with the EH philosophy of providing technical and programmatic assistance to field organizations in order to improve worker and public health and safety and protect environmental integrity. The spirit of cooperation and commitment demonstrated by the Chemical Safety Vulnerability Working Group was reflected in the candor of the information provided, the thoroughness of the review, and the detailed nature of the vulnerabilities identified.

Although a number of significant chemical vulnerabilities have emerged from this study, none represents imminent danger to the public, to worker health and safety, or to the environment. However, these vulnerabilities do require immediate and sustained management attention and may lead to more serious problems if preventive actions are not undertaken now. There are several underiying weaknesses in various DOE management systems that contribute to the perpetuation of these vulnerabilities. The best performers in the private sector have long recognized the need to eliminate or mitigate the risks associated with hazardous chemicals. DOE must learn from these examples and must also apply its own commendable practices more widely to reduce or remove chemical safety vulnerabilities from our facilities.

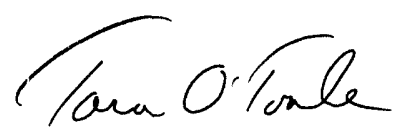

Tara O'Toole, M.D., M.P.H.

Assistant Secretary

Environment, Safety and Health 


\title{
Executive Summary
}

\section{The objective of this review was to identify and characterize adverse conditions or circumstances involving potentially hazardous chemicals at DOE facilities.}

\begin{abstract}
O n February 14, 1994, Secretary of Energy Hazel R. O'Leary directed the Office of Environment, Safety and Health to lead a broad-based review to identify chemical safety vulnerabilities confronting the Department of Energy (DOE). These vulnerabilities represent circumstances or conditions that could result in fires or explosions from uncontrolled chemical reactions, exposure of workers or the public to hazardous chemicals, or releases cf hazardous chemicals to the environment. The Chemical Safety Vulnerability Review is an integral part of an overall strategy to increase the Department's emphasis on the safe and effective handling, use, and disposal of hazardous chemicals and to raise awareness abcut the importance of issues related to chemical safety. The review was conducted by the Chemical Safety Vulnerability Working Group, which was composed of environmental, safety, and health $(E S \& H)$ professionals representing DOE line and contractor organizations in partnership with the Office of Environment, Safety and Health.
\end{abstract}

The process of selecting sites examined during this review was based on sampling techniques intended to provide a representative cross section of sites and facilities. This process considered a number of factors, including the nature of the operation (e.g., production, laboratory, support, treatment, storage, or disposal); the status of the operation (e.g., ongoing, in transition, or undergoing decontamination and decommissioning); and the types and quantities of chemicals involved. Accordingly, 84 facilities at 29 sites across the DOE complex participated in a self-evaluation effort to identify chemical safety vulnerabilities having potential ES\&H consequences. Thirteen of these sites were subsequently visited by independent Working Group verification teams that sought to confirm the findings of the self-evaluations, to determine whether additional chemical safety vulnerabilities existed, and to assess the seriousness of the vulnerabilities identified. As part of the effort to provide a broader perspective for this process, 64 additional facilities that were not included in the self-evaluations were examined during the field verification phase of the review. Although the 148 facilities evaluated represent only a small fraction of the thousands of DOE facilities that use or store hazardous 
chemicals, it is the Working Group's judgment that this sample is representative of the range of chemical safety concerns that confront the Department.

\section{Chemical Safety Vulnerabilities}

During the field verification effort, the Chemical Safety Vulnerability Review identified 35 facility- and site-specific vulnerabilities. Although these vulnerabilities are indicative of serious chemical safety issues, none represents imminent danger to the public, to worker health and safety, or to the environment. These facility- and site-specific vulnerabilities were grouped into eight generic vulnerabilities that have broad application to the DOE complex. This review did not include a comprehensive survey of chemical safety at all DOE facilities that use or contain hazardous chemicals. Nonetheless, it is the Working Group's judgment that these generic vulnerabilities are representative of vulnerabilities at other sites across the DOE complex. Specifically, the circumstances or conditions that gave rise to the generic vulnerabilities exist elsewhere; the types and quantities of chemicals used at other sites are comparable; the processes or operations performed are common to multiple sites; or the management practices used by other sites for chemical safety are comparable. The actual applicability of these generic vulnerabilities to specific sites or facilities not reviewed by the Working Group cannot be determined without

\section{Chemical Safety Vulnerabilities}

- Characterization of Cheinicals

- Unanalyzed Hazards

- Past Chemical Spills

- Planning for Disposition of Chemicals

- Chemical Storage Practices

- Condition of Facilities and Safety Systems

- Abandoned and Residual Chemicals

- Inventory Control and Tracking 
further evaluation. This review should be used as a guide or "roadmap" for managers in the identification, prevention, and mitigation of vulnerabilities at those sites and facilities.

- Characterization of Chemicals. Many hazardous materials found at DOE facilities have not been adequately characterized to determine the types or quantities of the chemicals they contain or the potential risks they represent. This situation increases the likelihood of worker exposure to these materials resulting from lack of knowledge about where they are located, the specific hazards they pose, and the actions necessary to prevent or mitigate such hazards. The presence of these materials increases the risk of worker exposures during the conduct of routine and nonroutine operations (e.g., during decontamination and decommissioning activities at facilities containing residues, during emergency response efforts in areas containing uncharacterized hazards, or because of the increased potential for accidents resulting from the storage of incompatible chemicals).

- Unanalyzed Hazards. Many facilities and activities have not been thoroughly analyzed for the presence and magnitude of hazards associated with the use of chemicals. Failure to recognize and analyze such hazards increases the risk of personnel exposures and environmental releases due to accidents such as fires or explosions.

- Past Chemical Spills. Many facilities have experienced spills and releases of hazardous chemicals to the soil. Known incidents have been identified and characterized in some cases. Additional spill or discharge areas are likely to be discovered. Both known and currently undiscovered contaminated soil could pose hazards to workers as construction environmental restoration, and decontamination and decommissioning activities increase.

- Planning for Disposition of Chemicals. DOE has significant quantities of hazardous and specialty chemicals that are no longer required to support ongoing activities. DOE facilities also have a wide range of smaller quantities of laboratory chemicals. At many sites, there is little incentive to reduce the inventory of chemicals that are no longer needed. The lack of systematic inventory planning and control increases DOE's overall vulnerability to worker exposures and environmental releases. Furthermore, chemicals held in the absence of continuing need may be viewed as 
waste by Federal and State regulatory agencies and could be subject to the requirements of the Resource Conservation and Recovery Act.

- Chemical Storage Practices. Improper chemical storage practices are in use at many DOE facilities. Appropriate chemical storage practices should consider such factors as the adequacy and integrity of chemical containment (e.g., tanks, drums, secondary containment), segregation of incompatible chemicals, ventilation, temperature and humidity controls, fire protection, and protection from weather. A reluctance to dispose of inventories of hazardous materials that are no longer needed has exacerbated problems associated with the storage of chemicals. Further, chemicals are often stored in aging facilities that are neither properly designed nor equipped for chemical storage.

- Condition of Facilities and Safety Systems. The structural deterioration of many DOE facilities in which chemicals are stored, handled, or processed increases the potential for worker exposures and environmental releases involving hazardous chemicals. In many instances, safety and essential support systems (e.g., utilities and ventilation systems) have not been effectively maintained, thus decreasing the margin of protection provided to workers, the public, and the environment against chemical hazards. Deficiencies due to inadequate maintenance budgets and the change in DOE mission have resulted in an increased number of "surplus" facilities (i.e., facilities declared by DOE program offices to be available for other uses).

- Abandoned and Residual Chemicals. Chemicals and chemical residues have been abandoned in place in equipment or facilities that are no longer needed. As facility missions changed or were terminated, chemical inventories were often left in place; tanks, pipes, and other equipment were not flushed to eliminate chemical residues. These conditions have created vulnerabilities that are exemplified by workers inadvertently coming into contact with hazardous chemicals or chemical residues, particularly during decontamination and decommissioning operations; by increased public access to areas and facilities containing chemical hazards; and by environmental releases of hazardous chemicals due to degradation of abandoned facilities or equipment. 
- Inventory Control and Tracking. Although most DOE sites have systems in place to record and monitor onsite chemical inventories, some systems do not provide up-todate information on chemical quantities and locations. The absence of comprehensive inventory control systems creates the potential for exposure of workers to hazardous chemicals that are not known to be present; fires and explosions due to mixing co-located, incompatible chemicals; and diminished effectiveness of emergency response plans due to unidentified chemical hazards.

\section{Management Weaknesses}

Analysis of facility-specific, site-specific, and generic vulnerabilities identified during this effort indicates several areas of weakness in DOE's management of chemical safety. The Chemical

\section{Management Weaknesses}

- Emphasis on, Commitment to, and Implementation of Chemical Safety Programs

- Management of Aging Facilities

- Transition of Facilities from Active Status to New Missions or to Decontamination and Decommissioning

- Budget Decision Making for Chemical Safety

Safety Vulnerability Review identified four management system weaknesses that significantly contribute to the perpetuation of these vulnerabilities.

- Emphasis on, Commitment to, and Implementation of Chemical Safety Programs. Many physical deficiencies and programmatic weakness can be partially attributed to an overall lack of management emphasis on, commitment to, and strategic planning for chemical safety. This area of weakness is evidenced by the low priority accorded to chemical safety issues, by the dispersal of chemical safety 
requirements among numerous Federal regulations and DOE Orders and the inadequacy of guidance for their implementation, and by inadequate consideration of chemical safety in strategic and program planning. As a result, the structure and formulation of chemical safety programs at sites throughout DOE are not well articulated or comprehensively defined, are not integrated with other safety functions, and are often neither implemented fully nor applied consistently.

- Management of Aging Facilities. DOE has a significant number of aging operational facilities that store or process chemicals. Many aging facilities present chemical safety vulnerabilities because physical structures, support systems, and equipment have deteriorated rapidly due to insufficient priority for facility maintenance; facilities being used for chemical storage were not designed for that purpose and do not meet existing safety requirements; and chemical practices currently being used do not meet regulatory and departmental requirements.

- Transition of Facilities from Active Status to New Missions or to Decontamination and Decommissioning. Due to the Department's shift in focus, many DOE facilities are either awaiting or undergoing transition to decontamination and decommissioning. Although the Department has committed to clean up and restore or dismantle these facilities, the process will require many years to complete. Weaknesses in the current transition process include lack of clearly understood and accepted facility ownership and ownership responsibilities; failure to remove chemical residues; loss of corporate knowledge (i.e., operating histories and as-built drawings) at DOE facilities; and inadequate configuration management.

- Budget Decision Making for Chemical Safety. DOE budget decision making does not provide for consistent and effective budgeting and allocation of resources to support chemical safety programs. This weakness is a result of several factors. Current funding approaches used by sites make it difficult to establish comprehensive chemical safety programs; guidance and requirements for budgeting chemical safety activities are not well defined; many resource allocation decisions do not adequately consider chemical risk; and funding for maintenance of aging facilities and for facility deactivation does not receive adequate priority. 


\section{A number of commendable practices representing "pockets of innovation and excellence" have been identified. Application of these practices should and will be encouraged throughout the DOE complex.}

\section{Commendable Practices}

The Chemical Safety Vulnerability Review also identified a number of commendable practices at DOE sites, including innovative activities, programs, or management systems that have merit and may have the potential for further application. These practices represent "pockets of innovation and excellence," and their visibility and application should and will be encouraged throughout the DOE complex. (See Appendix O.) Major categories of commendable practices observed in the field involve efforts to reduce inventories of hazardous chemicals, management programs to increase awareness of the hazards associated with chemical operations, and site recognition of the need for better characterization of chemicals and hazards.

\section{Management Response Plan}

The complex-wide implications of the generic vulnerabilities and management system weaknesses identified during this review are addressed in a management response plan that was coordinated by the Office of Environment, Safety and Health and collectively developed by DOE Headquarters program offices and affected field organizations. The management response plan is being released under separate cover concurrent with this report.

The Department acknowledges that chiemical safety has not historically received the attention and rigor accorded to other safety issues, such as radiation protection; this fact is borne out by the significance of the vulnerabilities and management system weaknesses identified by this review.

To resolve these problems, DOE is undertaking a number of programmatic initiatives designed to improve the overall state of chemical safety. The development and implementation of management response plans by DOE Headquarters and field organizations, plus the increased visibility of commendable practices and emphasis on successful private-sector chemical safety initiatives, should form the basis for providing meaningful and lasting solutions to problems associated with chemical safety and achieving an effecitve chemical safety program that can be applied consistently throughout the Department.
Chemical safety has not historically received the attention and rigor accorded to other safety issues. 


\section{Contents}

i FOREWORD

iii EXECUTIVE SUMMARY

1 INTRODUCTION

16 SUMMARY OF VULNERABILITIES

46 MANAGEMENT SYSTEM WEAKNESSES

62 COMMENDABLE PRACTICES

65 SUMMARY OF MANAGEMENT RESPONSE PLAN

67 CONCLUSIONS

68 GLOSSARY OF CHEMICAL TERMS

NOTE: Two volumes of appendixes accompany this report. 


\section{Introduction}

A chemical safety vulnerability is defined as a condition or circumstance that might result in the following:

- fires or explosions from uncontrolled chemical reactions,

- exposure of workers or the public to hazardous chemicals, or

- releases of hazardous chemicals to the environment.

A s part of the Department of Energy's (DOE) effort to improve its understanding and management of risks associated with the handling, use, treatment, storage, and disposal of hazardous chemicals, the Secretary of Energy initiated a comprehensive review of chemical safety practices and programs to identify chemical safety vulnerabilities confronting the DOE complex. The Chemical Safety Vulnerability Review was performed in recognition of the extent, diversity, and (all too often) uncharacterized condition of hazardous chemicals at many DOE facilities. Conducting the Chemical Safety Vulnerability Review at this time was particularly important because of the fundamental shift in the Department's mission away from defense nuclear production and toward environmental cleanup and restoration. This change in mission represents a significant challenge to DOE because of the difficulties inherent in cleanup of chemicals during decontamination and decommissioning (D\&D) operations, the Department's limited experience with such activities, and the difficulties associated with recognizing and analyzing the chemical hazards likely to be posed by these activities.

The Office of Environment, Safety and Health (EH) was directed to lead this assessment, and the Assistant Secretary for Environment, Safety and Health established the Chemical Safety Vulnerability Working Group to manage its overall implementation. (See Appendix A, "Tasking Memorandums.") The Working Group consisted of line management representatives from DOE and contractor organizations, including a core group of $\mathrm{EH}$ personnel. (See Attachment 2 of Appendix B for a list of Working Group members.) 
The Chemical Safety Vulnerability Review was conducted between February and July 1994 and involved the identification of chemical safety vulnerabilities for a cross section of DOE sites and facilities (i.e., 148 facilities at 29 sites), as shown in Figure 1. A sampling approach was adopted because, given the widespread use of chemicals across the Department, a comprehensive survey was not possible within the timeframe provided. The sites and facilities reviewed form a representative sample of chemicals used, chemical safety practices and programs in place, operations and processes conducted, and types and extent of chemical safety issues confronting DOE. This report documents the findings of the Chemical Safety Vulnerability Working Group.

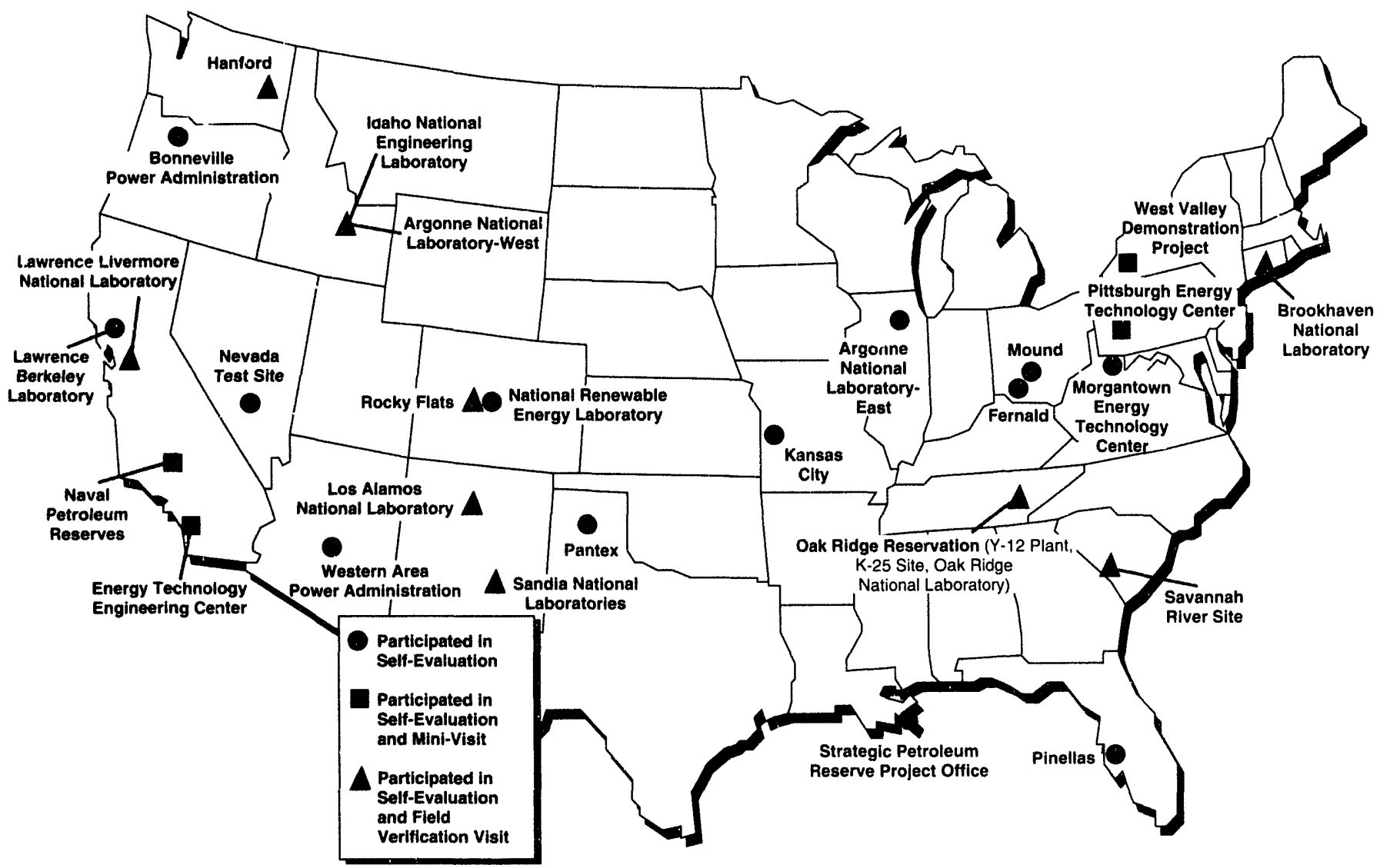

Figure 1. Sites Participating in the Chemical Safety Vulnerability Review 


\section{Background}

Carrying out the various historic missions of the DOE complex has required the use of numerous chemicals, ranging from common acids, bases, oxidizing agents, solvents, heavy metals, and maintenance reagents (e.g., oils, greases, paints, and adhesives) to specialty organics, explosives, hydrocarbon fuels, and toxic, corrosive, or flammable gases. (See Appendix R.) The quantities used vary widely (ranging from small laboratory quantities to large volumes of hazardous chemicals needed for manufacturing or large-scale processing operations), sometimes exceeding the threshold quantities established by the Occupational Safety and Health Administration's (OSHA) chemical process safety management rule (29 CFR 1910.119, "Prciess Safety Management of Highly Hazardous Chemicals," dated June 1, 1992). (See Table 1 for a list of DOE facilities that exceed

OSHA-established thresholds for hazardous chemicals.) In addition, DOE facilities treat, store, and dispose of a variety of hazardous wastes (which are regulated under the Resource Conservation and Recovery Act, or RCRA) and polychlorinated biphenyls (which are regulated under the Toxic Substances Control Act). To complicate matters further, some of these chemical wastes are contaminated with radionuclides.

Table 1. DOE Sites and Facilities Covered by the OSHA Process Safety Management Rule

\begin{tabular}{|c|c|c|c|}
\hline Site & $\begin{array}{l}\text { Chemical } \\
\text { (threshold } \\
\text { quantity) }\end{array}$ & $\begin{array}{c}\text { Quantity } \\
\text { (in pounds) }\end{array}$ & Process and Location \\
\hline \multicolumn{4}{|c|}{ ALBUQUERQUE OPERATIONS OFFICE } \\
\hline $\begin{array}{l}\text { Los Alamos } \\
\text { National Laboratory } \\
\text { (LANL) }\end{array}$ & Chlorine ( 1,500 lbs.) & 4,000 & $\begin{array}{l}\text { Waste Water Treatment } \\
\text { Facility/Building } 340\end{array}$ \\
\hline $\begin{array}{l}\text { LANL } \\
\text { (future process) }\end{array}$ & $\begin{array}{l}\text { Hydrachloric Acid } \\
\text { (30\% or greater, } \\
15.000 \text { lbs.) }\end{array}$ & 47,885 & $\begin{array}{l}\text { Nuclear Materials } \\
\text { Processing/Chloride } \\
\text { Systems }\end{array}$ \\
\hline Mound & Explosives (any amount) & unknown & Residuals/Equipment and Components \\
\hline Pantex & Explosives (any amount) & 4,400 & Parts \& Scraps/Explosives, Machining Facilities \\
\hline Pinellas & Explosives (any amount) & unknown & Residuals/Equipment and Components \\
\hline \multicolumn{4}{|l|}{ FOSSIL ENERGY } \\
\hline $\begin{array}{l}\text { Naval Petroleum } \\
\text { Reserves in } \\
\text { California (NPRC) }\end{array}$ & $\begin{array}{l}\text { Crude Oil } \\
(10,000 \text { lbs. })\end{array}$ & N/A & Oil Production/Pipelines \\
\hline NPRC & $\begin{array}{l}\text { Propane Liquid } \\
(10,000 \mathrm{lbs} .)\end{array}$ & 370,000 & Separation/Gas Operations \\
\hline NPRC & $\begin{array}{l}\text { Butane Liquid } \\
(10,000 \mathrm{lbs} .)\end{array}$ & 440,000 & Separation/Gas Operations \\
\hline NPRC & $\begin{array}{l}\text { Isobutane Liquid } \\
(10,000 \text { lbs. })\end{array}$ & 490,000 & Separation/Gas Operations \\
\hline NPRC & $\begin{array}{l}\text { Ethyl Mercaptan } \\
(10,000 \text { lbs. })\end{array}$ & 14,800 & Odorant/Gas Operations \\
\hline NPRC & $\begin{array}{l}\text { Nitrogen Oxide } \\
\text { (250 lbs.) }\end{array}$ & 250 & Lab/Gas Operations \\
\hline $\begin{array}{l}\text { NPRC (under } \\
\text { construction) }\end{array}$ & $\begin{array}{l}\text { Anhydrous Ammonia } \\
(10,000 \mathrm{lbs} .)\end{array}$ & 32,000 & $\begin{array}{l}\text { Cogeneration Plant/Gas } \\
\text { Operations }\end{array}$ \\
\hline $\begin{array}{l}\text { Naval Petroleum } \\
\text { Reserve No. } 3 \text { in } \\
\text { Wyoming (NPR-3) }\end{array}$ & $\begin{array}{l}\text { Crude Oil } \\
(10,000 \text { lbs. })\end{array}$ & N/A & Oil Production/Pipeline \\
\hline NPR-3 & Butane $(10,000 \mathrm{lbs})$. & 74,970 & $\begin{array}{l}\text { Low Temperature } \\
\text { Separation Gas Plant }\end{array}$ \\
\hline NPR-3 & Propane (10,000 lbs.) & 68,800 & $\begin{array}{l}\text { Low Temperature } \\
\text { Separation Gas Plant }\end{array}$ \\
\hline $\begin{array}{l}\text { Strategic Petroleum } \\
\text { Reserve-New } \\
\text { Orleans }\end{array}$ & Crude Oil $(10,000$ lbs.) & $\begin{array}{c}140 \text { trillion } \\
\text { lbs. in } 65 \\
\text { separate } \\
\text { caverns }\end{array}$ & Storage/Caverns \\
\hline
\end{tabular}

The infornation in the table is based on data available from site contacts and has not been field verified. (Hydrocarbon fuel exempted by the Occupational Safety and Health Administration has not been included.) 
Table 1 (continued). DOE Sites and Facilities Covered by the OSHA

Process Safety Management Rule

\begin{tabular}{|c|c|c|c|}
\hline Site & $\begin{array}{l}\text { Chemical } \\
\text { (threshold } \\
\text { quantity) }\end{array}$ & $\begin{array}{c}\text { Quantity } \\
\text { (in pounds) }\end{array}$ & Process and Location \\
\hline \multicolumn{4}{|c|}{ OAKLAND OPERATIONS OFFICE } \\
\hline $\begin{array}{l}\text { Energy Technolocy } \\
\text { Engineering Center (ETEC) }\end{array}$ & $\begin{array}{l}\text { Anhydrous Ammonia } \\
(10,000 \text { lbs. })\end{array}$ & 12,000 & Cycle Demo PlantKalina \\
\hline ETEC & $\begin{array}{l}\text { Ammonia (44\% or greater. } \\
15,000 \mathrm{lbs})\end{array}$ & 66,400 & Cycle Demo Plant/Kalina \\
\hline $\begin{array}{l}\text { Lawrence Berkeley } \\
\text { Laboratory }\end{array}$ & $\begin{array}{l}\text { Nitric Acid }>94.5 \% \\
\text { (500 lbs.) }\end{array}$ & 1.000 & Plating Shop/Building 77 \\
\hline $\begin{array}{l}\text { Lawrence Livermore } \\
\text { National Laboratory }\end{array}$ & Explosives (any amount) & Unknown & 300 Area \\
\hline \multicolumn{4}{|c|}{ OAK RIDGE OPERATIONS OFFICE } \\
\hline Y-12 Plant & $\begin{array}{l}\text { Hydrochloric Acid (30\% } \\
\text { or greater, } 15,000 \text { lbs.) }\end{array}$ & 294,000 & $\begin{array}{l}\text { Disassembly and Special } \\
\text { Materials }\end{array}$ \\
\hline Y-12 Plant & $\begin{array}{l}\text { Hydrogen Fluoride } \\
(1,000 \text { lbs. })\end{array}$ & 11,000 & $\begin{array}{l}\text { From inactive process, in } \\
\text { storage/Building } 9212\end{array}$ \\
\hline Y-12 Plant & Nitrogen Oxide (250 lbs.) & 1.700 & $\begin{array}{l}\text { From inactive process, in } \\
\text { storage/Building } 9212\end{array}$ \\
\hline Y-12 Plant & Methanol $(10,000 \mathrm{lbs})$. & 350.000 gals & $\begin{array}{l}\text { Brine Cooling System/ } \\
\text { Utillities }\end{array}$ \\
\hline K-25 Siıe & Chlorine (1,500 lbs.) & 2.000 & $\begin{array}{l}\text { Recirculating Cooling } \\
\text { Water/K-802 }\end{array}$ \\
\hline K-25 Site & Chlorine (1,500 lbs.) & 4,300 & Sanitary Water/K-1515 \\
\hline K-25 Site & Chlorine (1,500 lbs.) & 6,000 & Chlorine Storage/K-1058 \\
\hline $\begin{array}{l}\text { Oak Ridge National } \\
\text { Laboratory }\end{array}$ & Explosives (any amount) & Unknown & $\begin{array}{l}\text { Explosives A Storage } \\
\text { Shed/Building } 7666\end{array}$ \\
\hline Y-12 Plant & Chlorine (1,500 lbs.) & 16,000 & $\begin{array}{l}\text { Chlorine Water } \\
\text { Treatment Plant }\end{array}$ \\
\hline \multicolumn{4}{|c|}{ AICHLAND OPERATIONS OFFICE } \\
\hline Hanford & Chlorine (1,500 lbs.) & 12,000 & Storage/183-D \\
\hline Hanford & Chlorine (1,500 lbs.) & 8,000 & Water Treatmenv283-W \\
\hline Hanford & Chlorine ( $1,500 \mathrm{lbs})$. & 8,000 & Water Treatment283-E \\
\hline Hanford & Chiorine (1,500 ibs.) & 4,000 & Water Treatment/315 \\
\hline Hanford & Chlorine (1.500 lbs.) & 4,000 & Water Disinfection/183-N \\
\hline Hanford & Chlorine (1,500 lbs.) & 4,000 & Water Disinfection/183-KE \\
\hline \multicolumn{4}{|l|}{ ROCKY FLATS OFFICE } \\
\hline Rocky Flats Plant & Chlorine ( $1.500 \mathrm{lbs})$. & 2,250 & Compressed Gas Storage \\
\hline
\end{tabular}

The information in the table is based on data available from site contacts and has not been field verified. (Hydrocarbon fuel exempted by the Occupational Safety and Health Administration has not been included.)

An analysis of events reported in DOE's Occurrence Reporting and Processing System over the past 20 months indicates that more than 600 occurrences-an average of about one per day-involved chemical safety concerns. These occurrence reports are periodically analyzed and categorized into classes, depenaing on the severity (or potential severity) of their impact on worker health and safety, the public, or the environment. Class 1 and 2 events represent the most significant occurrences. Significant events involving chemical safety occur at an average rate of more than once per week. (Figure 2 provides DOE occurrence data related to chemical safety for the past 20 months.) Some of these significant events have involved personnel injuries (e.g., burns); others (e.g., spills, sprays, reactions) have resulted in environmental releases. The Chemical Safety Vulnerability Review was designed to identify conditions and circumstances contributing to such events and to specify mitigating actions to prevent their recurrence.

The Department of Energy is undergoing a dramatic shift in missions as the United States enters the post-Cold War era. The size of the nuclear weapons complex is being sharply reduced, and the Department is redirecting its emphasis from nuclear weapons 
production toward environmental cleanup and the development of new energy technologies. This change in emphasis is illustrated by an analysis of departmental funding, depicted in Figure 3.

DOE and its predecessor agencies have operated a wide range of facilities (including laboratories) that use and store hazardous chemicals. Despite sophisticated engineered

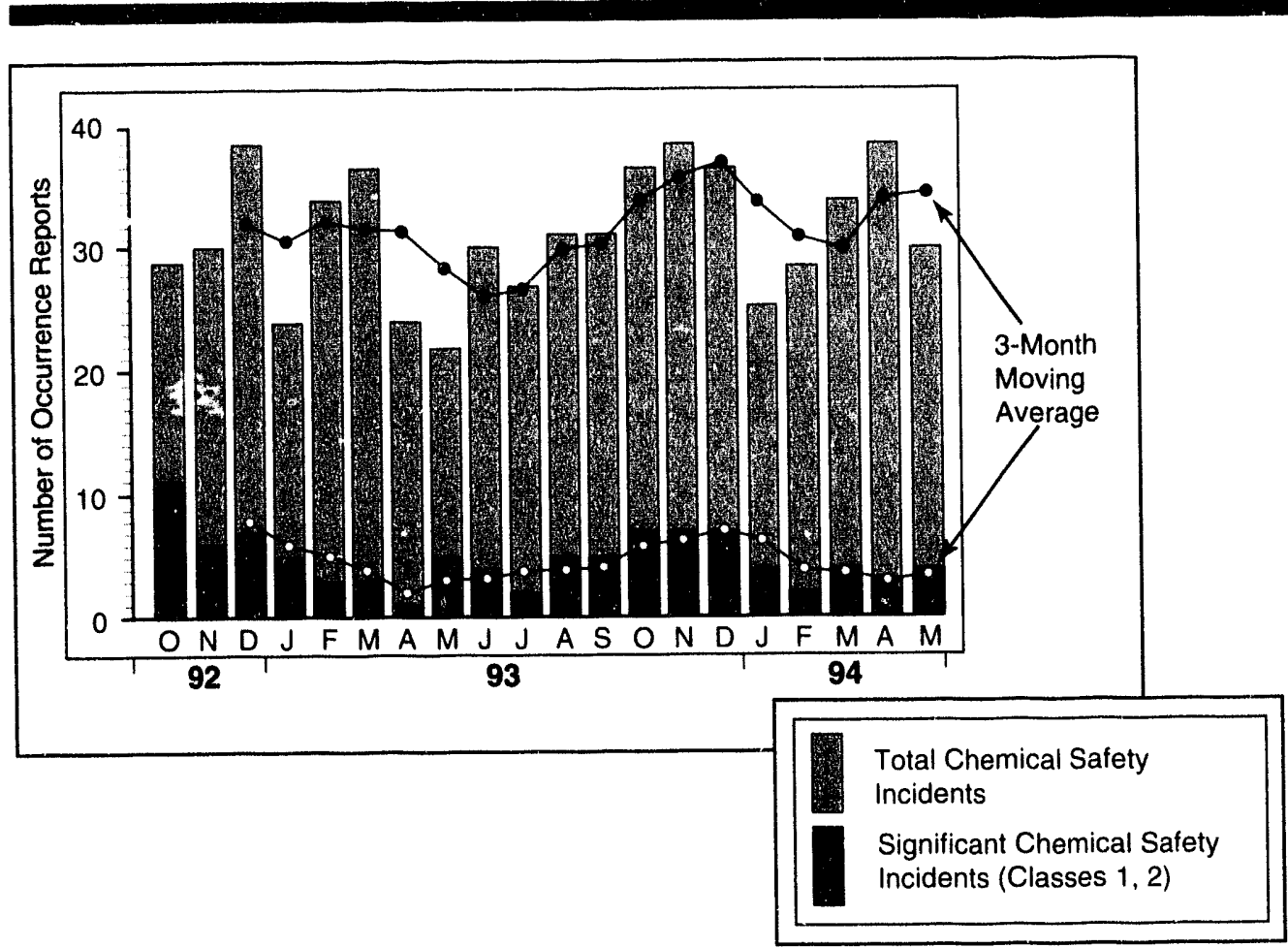

Figure 2. Oscurrence Reports Associated with Chemical Safety Incidents safety systems and administrative controls at some of these facilities, chemical safety vulnerabilities persist. Many of the facilities used for defense nuclear production were constructed during or shortly after World War II and incorporated few of the safety systems and facility design features currently required by the Department. Several factors affect

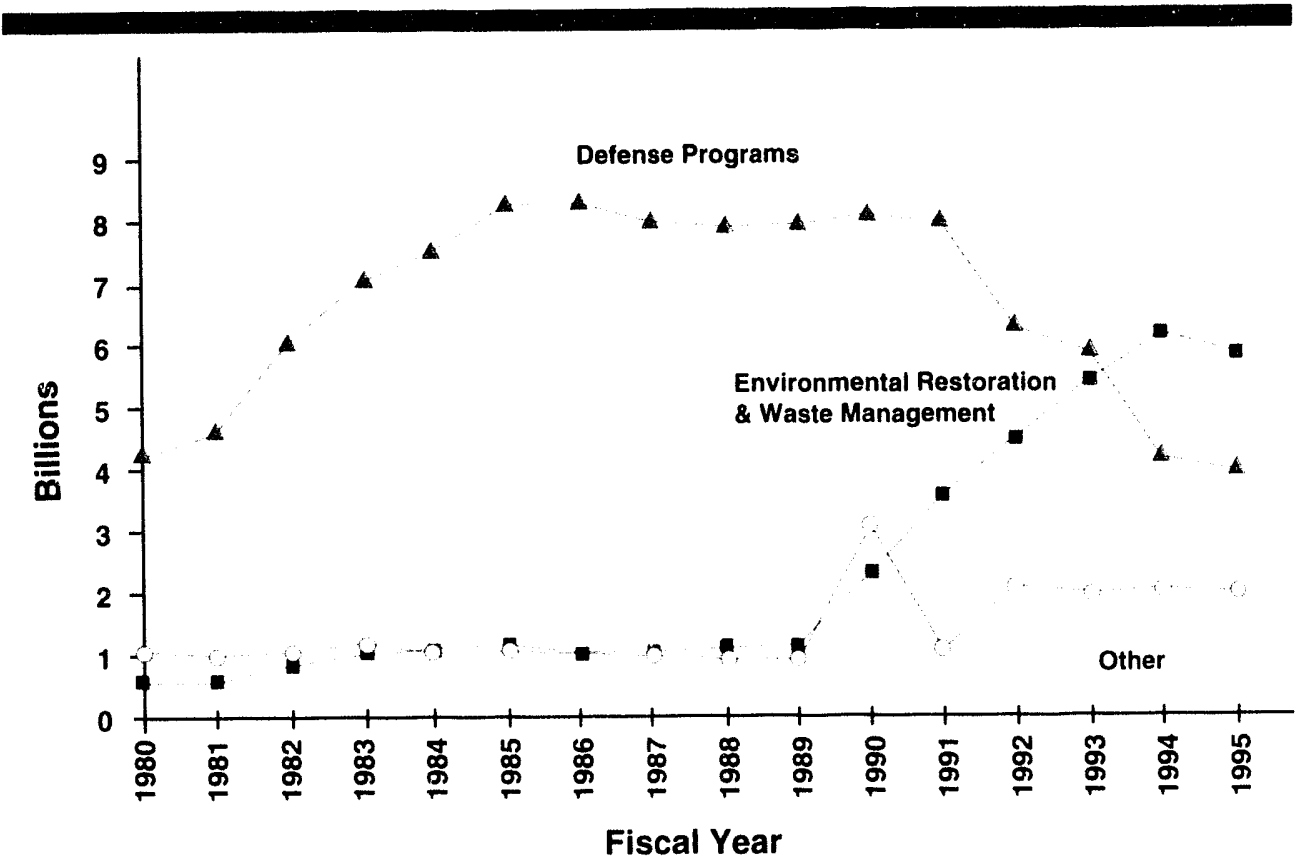

Figure 3. Historical Funding Levels for Departmental Activities 


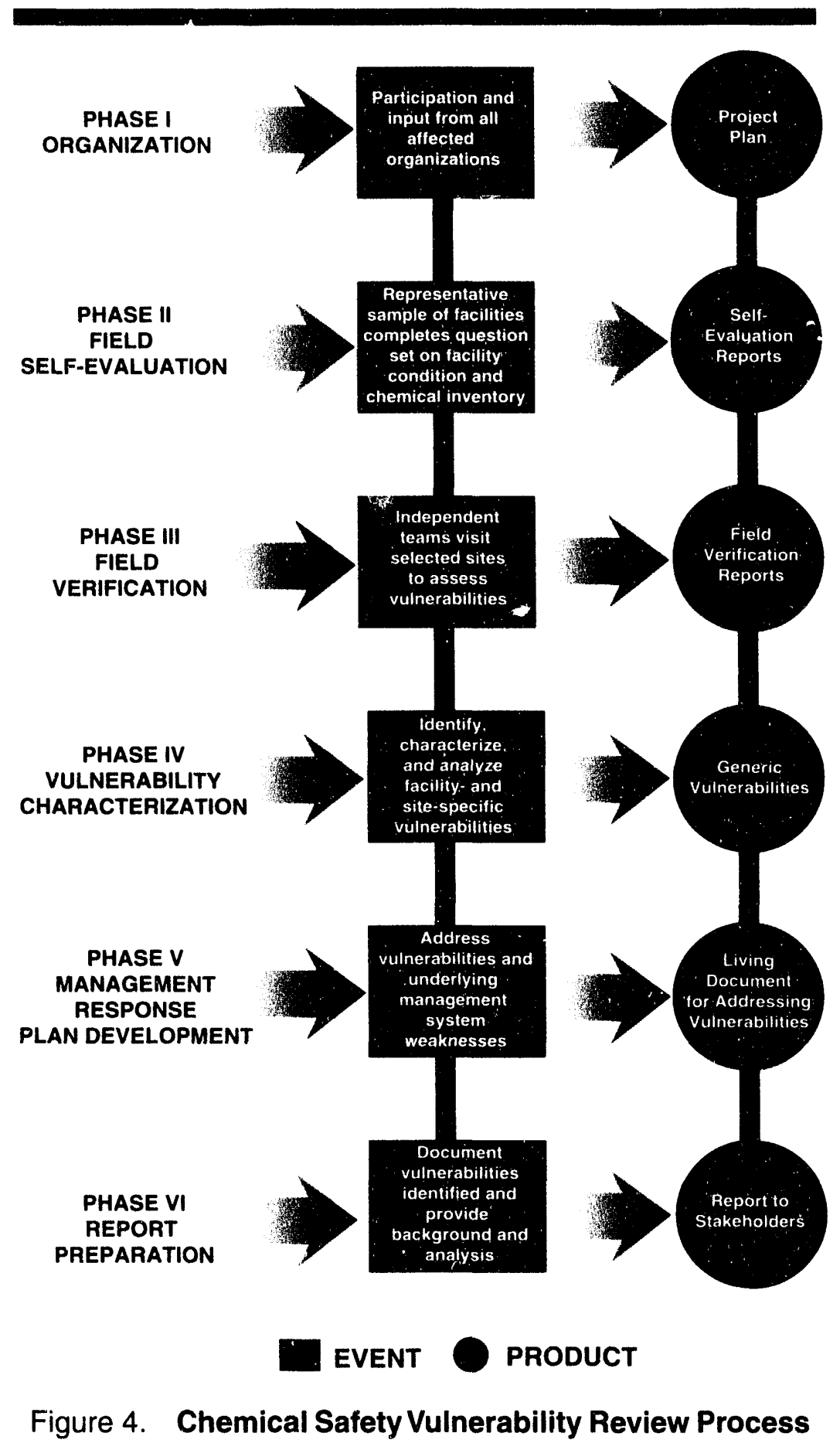

Figure 4. Chemical Safety Vulnerability Review Process the potential vulnerability of individual facilities, including the age of the facility, changes in its mission and use, historically weak configuration management, and the accumulation of hazardous chemicals and wastes. Chemical safety issues associated with facility transition and D\&D activities are not well defined and-in the absence of departmental action-will pose an increasing threat to the environment, the public, and worker health and safety. Dangers could result from construction-type activities (including D\&D) because of the Department's limited experience with such activities in conjunction with chemical hazards that might be unrecognized, uncharacterized or unanalyzed.

\section{Methodology}

The initial meeting of the Chemical Safety Vulnerability Working Group was held March 1-2, 1994, to develop an approach and methodology for conducting the Chemical Safety Vulnerability Review. The methodology outlined in the project plan was based on sampling a range of DOE facilities and required the active involvement of DOE line management and contractor personnel having operational responsibilities. This approach was designed to ensure that the information provided was accurate, timely, and complete. As established in the project plan (provided in Appendix B), the Chemical Safety Vulnerability Review was designed to be conducted in six phases. (See Figure 4.)

\section{Phase I - Organization}

Phase I focused on developing a project plan, structure, and schedule that would permit completion of the Chemical Safety Vulnerability Review by July 29, 1994. During this phase, contact 
was established with representatives of the Office of Environmental Management's (EM) Surplus Facility Inventory and Assessment Project and the Office of Defense Programs' Review of OrganicOxidizer Vulnerabilities, thereby ensuring that the three related efforts were properly coordinated. (See Appendix $P$ for more information on these initiatives.)

Phase II was designed to obtain information on chemical safety from a wide range of facilities and to encourage participation by DOE line organizations. Because the use of chemicals is widespread across the entire DOE complex, an evaluation of all facilities and sites was not possible within the timeframe provided for this review. Consequently, a sample of 84 facilities (e.g., laboratories, process facilities, waste locations, and storage areas) at 29 sites was selected for inclusion in the field self-evaluation process. The self-evaluation was also based on the types of chemical hazards known to exist at specific facilities. This process cc nsidered a number of factors, including the nature of the operation (e.g., production, laboratory, support, treatment, storage, or disposal); the status of the operation (e.g., ongoing, in transition, or D\&D); and the types and quantities of chemicals involved.

The chemical contents of each facility included one or more of the following:

- hazardous chemical inventories potentially in excess of 25 percent of the threshold quantities defined by OSHA in 29 CFR 1910.119, "Process Safety Management of Highly Hazardous Chemicals";

- chemical mixtures, byproducts, intermediate products, or other products generated as a result of process upsets involving hazardous substances defined by 29 CFR 1910.119;

- large numbers of hazardous chemicals in small quantities;

- characterized hazardous waste or mixed waste; or

- wastes with unknown constituents. 
Selection of facilities for the field self-evaluation phase of the review was also aided by the results of the EM Surplus Facility Inventory and Assessment Project.

To ensure that the field self-evaluations were conducted consistently and to facilitate a comparison of results, a self-evaluation question set was developed by the Chemical Safety Vulnerability Working Group and was completed for each facility selected for review. (The question set is provided in Attachment 6 of Appendix B.) Field selfevaluations were performed by site contractors, reviewed by local DOE line management, and submitted to the Working Group.

Phase III used independent teams of environmental, safety, and health $(E S \& H)$ professionals led by $E H$ to confirm the accuracy and completeness of information provided as part of the field self-evaluations, to examine facility- and site-specific chemical safety vulnerabilities, and to assess the seriousness of the vulnerabilities identified. (See Appendix C.) Each team included members of the Working Group and was composed of 11 individuals, including a DOE team leader, ES\&H professionals, a DOE site liaison, and administrative support professionals. The ES\&H professionals included DOE and contractor personnel having expertise in chemical process systems, industrial hygiene, ES\&H management systems, emergency management, facility maintenance, and environmental protection.

Nine large sites were selected to participate in the field verification phase of the review, based on the need to obtain a representative cross section of facilities, to conduct further investigations of selected facilities, and to clarify questionable data. The nine sites that hosted the 10-day field verification visits were Lawrence Livermore National Laboratory; Oak Ridge Reservation (including the K-25 Site, Oak Ridge National Laboratory, and Y-12 Plant); Savannah River Site; Hanford Site; Idaho National Engineering Laboratory; Rocky Flats Plarit; Brookhaven National Laboratory; Los Alamos National Laboratory; and Sandia National Laboratories, New Mexico. (See Appendixes D through L, respectively.)

In addition, "mini-visits" (1- or 2-day visits by teams of three ES\&H professionals) were conducted at four small sites (i.e., fewer than 1,000 DOE and contractor employees) to provide supplementary information and to determine whether unique vulnerabilities existed at smaller sites. These four sites were the Energy Technology En- 
gineering Center, West Valley Demonstration Project, Pittsburgh Energy Technology Center, and Naval Petroleum Reserves in California. (See Appendix M.)

The field verification visits addressed five functional areas, including identification of chemical holdings, facility physical condition, operational control and management systems, human resources programs, and emergency management programs. Each functional area was evaluated on the basis of standardized lines of inquiry provided in the "Field Verification Guide for the Chemical Safety Vulnerability Review," dated April 8, 1994. (See Appendix C.) The Field Verification Guide and lines of inquiry ensured that a common approach to verification activities was used at each site. Selfevaluation data from Phase II of the review were verified by means of facility walkthroughs, interviews with management and technical personnel, examination of facility and site documentation, and review of incident reports and other documents.

The field verification teams visited 50 of the 84 facilities examined during Phase II and 64 facilities not previously examined, for a total of 114 facilities. The 64 additional facilities were selected to expand the range of facilities sampled and were examined against the technical criteria set forth in the Field Verification Guide. During the course of the review, a total of 148 facilities was evaluated (i.e., 84 examined by the sites during Phase II and 114 visited by the field verification teams during Phase III).

The field verification process resulted in the identification of 35 facility- and site-specific vulnerabilities. Local DOE and contractor personnel participated in all aspects of the field verification process and conducted factual accuracy reviews of draft field verification reports and their associated vulnerabilities. (See Table 2 for a list of all facilities visited during the field verification process.)

Phase IV - Vulnerability Characterization

Facility- and site-specific vulnerabilities were identified based on input from the field self-evaluations and observations by team members during field verification visits. Facility- and site-specific vulnerabilities were then prioritized in terms of the immediacy (immediate, short term, medium term, or long term) and severity (high, medium, or low) of their potential consequences. During the 
Table 2. Facilities Visited During Field Verification Phase

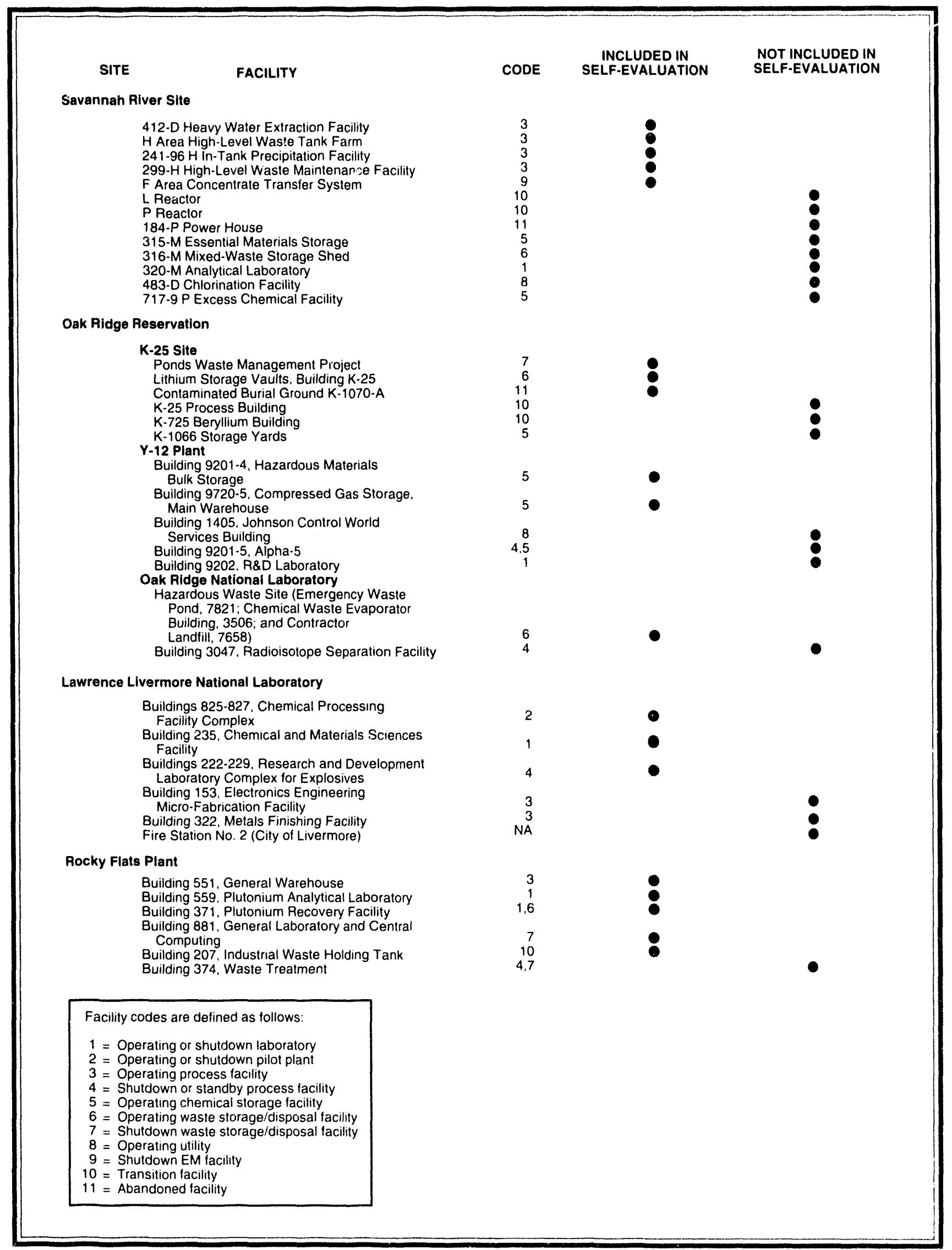


SITE

FACILITY

Hanford Site

Building 2703E, Chemical Engineering Laboratory

Building 234-5Z, Plutonium Finishing Plant

Building 202A, PUREX Plant

Building 324, High Bay Engineering Laboratory

Building 331, Life Sciences Laboratory

Building 3718G. Warehouse

Building 283E. Water Treatment Plant

Building 616, RCRA Hazardous Waste Storage

Facility

Building 305B, RCRA Hazardous Waste Storage

Facility

Idaho Natlonal Englneering Laboratory

Buildings 601, 602, and 621, Fuel Processing

Facility

Tank Farm

Waste Storage Pad A and Waste Disposal

Pit 9 at the Radioactive Waste Management

Complex

Army Reentry Vehicle Facility Site

Sodium-Potassium Storage Unit

Power Burst Facility Reactor Area

Evaporation Pond

ANL-W Analytical Laboratory

Fluorinel Dissolution Process \& Fuel Storage Facility

Waste Calcining Facility

Rover Headend Process Plant

Radioactive Sodium Storage Facility

Radioactive Scrap \& Waste Facility

Sandla National Laboratories, New Mexico

Building 858, Microelectronics Development

Facility

Buildings 805,806 , and 807 , Laboratory

Facilities

Building 878, Advanced Manufacturing Process

Laboratory

Building 958, Hazardous Waste Management

Facility

Light Initiated Explosive Test Facility

Building 6526, Large Centrifuge Facility

Building 6587, Facility Operation and Maintenance

Lurance Canyon Burn Site

Thunder Range Explosive Facility

Chemical Waste Landfill

KAFB Fire Department

Building 893, Compound Semiconductor

Research Laboratory

Building 983, Particle Beam Fusion

Accelerator II

Los Alamos National Laboratory

TA-3-170, Gas Cylinder Distribution Plant

TA-33-86, Tritium High Pressure Lab

TA-54, Waste Storage Facilities

TA-16-0342, S-Site Explosives Blending Facility

TA-3-29, Chemical and Metallurgy Research

Facility

TA-3, Building SM-30, General Warehouse

TA-3, Building SM-31, Chemical Warehouse

TA-46, Wastewater Treatment Facilities

TA-54, Building 1008, Chlorination Station
CODE

INCLUDED IN SELF-EVALUATION

NOT INCLUDED IN SELF-EVALUATION

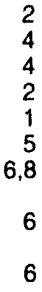

8

6

6

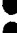

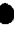

-

4
6

8

O

○

9

11
11

8 
Table 2 (continued). Facilities Visited During Field Verification Phase

SITE

FACILITY

Brookhaven National Laboratory

Hazardous Waste Management Facility

Wastewater Treatment Facility

Personnel Decontamination Facility Tank 490.07

Tandem Van de Graaff Accelerato

Central Water Treatment Facility

Energy Technology Engineering Center

Kalina Demonstration Plant

Sodium Storage Building

Sodium Component Test Installation

Cleaning and Handling Facility

Hazardous Waste Treatment Facility

Chemistry Laboratory

Sodium Pump Test Facility

Naval Petroleum Reserves in Callfornia

35R Complex

Loading Rack

Storage Area

Laboratory

Lab Chemical Storage Building

Lean Oil Absorption Plant

Low Temp Separation Unit No. 1

Hazardous Waste Temporary Storage Pad

Compressed Gas Storage Warehouse

Pittsburgh Energy Technology Center

Building 74, Wastewater Treatment Facility

Building 64. Chemical Handling Facility

Building 65, Gas Cylinder Storage

Building 83, Liquefaction Facility

Building 84. Chemical Engineering Lab

Building 92, Chemical Handling Facility

Building 93, Combustion Test Facility

Building 94, Analytical Chemistry Lab

Building 99, Cylinder Gas Distribution System

Building 141, Coal Preparation Facility

West Valiey Demonstration Project

Hazardous Waste Storage Area Locker

Analytical Environmental Lab

Supernate Treatment System
CODE

INCLUDED IN SELF.EVALUATION

NOT INCLUDED IN SELF-EVALUATION

6
8
11

8

:

8

O

8

Facility codes are defined as follows:

$1=$ Operating or shutdown laboratory

2 = Operating or shuldown pilot plan

$3=$ Operating process facility

$4=$ Shutdown or standy process facility

$5=$ Operating chemical storage lacility

$6=$ Operating waste storage/disposal facility

7 = Shutdown waste storage/disposal facility

8 = Operating utility

$9=$ Shutdown EM lacility

$10=$ Transition facility

11 = Abandoned facility 
course of the nine field verification visits, 35 facility- and site-specific chemical safety vulnerabilities were characterized. (See Appendixes $D$ through $L$.)

On completion of Phase III, the Working Group met to evaluate information gathered during the review to identify generic chemical safety vulnerabilities (i.e., vulnerabilities potentially having broad application to the DOE complex). Information considered included data from the field self-evaluation effort, vulnerabilities identified at sites visited by the field verification teams, observations from minivisits to smaller DOE sites, data from the Occurrence Reporting and Processing System, and information provided by the EM Surplus Facility Inventory and Assessment Project. Generic vulnerabilities were developed by reviewing the sources of information noted above and organizing these data around common issues and circumstances. This "generalization" process resulted in the identification of eight generic vulnerabilities, each of which was supported by many specific examples observed at DOE sites. These generic vulnerabilities are believed to be representative of vulnerabilities at other sites across the DOE complex. Specifically, the circumstances or conditions that gave rise to the generic vulnerabilities exist elsewhere; the types and quantities of chemicals used at other sites are comparable; the processes or operations performed are common to multiple sites; or the management practices by other sites for chemical safety are comparable. During this process, four underlying management system weaknesses that contributed to the presence of the generic vulnerabilities were also identified.

\section{Phase V - Management Response Plan Development}

Phase $V$ involved identification of actions to eliminate or mitigate the potential consequences of chemical safety vulnerabilities. Responsibility for preparing management response plans for facilityand site-specific vulnerabilities was assigned to DOE field organizations (e.g., operations offices, area offices, site offices), as appropriate. Management response actions are being developed and incorporated into existing site corrective action programs for all facility- and site-specific vulnerabilities. Local DOE line management organizations will approve site management response plans and track the effectiveness of proposed responses using existing management systems. 
The management response plan for addressing generic vulnerabilities was prepared by the Chemical Safety Vulnerability Working Group and was coordinated with responsible program offices and field organizations. This plan includes actions that should be implemented immediately, as well as those that should be implemented over a 3-5-year timeframe, to address programs, funding, and policy decisions for the Department as a whole. In developing this overall management response plan, the Working Group considered recommendations and suggestions included in site-specific management response plans.

The management response plan was developed as a separate document to allow modifications and updates, as appropriate. Key management factors considered while the plan was being developed included (1) a DOE commitment to improve the efficiency of its directives system, (2) reliance on performance-based contracting, (3) emphasis on the principles of "total quality management," (4) recognition of budget limitations, (5) realistic appreciation of chemical safety expertise within DOE organizations, and (6) a commitment to build on existing departmental initiatives related to chemical safety.

\section{Phase VI - Report Preparation}

Phase VI was completed by a designated subgroup of the Chemical Safety Vulnerability Working Group after completion of Phases III and IV above. Drafts of the report were provided to DOE program and field offices for factual accuracy review.

\section{Report Organization}

Volume 1 of this report summarizes the results of the Chemical Safety Vulnerability Review, with key information provided in four chapters entitled "Summary of Vulnerabilities," "Management System Weaknesses," "Commendable Practices," and "Summary of Management Response Plan." A series of conclusions presented in a fifth chapter summarizes the significant findings of the review. A glossary of chemical terms used in this report is provided at the end of Volume 1. Volumes 2 and 3 contain 18 appendixes. Table 3 describes and summarizes the information in each appendix. 


\section{Table 3. Summary of Appendixes}

\begin{tabular}{|c|c|c|}
\hline APPENDIX & DESCRIPTION & CONTENT \\
\hline A & Tasking Memorandums & $\begin{array}{l}\text { Memorandums From Secretary of Energy and From Assistant Secretary for } \\
\text { Environment, Safety and Health Establishing the Chemical Safety } \\
\text { Vulnerability Review and Providing Overall Guidance }\end{array}$ \\
\hline B & Project Plan & $\begin{array}{l}\text { Scope, Project Approach, Project Schedule, Sites and Facilties Examined, } \\
\text { Vulnerability Prioritization Criteria, List of Working Group Mermbers }\end{array}$ \\
\hline $\mathrm{C}$ & Field Verification Guide & $\begin{array}{l}\text { Verification Methodology, Team Administration, Lines of Inquiry, Team } \\
\text { Members' Areas of Responsibilties, Daily Schedules for Field Verification Visits }\end{array}$ \\
\hline $\mathrm{D}$ & $\begin{array}{l}\text { Lawrence Livermore National Laboratory } \\
\text { Field Verification Report }\end{array}$ & $\begin{array}{l}\text { Vuinerabilities, Commendable Practices, Summary of Results, and Team } \\
\text { Composition }\end{array}$ \\
\hline $\mathrm{E}$ & $\begin{array}{l}\text { Oak Ridge Reservation Field Verification } \\
\text { Report }\end{array}$ & $\begin{array}{l}\text { Vulnerabilities, Commendable Practices, Summary of Results, and Team } \\
\text { Composition }\end{array}$ \\
\hline$F$ & $\begin{array}{l}\text { Savannah River Site Field Verification } \\
\text { Report }\end{array}$ & $\begin{array}{l}\text { Vulnerabilities, Commendable Practices, Summary of Results, and Team } \\
\text { Composition }\end{array}$ \\
\hline $\mathbf{G}$ & Hanford Site Field Verification Report & $\begin{array}{l}\text { Vulnerabilities, Commendable Practices, Summary of Results, and Team } \\
\text { Composition }\end{array}$ \\
\hline $\mathrm{H}$ & $\begin{array}{l}\text { Idaho National Engineering Laboratory } \\
\text { Field Verification Report }\end{array}$ & $\begin{array}{l}\text { Vulnerabilities, Commendable Practices, Summary of Results, and Team } \\
\text { Composition }\end{array}$ \\
\hline 1 & Rocky Flats Plant Field Verification Report & $\begin{array}{l}\text { Vulnerabilities, Commendable Practices, Summary of Results, and Team } \\
\text { Composition }\end{array}$ \\
\hline$J$ & $\begin{array}{l}\text { Brookhaven National Laboratory Field } \\
\text { Verification Report }\end{array}$ & $\begin{array}{l}\text { Vulnerabilities, Commendable Practices, Summary of Results, and Team } \\
\text { Composition }\end{array}$ \\
\hline K & $\begin{array}{l}\text { Los Alamos National Laboratory Field } \\
\text { Verification Report }\end{array}$ & $\begin{array}{l}\text { Vulnerabilities, Commendable Practices, Summary of Results, and Team } \\
\text { Composition }\end{array}$ \\
\hline$L$ & $\begin{array}{l}\text { Sandia National Laboratories, New Mexico, } \\
\text { Field Verification Report }\end{array}$ & $\begin{array}{l}\text { Vulnerabilities, Commendable Practices, Summary of Results, and Team } \\
\text { Composition }\end{array}$ \\
\hline M & Mini-Visits to Small DOE Sites & $\begin{array}{l}\text { Summary of Field Verification Mini-Visits to Energy Technology Engineering } \\
\text { Center, Naval Petroleum Reserves in California, Pittsburgh Energy } \\
\text { Technology Center, and West Valley Demonstration Project }\end{array}$ \\
\hline N & Working Group Meeting, June 7-8, 1994 & Agendas, Participant List for June 7-8, 1994, Working Group Meeting \\
\hline 0 & Commendable Practices & Descriptions of Commendable Practices and Points of Contact \\
\hline$P$ & Related Chemical Safety Initiatives at DOE & $\begin{array}{l}\text { Surplus Facility Inventory and Assessment Project and Defense Programs' } \\
\text { Tomsk-7 Review }\end{array}$ \\
\hline$Q$ & $\begin{array}{l}\text { Regulatory Framework and Industry } \\
\text { Initiatives Concerning Chemical Safety }\end{array}$ & $\begin{array}{l}\text { Description of Regulations Governing Chemical Safety Activities and } \\
\text { Industry Initiatives Regarding Chemical Safety }\end{array}$ \\
\hline $\mathbf{R}$ & $\begin{array}{l}\text { Chemical Inventory Data From Field } \\
\text { Self-Evaluation Reports }\end{array}$ & $\begin{array}{l}\text { List of Reported Quantities of Selected Hazardous Chemicals From } \\
\text { Field Self-Evaluation Reports }\end{array}$ \\
\hline
\end{tabular}




\section{Summary of Vulnerabilities}

D uring the field verification effort, the Chemical Safety Vulnerability Review identified 35 facility- and site-specific vulnerabilities. Although these vulnerabilities are indicative of serious chemical safety issues, none represents imminent danger to the public, to worker health and safety, or to the environment. These facilityand site-specific vulnerabilities were grouped into the eight generic vulnerabilities with broad application to the DOE complex that are described in this chapter. The review did not include a comprehensive survey of chemical safety at all DOE facilities that use or contain hazardous chemicals. Nonetheless, it is the Working Group's judgment that these generic vulnerabilities are representative of vulnerabilities at other sites across the DOE complex. Specifically, the circumstances or conditions that gave rise to the generic vulnerabilities exist elsewhere; the types and quantities of chemicals used at other sites are comparable; the processes or operations performed are common to multiple sites; or the management practices used by other sites for chemical safety are comparable. The actual applicability of these generic vulnerabilities to specific sites or facilities not reviewed by the Working Group cannot be determined without further evaluation. This review should be used as a guide or "roadmap" for managers in the identification, prevention, and mitigation of vulnerabilities at those sites and facilities.

In the discussions that follow, the overall nature of each vulnerability has been characterized and is illustrated by specific examples of that vulnerability excerpted from field verification reports. (See Appendixes D through L.)

\section{Characterization of Chemicals}

Description of Vulnerability. Chemical inventories at many DOE facilities have not been adequately characterized to determine the types or quantities of hazardous substances they contain. This situation increases the likelihood that workers will be exposed to hazards that are not adequately recognized or mitigated. Specifically, the presence of poorly characterized hazardous materials increases the risk of worker injuries or environmental releases during routine work activities, when $D \& D$ operations are coriducted in facilities containing uncharacterized hazardous residues, and in the event of emergencies involving uncharacterized materials.

Efforts to characterize hazardous materials, particularly abandoned chemicals and chemical residues, are in the early stages of deveiopment at a few DOE sites. These activities are a result of 
individual site initiatives rather than a comprehensive Departmentwide program for the characterization of hazardous materials. In fact, neither DOE Headquarters nor DOE line organizations have developed and implemented consistent requirements for the characterization of hazardous substances. As the examples below illustrate, consistent hazardous material characterization requirements generally do not exist, de-

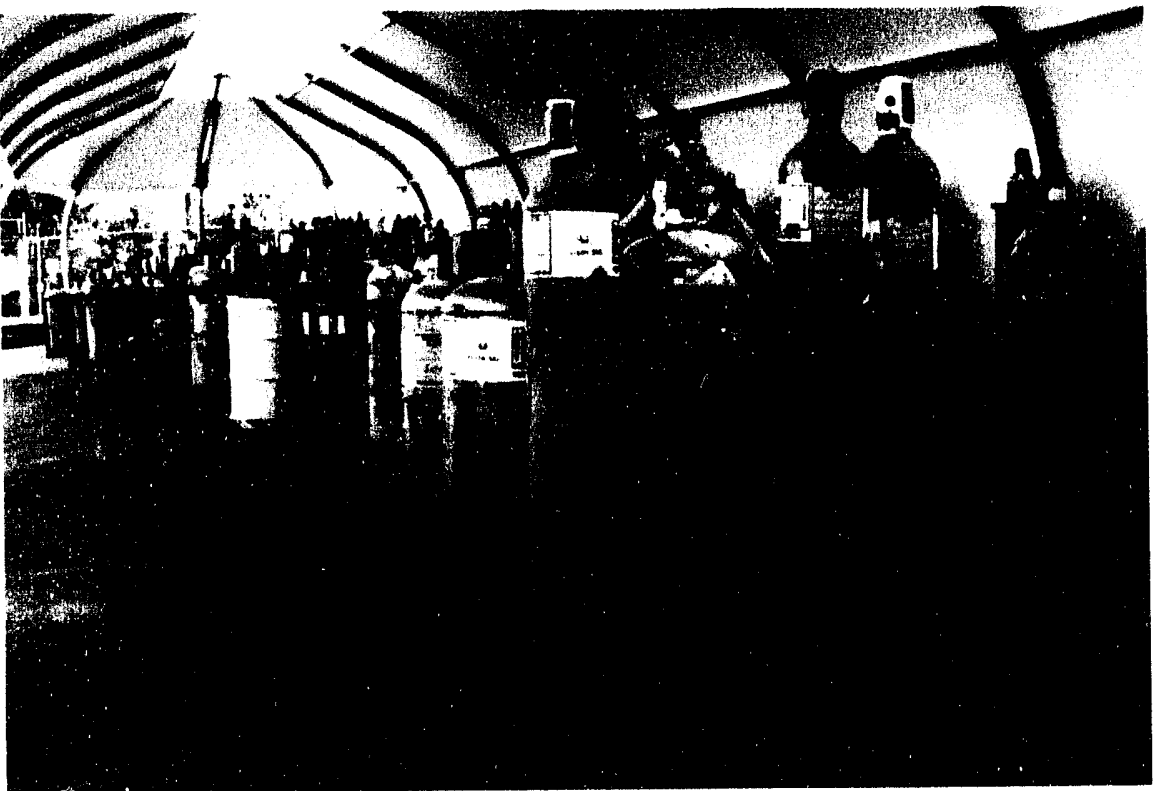

Cylinders of uncharacterized gases are stored in Area $L$ at Los Alamos. spite significant quantities of uncharacterized chemical residues in DOE facilities. These observations indicate that DOE and contractor organizations must increase their efforts to prevent and mitigate the potential risks associated with uncharacterized chemicals.

Examples. Hazardous chemicals and wastes have been produced over several decades of operations at several DOE sites. At Los Alamos, efforts are being made to characterize such materials for eventual disposal, but the field verification team found chemicals in the form of uncharacterized gases stored in cylinders at Area $L$ in Technical Area (TA)-54. (See Vulnerability CSVR-LANL-CH-01 in Appendix K.) Many of the cylinders are old and corroded, and the chemicals they contain include flammables (e.g., propylene, isobutane, hydrogen, and methane), corrosive gases (e.g., hydrogen fluoride, hydrogen chloride, nitric oxide, and sulfur dioxide), and toxic gases (e.g., arsine, phosgene, cyanogen, and phosphine). (See Chemical Storage Practices, p. 32.) Similarly, the field verification team at Los Alamos observed 30 drums of uncharacterized waste at Area $L$. These drums contain chemical wastes in a variety of hazard classes including acids, oxidizers,

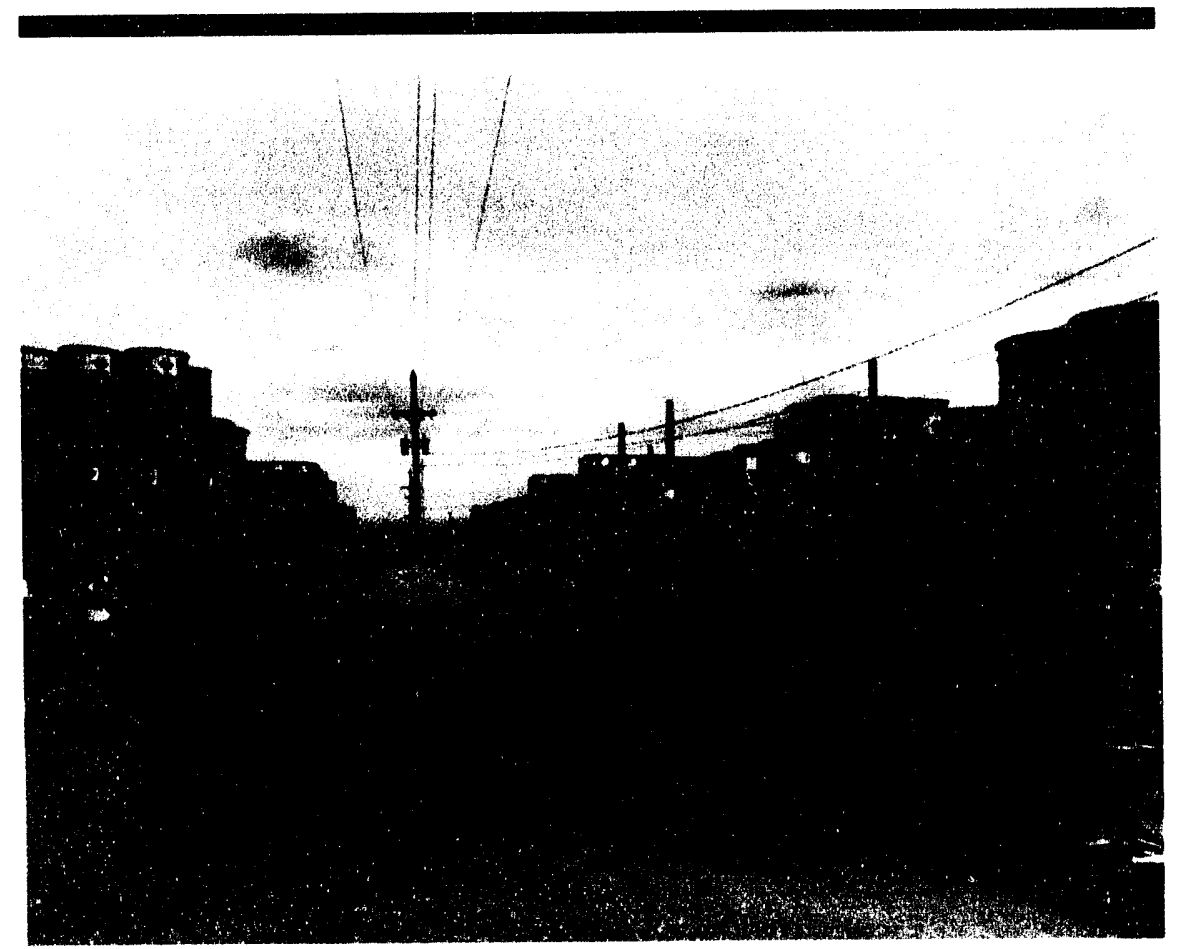

Drums of uncharacterized chemical waste are also stored in Area $L$ at Los Alamos. 


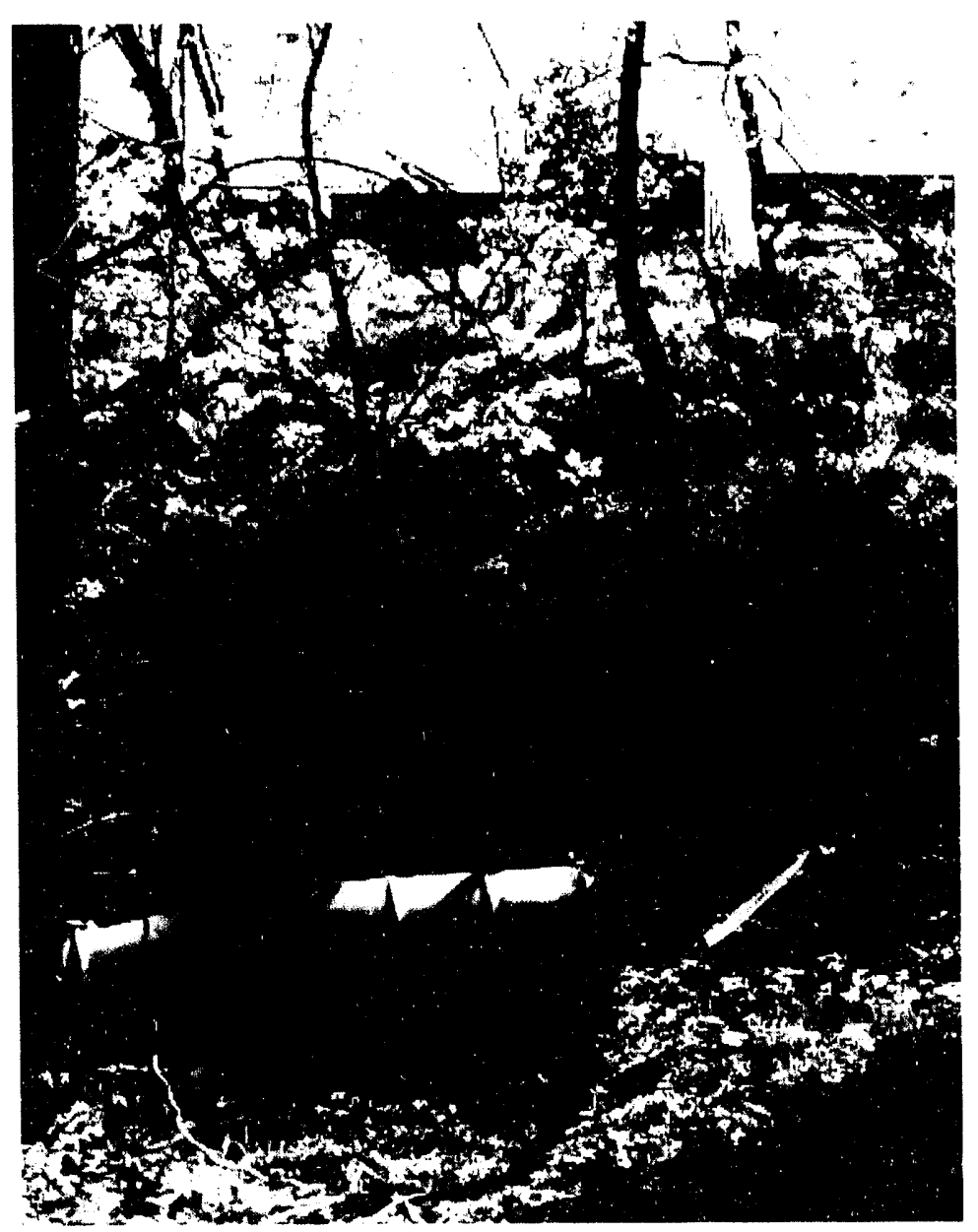

Shrinking security boundaries have increased public access to uncharacterized hazards in this old landfill at Oak Ridge National Laboratory. flammables, and caustics. In TA-3, Building 154 , the team observed four tanks containing about 3,100 gallons of uncharacterized chemical wastes. Personnel assigned to the Chemistry and Metallurgy Research Facility indicated that this waste has been housed in their facility for at least 18 months without being characterized. An abandoned physical chemistry laboratory in the same Los Alamos facility has held four drums of uncharacterized hazardous chemical wastes for about 2 years.

Hazardous chemical wastes in the Oak Ridge National Laboratory Contractor Landfill (Area 7658) are only partially characterized, and their hazard potential to the public has not been established with any degree of certainty. (See Vulnerability CSVR-OR-ORR-01 in Appendix E.) This area is no longer protected behind security fences and, thus, is increasingly accessible to the public.

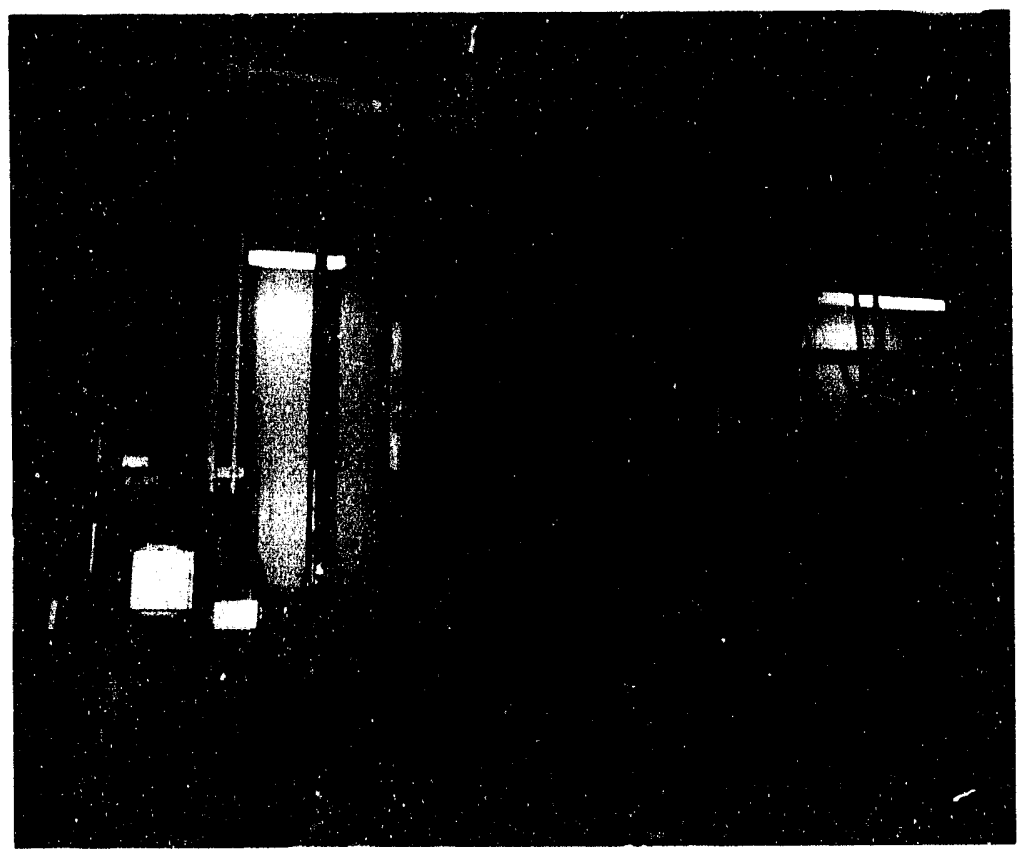

These tanks at Rocky Flats are believed to contain dilute acid solutions, but characterization information is incomplete. 
Chemical residues that have not been properly characterized are known to exist in a variety of locations. For example, the piping and drains of Building 881 at Rocky Flats contain chemical residues that are only partially characterized. (See Vulnerability CSVR-RFP000-01 in Appendix 1.) These residues represent potential hazards to workers during future D\&D operations. Several large tanks stored in Room 4101 of Building 374 at Rocky Flats are believed to contain dilute acid solutions, although the contents are labeled as concentrated acid. This situation has not been fully documented.

At Oak Ridge, uncharacterized hazardous material residues have been left in the process equipment and piping of several surplus and inactive facilities. (See Vulnerability CSVR-OR-ORR-01 in Appendix E.) In the 9201-4 Production Building at the Y-12 Plant, these residues are the result of operations involving polychlorinated biphenyl oils, mercury, lithium chloride, lithium hydroxide, lithium carbonate, and sodium hydroxide. In addition is unknown hazardous materials, residues of uncharacterized acids, bases, and carcinogens exist in Building 3047 at Oak Ridge National Laboratory. The sump for the shielded-cell facility in Building 3047 is known to contain a radioactive chemical residue. (See Vulnerability CSVR-OR-ORR03 in Appendix E.) The manner in which this material reached the sump is unknown, but it may have been transferred through a ventilation duct or via a leaking pipe. No device is in place to sample or flush the sump basin; thus, its precise contents are unknown. Chemical processing is no longer conducted in the shielded cells of Building 3047; however, past work in these cells involved acids, bases, solvents, and other materials that may still be in the sump. The chemical hazards associated with this uncharacterized residue have not been determined.

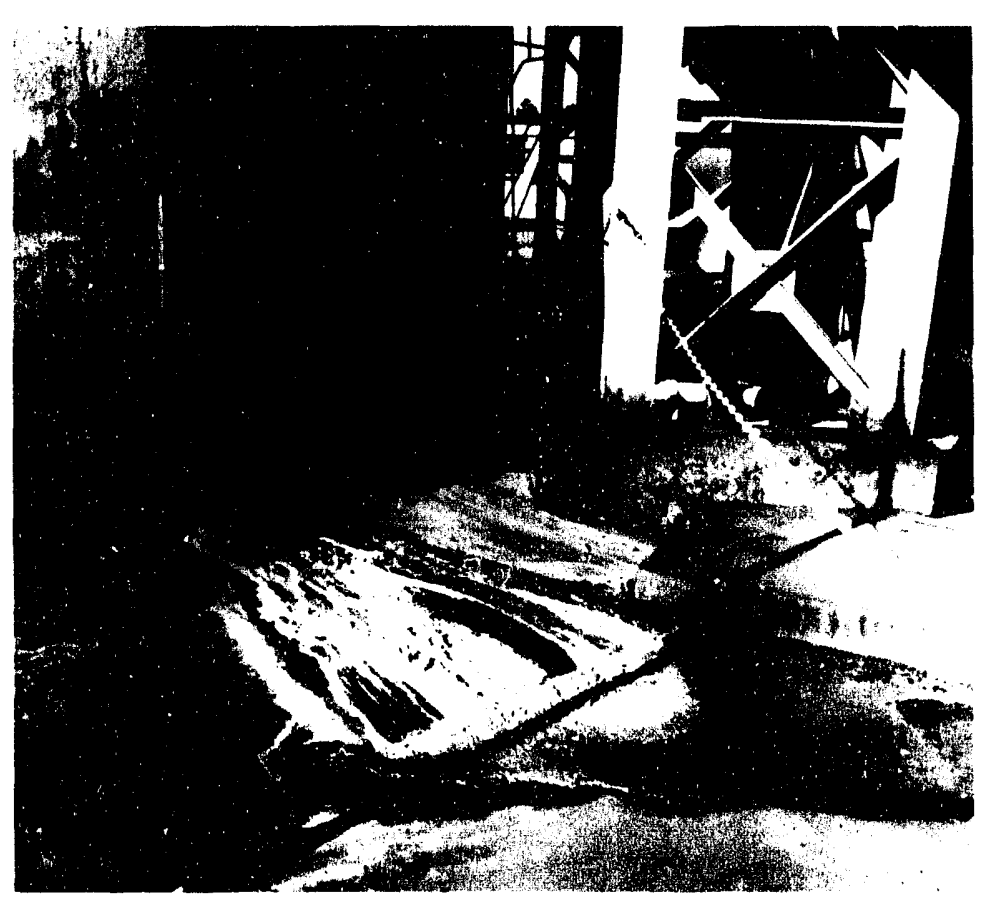

Uncharacterized solid residues were found at the base of an abandoned powerhouse smokestack at Savannah River.

At Savannah River, uncharacterized solid residues had seeped from beneath the cleanout door and were found at the base of the smokestack at the abandoned 184-P Power House. (See Vulnerability CSVR-SRS-000-02 in Appendix F.) Chemical residues at the 412-D Heavy Water Extraction Facility may have contributed to a November 11, 1993, incident involving the apparent inhalation of noxious gases by an employee after a co-worker used a torch to 
cut a pipe containing the residues. Another uncharacterized residue found in the Heavy Water Extraction Facility was described as an oily substance with a pH of about 3.3. At the time of the field verification visit, a sample of the residue had been submitted for analysis, but despite ongoing D\&D operations, a full characterization had not been pursued vigorously.

\section{Unanalyzed Hazards}

Description of Vulnerability. During the course of this review, unidentified and unanaly_ed hazards associated with the use or handling of chemicals were observed at numerous DOE sites and facilities. The review further determined that many DOE sites and facilities do not have adequate management systems to analyze processes and equipment for chemical hazards or to prepare and issue formal "hazards analyses." The purpose of a hazards analysis is to identify and document operational hazards and to determine appropriate boen conducted for many nonnuclear facilities. means for minimizing or mitigating the potential consequences of such hazards to workers, the public, and the environment. Safety-related Jocumentation at sites throughout the DOE complex is often out-of-date and incomplete; moreover, formal chemical hazards analyses have never been conducted for many nonnuclear facilities, despite the requirement to do so by DOE 5481.1B, "Safety Analysis and Review System," dated September 23, 1986.

The examples provided in this subsection confirm that unanalyzed chemical hazards are common throughout the Department. DOE Headquarters is responsible for requiring and enforcing the implementation of an effective hazards analysis system at all DOE sites; however, the responsibility for analyzing chemical hazards for individual activities or facilities rests with site management. (See Emphasis on, Commitment to, and Implementation of Chemical Safety Programs, p. 46.) Because operations at all sites involve the use of hazardous chemicals, local DOE and contractor organizations must assess the quality of their hazards analysis systems, determine the status of the hazards analyses for ongoing chemical activities, and correct the deficiencies identified. These measures are required to ensure that operating and maintenance personnel are aware of all chemical hazards and are prepared to address them safely and effectively. 
Examples. The dangers posed by unanalyzed hazards are exemplified by the incident involving a Savannah River worker who apparently inhaled noxious gas after a pipe containing chemical residues had been cut with a torch. (See Characterization of Chemicals, p. 19.) This task had not been formally analyzed for potential hazards related to a noxious gas release or for the effects of heating residues with a torch. After the incident, a Type B accident investigation was conducted, and the site introduced improvements in the process based on a hazards analysis completed before work resumed. Another operation at Savannah River that was performed without benefit of a hazards analysis involved the removal of carpet from specified areas in Buildings 773-A and 735-A. Tile containing asbestos was found underneath the carpet, seriously complicating efforts to complete the task and requiring significantly more resources than had been anticipated or provided.

A thorough hazards analysis review for chemical safety concerns related to D\&D is especially important because of the pervasive unknowns and uncertainties associated with such
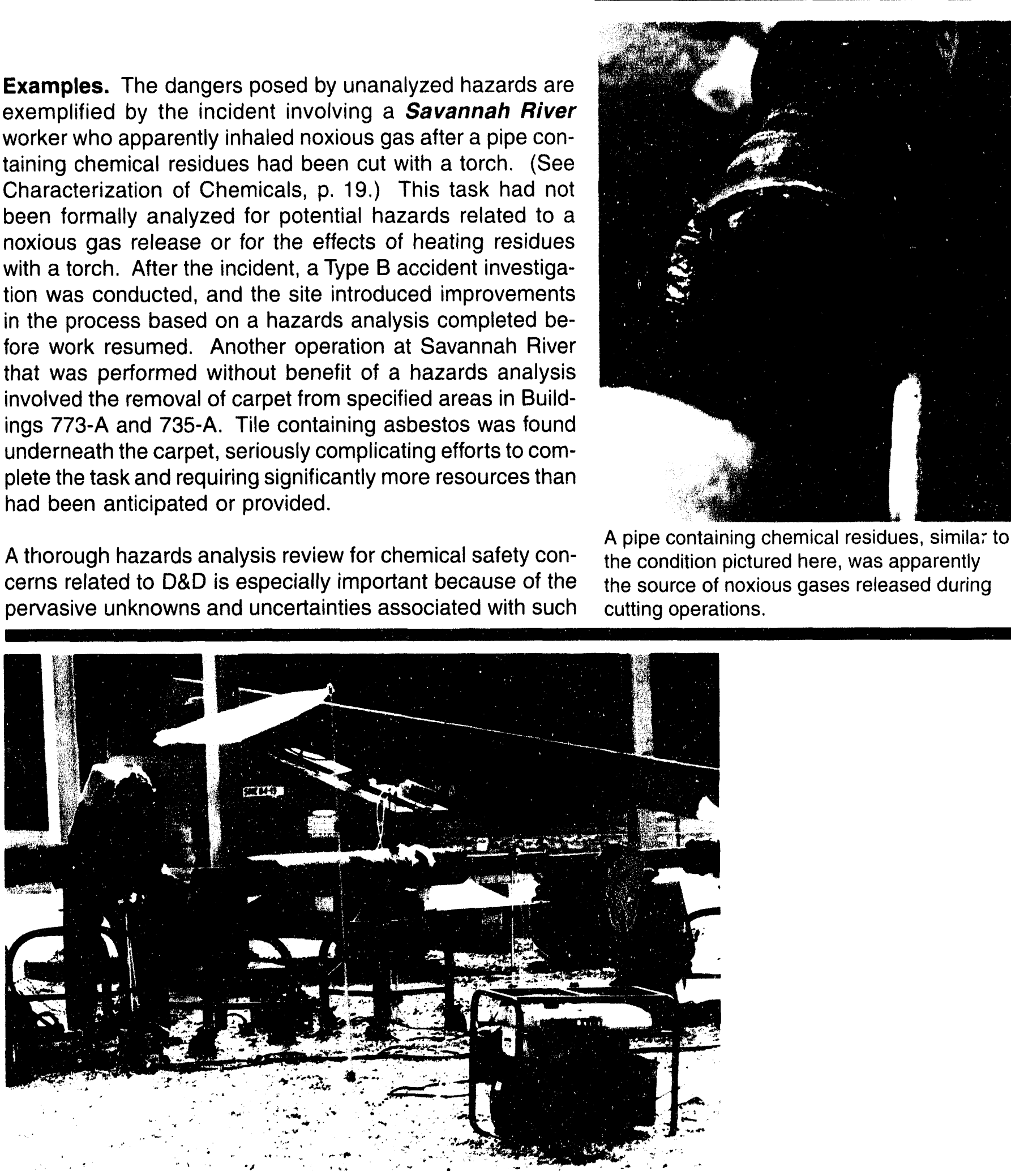

As part of a Type B investigation into a worker's apparent inhalation of noxious gases, sampling was performed to identify the extent of the potential hazards involved. 
D\&D operations have the potential to be significantly more hazardous because their technologies and requirements are unknown or unfamiliar to many workers. work and the Department's general lack of experience in this area. The incident involving the possible exposure of the worker at Savannah River exemplifies the importance of recognizing potential hazards related to $D \& D$ activities-hazards that may be even less apparent than those related to routine operations.

D\&D operations have the potential to be significantly more hazardous because their technologies and requirements are unknown or unfamiliar to many workers.

At Hanford, approved work plans for job hazards analyses at the Chemical Engineering Laboratory do not always receive indepth review by industrial hygiene and/or industrial safety personnel. (See Vulnerability CSVR-RL-HAN-02 in Appendix G.) In many cases, approvals are granted perfunctorily without conducting thorough analyses of the proposed work. A near-miss event still under investigation occurred at Hanford on April 20, 1994. Relying on information provided by a subcontractor, maintenance personnel were in the process of removing a blank in a low-pressure steamline without ensuring that the required double-valve isolation was in place upstream. The work began without management approval, which would not have occurred had a formal hazards analysis been prepared, reviewed, and approved. Although this near miss is not typical of chemical safety incidents, it illustrates the danger that can be caused by insufficient analysis of hazards for special operations. It also illustrates that job hazards analyses at Hanford are not always reviewed thoroughly or rigorously by management. These factors can contribute to an increased potential for personnel exposure to chemicals, as well as to other hazards in the workplace.

Weaknesses were also observed in programs for identifying, characterizing, and mitigating chemical hazards at Sandia. (See Vulnerability CSVR-SNL/NM-MO-02 in Appendix L.) For example, a project to install an acetone distillation apparatus in Building 878 received only limited input from industrial hygiene specialists. Acetone is a volatile, highly flammable liquid. The ventilation flow rate was designed to preclude generation of an explosive atmosphere, but no formal hazards analysis was performed; hence, there was no documentation that this flow rate was sufficient to protect workers. The facility design complied with code requirements and included venting panels to relieve pressure from an explosion involving up to 120 gallons of acetone. A fire safety engineer supporting the project determined that the Uniform Building Code required backup power for the ventilation system serving the distillation apparatus. This determination was based on the 
specialist's opinion that the system was not closed. When backup power was found to be unavailable, the facility design was modified accordingly, based on a second opinion from another fire protection engineer that the system was closed. A mechanism has not been established at Sandia to document or resolve such dissenting opinions, and an accident analysis covering loss of power has not been performed. At the time of the field verification visit, the distillation apparatus installation had not been turned over to the operating group. If a problem does arise, no formal mechanism will be in place to advise the operating group or DOE about these contradictory opinions concerning the system's compliance status with established codes.

At Sandia, a hazards analysis for chemical operations is provided by the responsible line organization, approved by line management, and reviewed by the appropriate ES\&H coordinator. Unfortunately, hazards analyses are not prepared in accordance with clear and formal guidance, and Sandia employees responsible for performing and recording these analyses are not provided adequate training. As a result, there is no assurance that all hazards have been addressed; that potential synergistic effects have been evaluated; or that workers, the public, and the environment will be adequately protected.

At Lawrence Livermore, a wide variety of hazardous chemicals is used for experimental research, development, and testing. Yet, safety analysis documents for laboratory facilities (e.g., the B-222229 Complex, B-235, the B-825-827 Complex, and Area 300) do not contain accident scenarios (including potential effects on workers and the public) or evaluation of safety systems that would prevent or mitigate those scenarios. (See Vulnerability CSVR-LLNL-MO01 in Appendix D.) Hazardous chemicals used in these facilities include beryllium hydride (toxic and a suspected carcinogen), lithium hydride, lithium beryllium hydride, heavy metal (uranium and thorium) compounds, flammable solvents, cryogens (liquid nitrogen and liquid argon), and explosives. Overall, weaknesses observed in the hazards analysis program as it affects chemical safety at Lawrence Livermore included lack of explicit definition for conditions under which project work plans are required to address new or modified operations or equipment, inadequate implementation of guidelines for submitting project work plans, and the absence of accident analyses.

An effective emergency management program requires that chemical hazards be assessed to enable informed judgments about the resources needed to respond to emergencies and to provide 
adequate protective measures. Some sites, including Brookhaven and Idaho National Engineering Laboratory, have not completed hazards assessments of chemical activities to support emergency management. (See Vulnerability CSVR-BNL-000-02 in Appendix J and Vulnerability CSVR-INEL-EMP-01 in Appendix H.) Previous reviews by the Chicago Operations Office at Brookhaven identified the need for hazard assessments to determine the extent and scope of emergency planning and preparedness activities required for managing events involving chemicals. At Idaho National Engineering Laboratory, a hazards assessment to determine emergency action levels had not been completed as of the time of the field verification visit, although one had been initiated. (Emergency action levels are specific indicators used to determine occurrence reporting categories and emergency classes for serious incidents, as well as to make determinations about the resources needed for emergency response or for appropriate protective measures.)

Commendable Practices. The field verification team observed several commendable practices that partially address problems related to unanalyzed hazards at DOE sites. Brookhaven National Laboratory uses a graded approach, based on the level of hazard, to review facilities and operations (i.e., operations with increasing hazard levels receive correspondingly more rigorous health and safety review and independent laboratory process review). At Oak Ridge, Martin Marietta Energy Systems uses both corporatewide and site-specific procedures to ensure that all stages of the life cycle of an operation are treated with an appropriate degree of rigor. A substantial effort has been made to apply this philosophy to processes used for evaluating and reducing hazards. At the Idaho National Engineering Laboratory, Westinghouse Idaho Nuclear Company is developing a nomograph to determine evacuation distance requirements for chemical incidents.

\section{Past Chemical Spills}

Disturbing the soil at spill sites can expose workers to hazardous chemicals and cause environmental releases.
Description of Vulnerability. During their operational lifetime, most DOE sites have experienced chemical spills and other releases that have contaminated the soil. Such spills are believed to have been common in the past and are of concern for virtually all DOE sites. In most cases, the resulting chemical contamination has been allowed to remain in the soil, based on the assumption that it did not constitute a hazard as long as the soil remained undisturbed. Given the Department's increased emphasis on site remediation and D\&D, the impact of these old spills on current operations needs to be 
reexamined. Remediation and D\&D operations, including those related to environmental restoration, often require excavation or other construction-related activities. Inadvertent disturbance of the soil at spill sites has the potential to expose workers to hazardous chemicals and to cause further environmental releases.

The examples provided here illustrate the magnitude of problems associated with past chemical spills. These examples also describe programs that are in place at most sites to define the scope of and mitigating actions for this vulnerability. However, continuing efforts by local DOE and contractor organizations are required to identify the location and extent of unknown or uncharacterized spills and to prevent or minimize worker exposures and environmental releases.

Examples. Four hundred spills, leaks, and discharges of hazardous chemicals have been identified at the Idaho National Engineering Laboratory, 83 of which occurred at the Idaho Chemical Processing Plant. (See Vulnerability CSVR-INEL-CH-01 in Appendix H.) Some of these spills to the soil originated from process lines and bulk storage areas. Intentional discharges of hazardous materials have

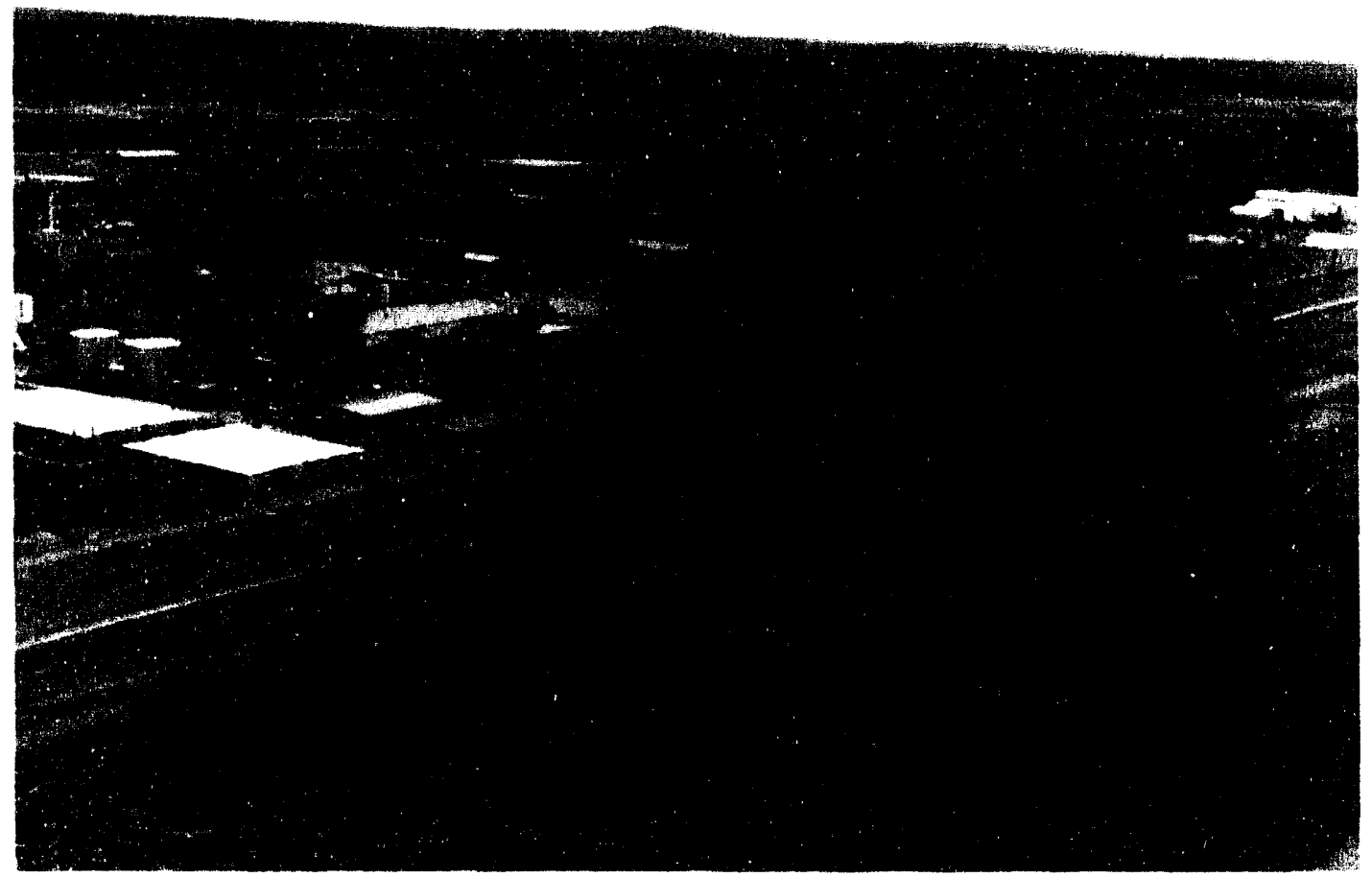

Numerous spills, leaks, and discharges of hazardous chemicals are known to have occurred at the Idaho Chemical Processing Plant. 


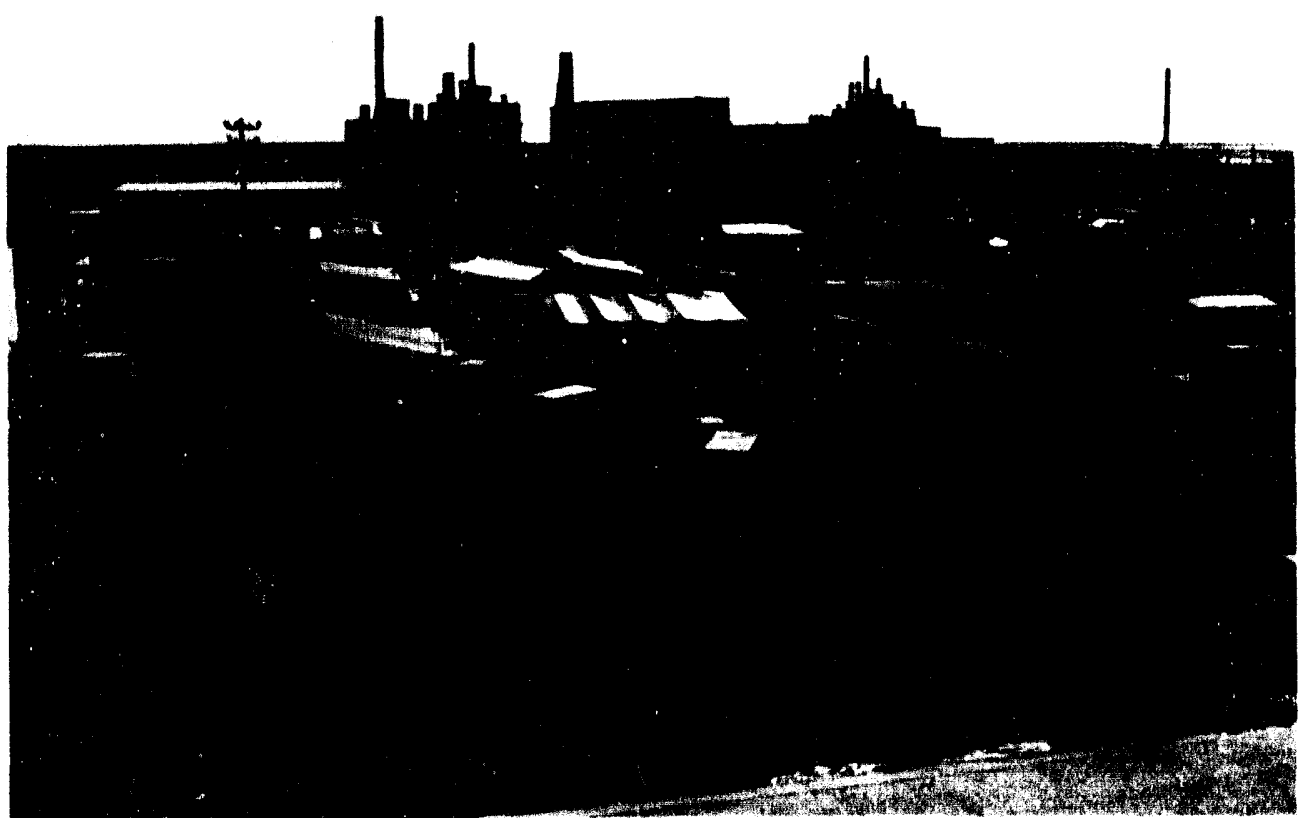

At the Idaho Chemical Processing Plant tank farm, valve replacements are under way to prevent further leaks of hazardous waste. also occurred. Known locations for such discharges at the Idaho National Engineering Laboratory have been at least partially characterized and, in some cases, remediated. In addition, administrative controls have been put in place to restrict access to those areas known to be contaminated. In the absence of reliable records for the early history of the Idaho National Engineering Laboratory, it seems likely that other spill and discharge sites will be identified that could pose threats to worker health and safety.

Several leaks and spills involving nitric acid, sulfuric acid, hydrofluoric acid, and aluminum nitrate occurred between 1950 and 1980 in the bulk chemical storage area adjacent to Building CPP-621 at the Idaho Chemical Processing Plant. The details of these leaks are not well documented. "French drains" were originally used to dispose of acid leaks and spills. Other discharges have occurred in the earthen pipe trench leading from the storage area to the chemical processing building. (A plastic liner was recently installed in this trench.) At the waste tank farm for the processing plant, two known instances of high-level liquid waste (containing hazardous chemicals as well as radionuclides) leaking to the soil have been documented. At least one leak at the tank farm is known to involve cooling water that contained potassium dichromate. Pipes used in the transfer of wastes to the tank farm have also leaked. In Building CPP-601, condensate leaked from the vent tunnel when a pipe corroded. Examination of sections of lines removed from Building CPP-601 showed no evidence of additional leaks; however, the lines could not be examined in their entirety. Thus, the possibility of other undetected leaks of hazardous materials cannot be disregarded. These leaks, spilis, and discharges create the potential for worker exposure to chemical hazards during environmental restoration, construction, D\&D, and other activities that disturb the soil. 
At Oak Ridge, hazardous materials have escaped and contaminated the soil around and beneath the 9201-4 Production Building at the Y-12 Plant. (See Vulnerability CSVR-OR-ORR-01 in Appendix E.) Contamination of the building from chemical leaks involving mercury, lithium chloride, sodium hydroxide, and lithium carbonate has been confirmed; subsurface contamination is assumed to have occurred as a result of seepage from sumps, floor cracks, and joints. Exposure of workers and the public to hazardous chemicals is possible whenever the soil is disturbed. Planning to control and mitigate such exposures has already begun.

At Sandia, waste management personnel are examining 200 known or potential release sites in an attempt to determine the extent of hazardous materials released to the soil. (See Section 2.1 of Appendix L.) Some leaks or spills involving process equipment and bulk chemical storage areas are known to have occurred. Others are the result of the dispersion of hazardous material during unconfined tests. In the past, liquid wastes were intentionally discharged via French drains, which in turn could have discharged hazardous materials to the soil. At Sandia, the potential consequences of old chemical spills have been mitigated through the preparation and implementation of procedures to control activities in proximity to unearthed waste sites, thereby protecting workers engaged in such activities from exposure to hazardous chemicals.

\section{Planning for the Disposition of Chemicals}

Description of Vuinerability. Lack of planning for reducing the quantities of hazardous and specialty chemicals increases DOE's overall vulnerability to chemical releases and exposures affecting workers, the public, and the environment. DOE has significant quantities of chemicals that are no longer required to support ongoing activities. Without an identified need for their use, such materials should be removed to minimize the potential for unnecessary worker exposures and environmental releases.

Large numbers of hazardous substances are located at many DOE sites in amounts ranging from industrial quantities of process chemicals to small laboratory quantities of a wide

Most DOE sites have little incentive to reduce the inventory of excess hazardous chemicals. range of hazardous or specialty chemicals. At most sites, there is little incentive to reduce the inventory of chemicals no longer being used. As a result, chemicals 


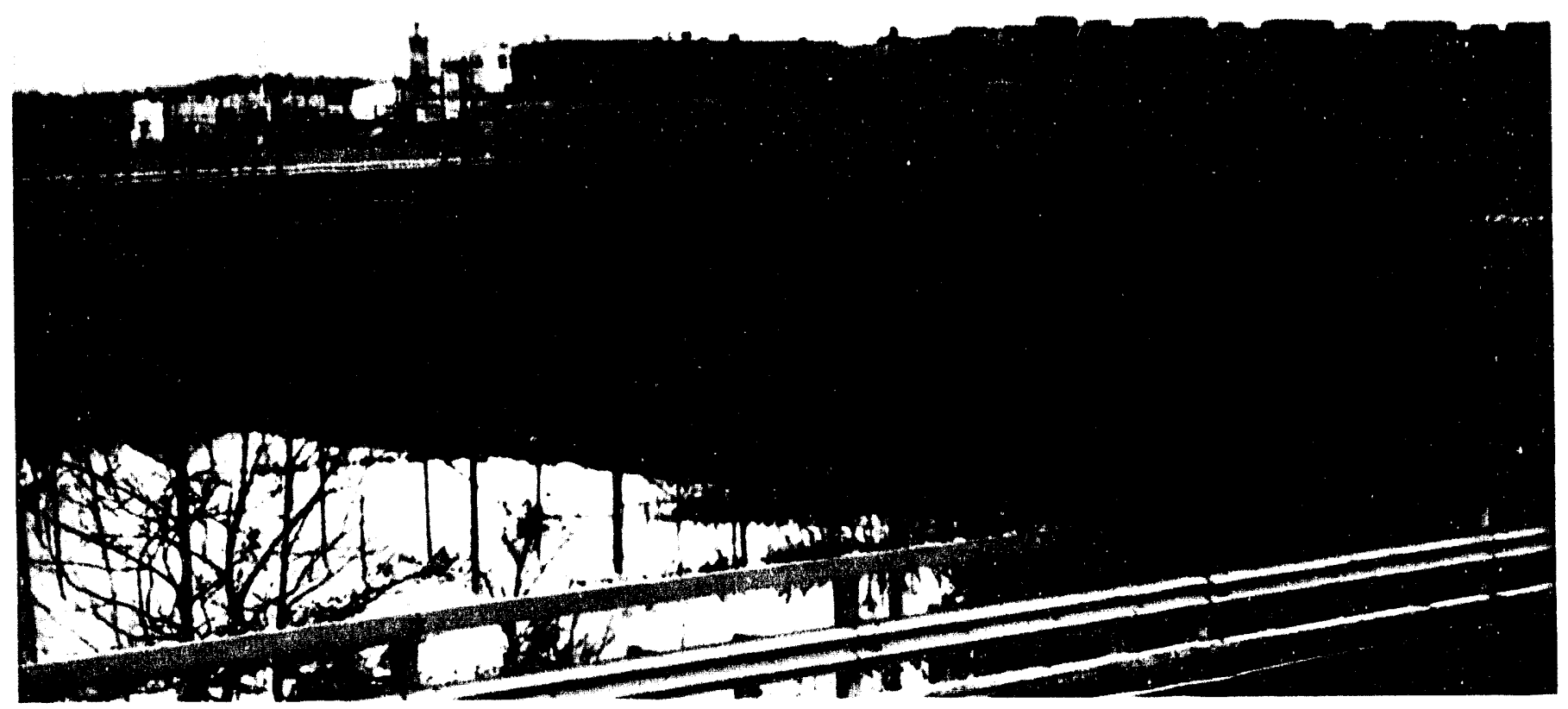

An estimated 50,000 tons of uranium hexafluoride are stored over several acres at Oak Ridge.

are being held without justification or hoarded because they "might be needed later." Chemicals held without any continuing need may be viewed as waste by regulatory agencies and could be subject to RCRA requirements. Moreover, some chemical wastes generated during past operations continue to be held because plans or technologies for their ultimate treatment or disposal have not been developed. In some cases, disposition has been delayed as a result of regulatory constraints.

As the examples in this subsection indicate, only limited progress is being made in planning for the disposition and removal of hazardous chemicals from DOE sites. Although such planning for chemical wastes is generally receiving increased attention, the same is not true for hazardous chemicals. Managers of local DOE and contractor organizations have not giveri sufficient priority to this aspect of planning. As a result, large quantities of chemicals are being retained at many sites, increasing the Department's vulnerability to chemical releases and exposures.

Examples. Because of the nation's changing defense requirements, large quantities of many unique chemicals are being held at Oak Ridge without a definitive, long-term strategy for their disposition. (See Vulnerability CSVR-OR-ORR-05 in Appendix E.) An estimated 50,000 tons of uranium hexafluoride are stored over several acres at the $\mathbf{K}-25$ Site. This material is being stored without engineered controls that would minimize the potential for environmental releases, even though many containers show evidence of excessive corrosion. Industrial quantities of lithium compounds have been stored for decades without plans for their disposition. (The exact amount 
of these materials is restricted information.) These materials are currently stored in the K-25 Process Building in vaults that were not intended for hazardous chemical storage and under less than ideal conditions. Over 50,000 pounds of mercury have been recovered from Building 9201-4 at the Y-12 Plant and are stored in flasks (76 pounds of mercury per flask). An estimated 50,000-100,000 pounds of mercury remain in the pipes and tanks of the building and are currently being recovered. In addition, over 43,000 pounds of beryllium and its compounds are known to exist in Building 9201-5.

At Hanford, about 3,000 gallons of nitric acid and 8,000 gallons of aluminum nitrate solution are being stored in 40 -year-old tanks at the Plutonium Finishing Plant, with no final plans for disposition. (See Vulnerability CSVR-RL-HAN-01 in Appendix G.) About 21,000 gallons of tributyl phosphate, slightly contaminated with radioactivity, are being held at the PUREX Plant. Plans to ship this material from Hanford to the Idaho National Engineering Laboratory for treatment have been impeded because regulatory differences between Washington and Idaho prevent its transport across State lines. Although other options are being assessed, the tributyl phosphate will probably be stored for several years before plans for treatment and disposal are finalized. Forty-eight 55-gallon drums of carbon tetrachloride, a suspected human carcinogen, are being stored outside the Plutonium Finishing Plant under a tent. Although inspection of the drums is difficult, several have already shown evidence of leaks. Preparations are being made to sell the material to a vendor, but this solution may not be implemented because carbon tetrachloride could be used as a solvent in cleanup operations under an option being considered in the Environmental Impact Statement for the facility.

At the Idaho National Engineering Laboratory, hazardous chemicals and wastes have been stored for extended periods of time without provisions for their final disposition. (See Vulnerability CSVR-INEL-CH-02 in Appendix H.) About 10,000 gallons of water used for cooling high-level radioactive waste tanks containing an estimated 500 parts per million of dichromate are being stored without secondary containment at the Idaho Chemical Processing Plant tank farm. Currently, the only plan for this material is to leave it in place until the tank farm is retired in 10-20 years, which only postpones disposition. About 1,000 gallons of hexone solvent extractant contaminated with fission products are being held in cell tankage in Building CPP-601 at the Idaho Chemical Processing Plant. Only tentative plans have been developed to transport this material to a licensed commercial incinerator for disposal. A bunker 
at the Army Reentry Vehicle Facility Site at the Idaho National Engineering Laboratory holds four containers of sodium-potassium mixed waste. The containers have been stored in this location since 1974 and were last inspected in 1979. During that last inspection,

two containers showed signs of external corrosion. Representatives from the DOE Chicago and ldaho Operations Offices recently met with

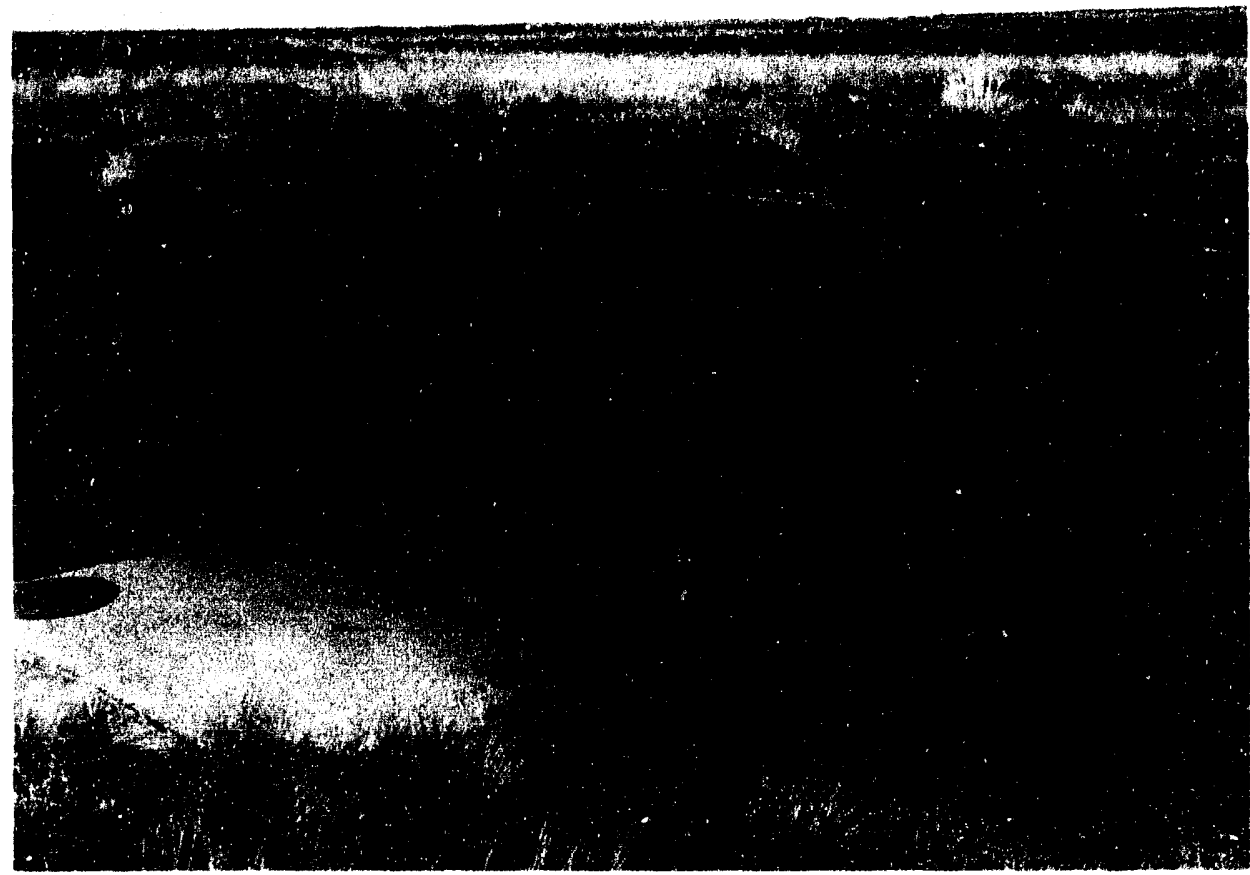
personnel from the Idaho Department of Environmental Quality to address treatment of this long-ignored waste.

Examples of inadequate planning for the removal and disposition of wastes generated within DOE facilities were found at Los Alamos. (See Vulnerability CSVR-LANL-CH01 in Appendix K.) In TA-3, Building 154, about 3,100 gallons of waste from the hot cells located in Wing 9 of the Chemistry and Metallurgy Research Facility have been held in four tanks for about 18 months without being adequately char-

Containers holding sodium-potassium mixed waste in this Army Reentry Vehicle Facility Bunker were last inspected in 1979, at which time they already showed signs of external corrosion. acterized. This waste was generated in hot cells where a variety of radionuclides and chemicals was handled; how-

ever, because the material has not been characterized, the exact composition of the waste is unknown. The field verification team also observed four drums of uncharacterized hazardous chemical waste in an abandoned physical chemistry laboratory at the Chemistry and Metallurgy Research Facility. Here, too, there was little indication that specific plans had been developed to dispose of these wastes. Uncharacterized waste is a source of hazards for workers. Components of such waste can readily degrade or react with other materials to generate more serious hazards through corrosion of containers or through formation of explosive or noxious gases that provide a mechanism for their release. 
Commendable Practices. The field verification team observed commendable practices related to the disposition of chemicals at two sites. At Savannah River, a chemical salvage program has been initiated to dispose of or find uses for chemicals that are no longer needed. This initiative is being integrated into a more comprehensive sitewide program under a newly formed Chemical Commodities Group. At Lawrence Livermore, the Chemical Exchange Warehouse Program has been established to enhance the use and control of chemicals, as well as to reduce the quantity of hazardous waste at the site.

\section{Chemical Storage Practices}

Description of Vulnerability. Some of the most serious vulnerabilities identified at DOE facilities derive from the improper storage of hazardous chemicals. Proper chemical storage conditions include (but are not limited to) the adequacy and integrity of chemical containment (e.g., tanks, drums, secondary containment), segregation of incompatible chemicals, ventilation, temperature and humidity controls, fire protection, and protection from weather. Field observations indicate that these conditions are not always met at sites. Problems related to chemical storage at some sites have been exacerbated by a reluctance to disposition inventories of hazardous chemicals that no longer have defined uses. (See Planning for the Disposition of Chemicals, p. 27.) Too often, older facilities that are not designed or equipped for chemical storage are being used for this purpose.

Chemicals are stored in varying quantities at all DOE sites. Although many storage conditions and practices observed during this review were adequate, examples of improper chemical storage, some of which are serious, were noted at virtually all participating sites. The widespread occurrence of improper chemical storage across many DOE sites and the lack of consistent storage practices within individual sites indicate that increased attention to these issues is needed by local DOE and contractor organizations.

Examples. At the Oak Ridge $\mathbf{K}-25$ Site, lithium hydroxide drums are stored in several vaults of the K-25 Process Building, an aging facilit that does not have adequate temperature or humidity controls. (See Vulnerability CSVROR-ORR-02 in Appendix E.) The drums, many of which

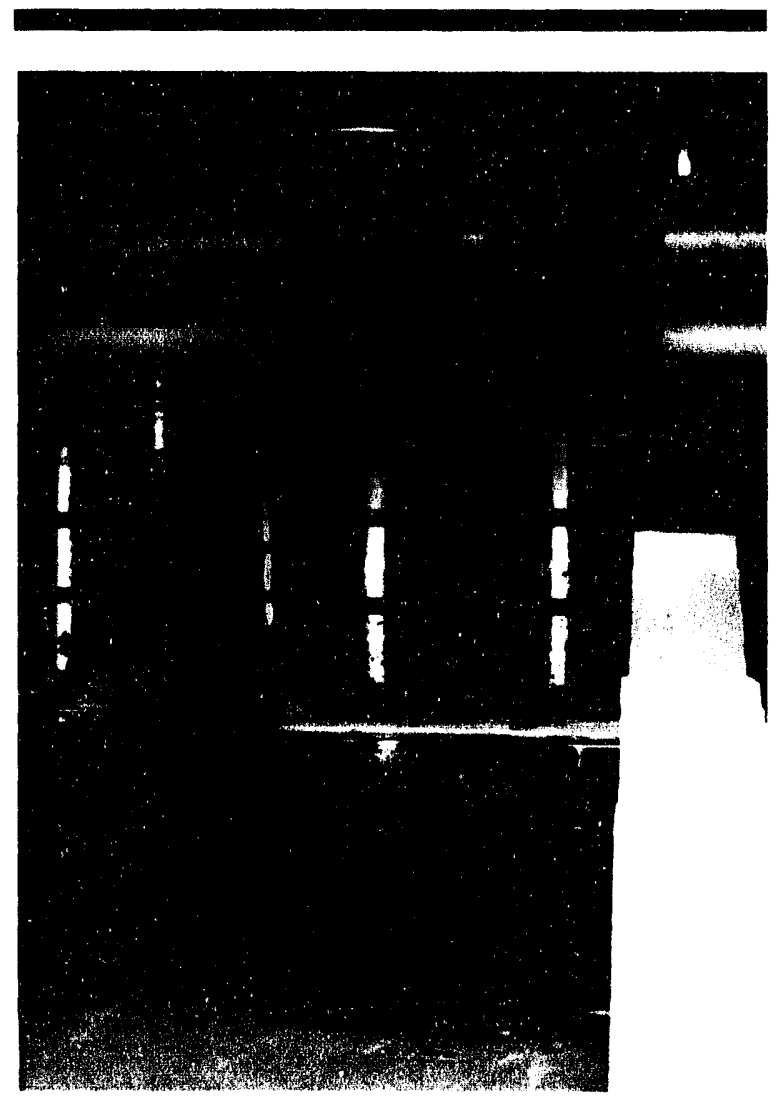

Several vaults in the K-25 Process Building at Oak Ridge house corroding drums containing lithium hydroxide. 
show significant corrosion, are stored on damaged wooden pallets that could fail and cause drums to fall and rupture. Although mitigating actions are being undertaken, personnel exposure to lithium hydroxide could result in caustic burns. As previously noted, about 4,500 cylinders containing as much as 50,000 tons of uranium hexafluoride are stored outdoors in another location at the $\mathrm{K}-25$ Site. (See Planning for the Disposition of Chemicals, p. 28.) Because the cylinders are exposed to the elements, corrosive failure of some cylinders has produced uranium hexafluoride leaks, which, in the absence of secondary containment, could pose a chemical hazard to anyone in the immediate vicinity.

Brookhaven stores hazardous materials in older facilities that often do not provide the minimal safety systems common to general industry. (See Vulnerability CSVR-BNL-000-01 in Appendix J.) The Hazardous Waste Management Facility lacks appropriate engineering controls and equipment to characterize and repackage hazardous materials. Therefore, resampling and repackaging, which are required because waste acceptance criteria and RCRA regulations have become more stringent, can only be performed by workers

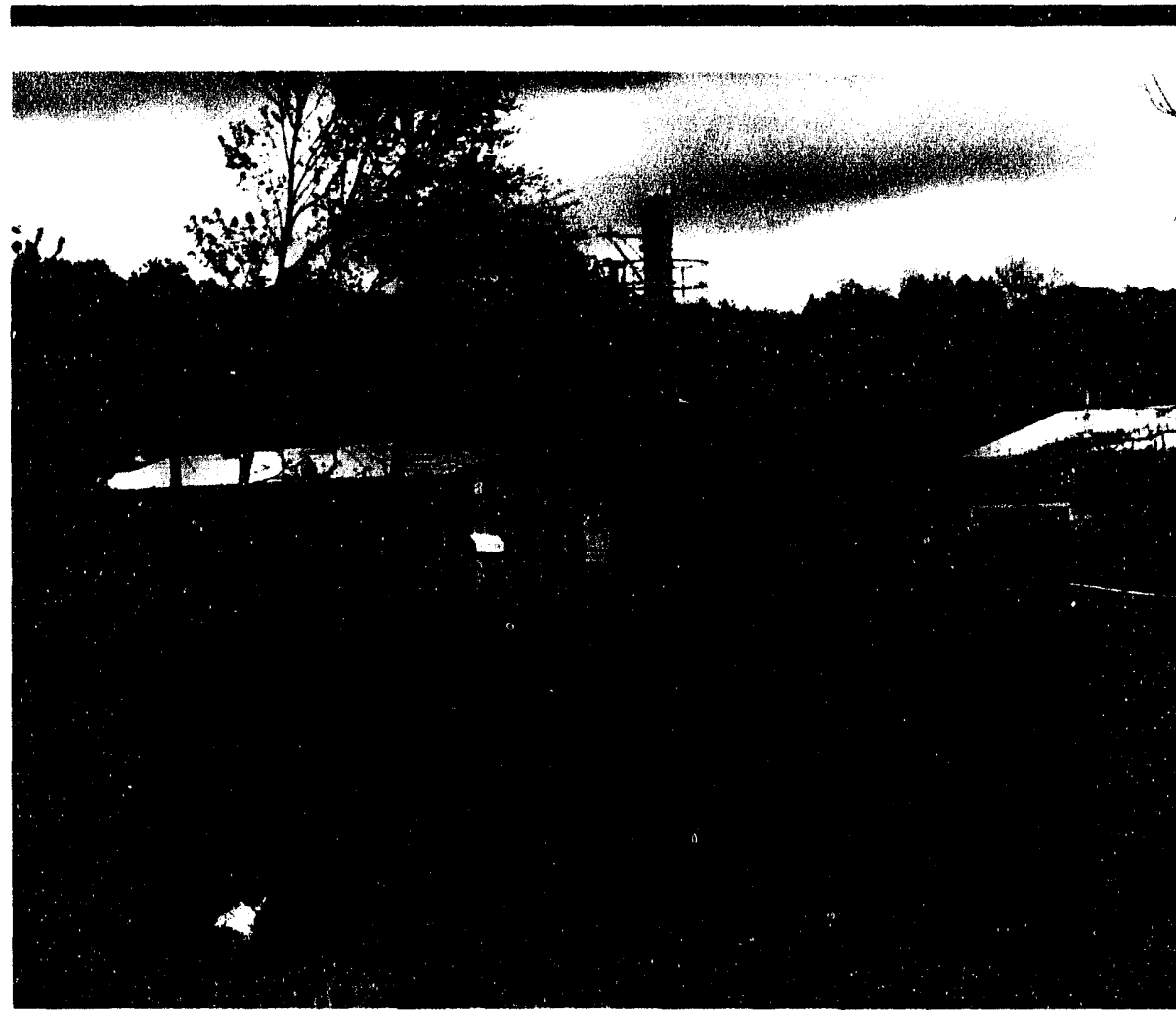

Maintenance at older facilities, such as the Hazardous Waste Management Facility at Brookhaven, has been deficient. wearing personal protective equipment. In general, predictive, preventive, and corrective maintenance of older facilities at Brookhaven has been deficient; for example, brass fittings on the chlorine gas manifold at Building 624 were corroded, and indications of a chlorine leak were observed immediately downstream from the pressure regulator on the six-bottle manifold. The inadequacies of facilities used to store hazardous materials at Brookhaven enhance the probability that storage containment will be breached, thereby exposing personnel to dangerous chemicals.

Hazardous chemicals and wastes are a legacy of decades of operations at Los Alamos. (See Vulnerability CSVR-LANL$\mathrm{CH}-01$ in Appendix K.) Many of 
these materials are being collected, characterized, stored, and prepared for disposal. Some are stored (at least temporarily) under less-than-sa'isfactory conditions that could lead to personnel hazards or environmental releases caused by leakage from corroded tanks, drums, or gas cylinders. About 500 waste cylinders are stored in TA-54, Area L. Many of these cylinders are old and corroded, and some (about 30) contain uncharacterized gases, including flammables (e.g., propylene, isobutane, hydrogen, and methane), corrosive gases (e.g., hydrogen fluoride, hydrogen chloride, nitric oxide, and sulfur dioxide), and toxic gases (e.g., arsine, phosphine, cyanogen, and phosgene). Efforts under way to resolve this vulnerability include completing the characterization of the contents of all waste cylinders and disposing of the cylinders as soon as possible. However, disposal of some cylinders will probably require the construction of new treatment units that could take years to complete. Leakage from corroded cylinders could release hazardous materials to the environment or expose workers to hazardous gases.

In Building 881 at Rocky Flats, potentially shock-sensitive chemicals were stored in metal office cabinets that were designed for interim storage of reactive chemicals. (See Vulnerability CSVR-RFP-000-01 in Appendix I.) The location of these cabinets in the hallway near Room 127 was easily accessible to personnel moving through the first-floor corridors and could have resulted in the contents of the cabinets being disturbed. Also, the plutonium aqueous recovery system in Building 371 (shut down in 1984) has large quantities of plutonium nitrate left in the facility's tanks and ancillary piping. (See Vulnerability CSVR-RFP-000-03 in Appendix I.) Some of the piping has no secondary containment, and none of the piping is constructed of material that is chemically suitable for longterm storage of corrosives such as nitric acid. A considerable fraction of the piping is located above floor level and in spaces that are difficult to access for inspection purposes. In the event of a leak, these circumstances

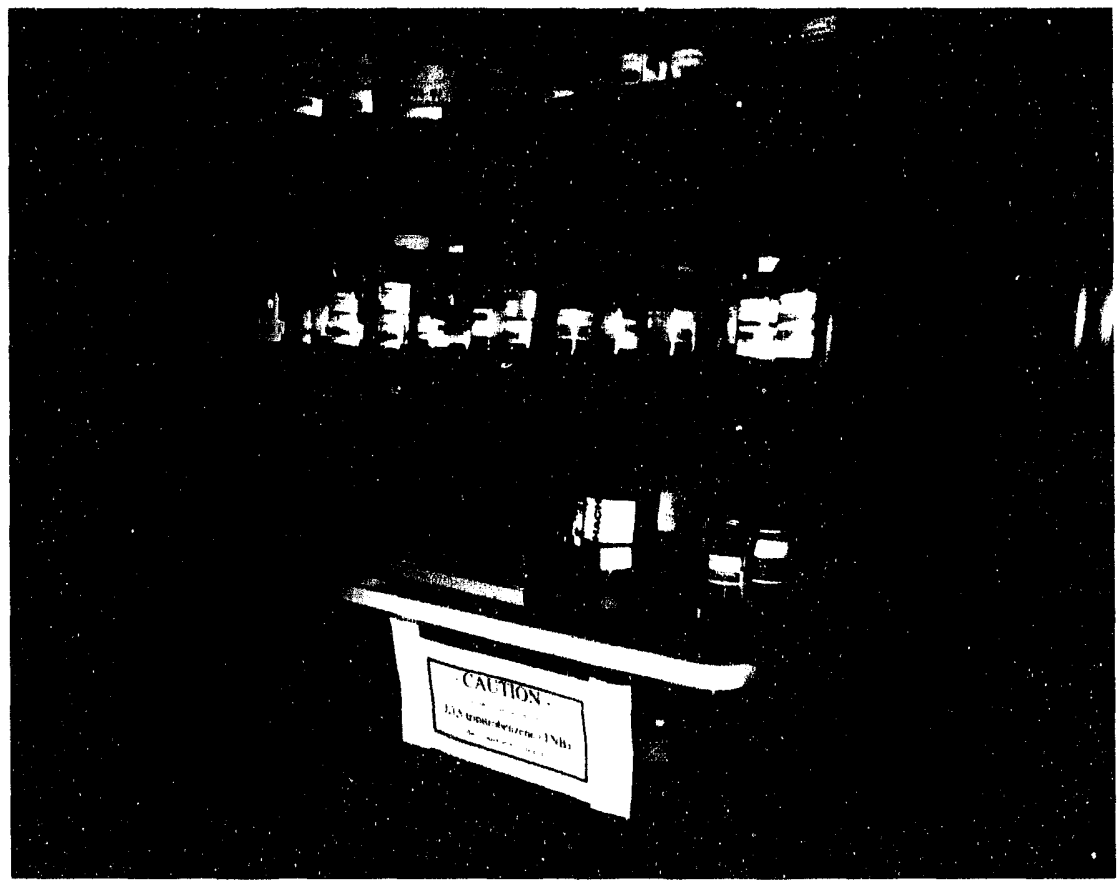

Metal office cabinets similar to these were used to store potentially shock-sensitive chemicals in a hallway of Building 881 at Rocky Flats. 
would provide the potential for serious injury to workers conducting routine inspections of the piping.

At Hanford, large quantities of surplus hazardous materials have been stored for prolonged periods in production facilities being transitioned to deactivated status. (See Vulnerability CSVR-RLHAN-01 in Appendix G.) Without adequate engineered and administrative controls, prolonged storage of hazardous chemicals in shutdown or deactivated facilities could lead to personnel hazards or environmental releases caused by spills, evaporation, leakage from corroded tanks or drums, or decomposition of chemicals. The relatively long-term storage of hazardous chemicals under less-thanoptimum conditions at the Plutonium Finishing Plant and the PUREX Plant represents a chemical safety vulnerability. Storage of corrosive chemicals (i.e., nitric acid, aluminum nitrate) in old tanks (for which corrosion surveillance may be difficult or impossible) poses the risk of leaks that could lead to environmental contamination and worker exposure. The carbon tetrachloride stored outdoors in drums near the Plutonium Finishing Plant was purchased for use in the plant process; however, if plans to deactivate the facility are implemented, the substance will no longer be needed. Meanwhile, carbon tetrachloride, a suspected human carcinogen, is being stored on poly-spill pallets with only a tent to provide protection from the weather. (See Planning for the Disposition of Chemicals, p. 29.) Several drums have already leaked because of corrosion. Although these releases have not resulted in injuries, the potential risk to workers is significant.

Storage of incompatible chemicals was cited at several facilities visited by the field verification teams. Because of space limitations at the Oak Ridge National Laboratory, a number of excess chemicals were placed together in a container at an open RCRA satellite storage area without regard to their potential incompatibilities. These chemicals included flammables, potential corrosives, and other materials. At Savannah River, storage of incompatible chemicals was observed in at least three areas. For example, gallon containers of nitric acid and hydrogen chloride acid were stored together in a corrosive storage cabinet at the 773-A Chemical Storage Facility. At Rocky Flats, materials identified as "reactive" were observed in the flammable storage area of the General Warehouse (Building 551). These chemicals were stored on a shelf with other types of chemicals and were segregated from one another by two strips of yellow tape. These examples all involve relatively small laboratory quantities that could nonetheless lead to fire, explosion, or worker injuries. 
Commendable Practices. At the Idaho National Engineering Laboratory, Argonne-West has taken a proactive approach to the implementation of a model chemical hygiene program to improve storage, labeling, and administrative controls for all chemicals in the Analytical Laboratory. Specifically, Argonne-West has formulated a methodology for segregating normal laboratory chemicals, carcinogens, organics, and other materials and has reduced the inventory of high-risk chemicals such as ethers.

\section{Condition of Facilities and Safety Systems}

Description of Vulnerability. Many DOE facilities that contain or handle hazardous chemicals have deteriorated to the extent that they represent chemical safety vulnerabilities to workers and the environment. Deficiencies related to deteriorating roof structures and ventilation systems at many facilities either provide pathways for dispersing hazardous chemicals to the environment or reduce the level of protection afforded workers against chemical hazards in the workplace. Safety and essential support systems provide engineered barriers within operating facilities and are used, along with administrative controls, to protect workers, the public, and the environment from operational hazards-including chemical hazards. In many instances, these systems have not been effectively developed and maintained, thereby decreasing the margin of protection.

\section{These deficiencies are due to:}

- declining maintenance budgets;

- DOE's change in mission, which has resulted in an increase in the number of surplus facilities (i.e., facilities declared by DOE program offices to be available for other uses);

- lack of clearly understood and accepted ownership responsibilities for surplus facilities that have not been formally accepted by the DOE Office of Environmental Management for transition to D\&D; and

- the overall aging of DOE facilities and equipment. (See Transition of Facilities From Active Status to New Missions or to Decontamination and Decommissioning, p. 56.)

The deterioration of facilities and their associated safety systems is widespread at most DOE sites. The examples that follow provide evidence that facility structures are degrading (which causes a corresponding rise in the risk of worker exposures and environmental 
releases); that maintenance of important safety systems has been inadequate; and that some facilities and safety systems are in use beyond their projected design life. DOE has not effectively addressed these issues. Since there is little evidence that this trend has been reversed, such conditions can be expected to worsen over time.

Examples. The Chemistry Laboratory (Building B-222) at Lawrence Livermore contains a large number of hazardous chemicals, including nitric acid, hydrochloric acid, and various thorium and ura-

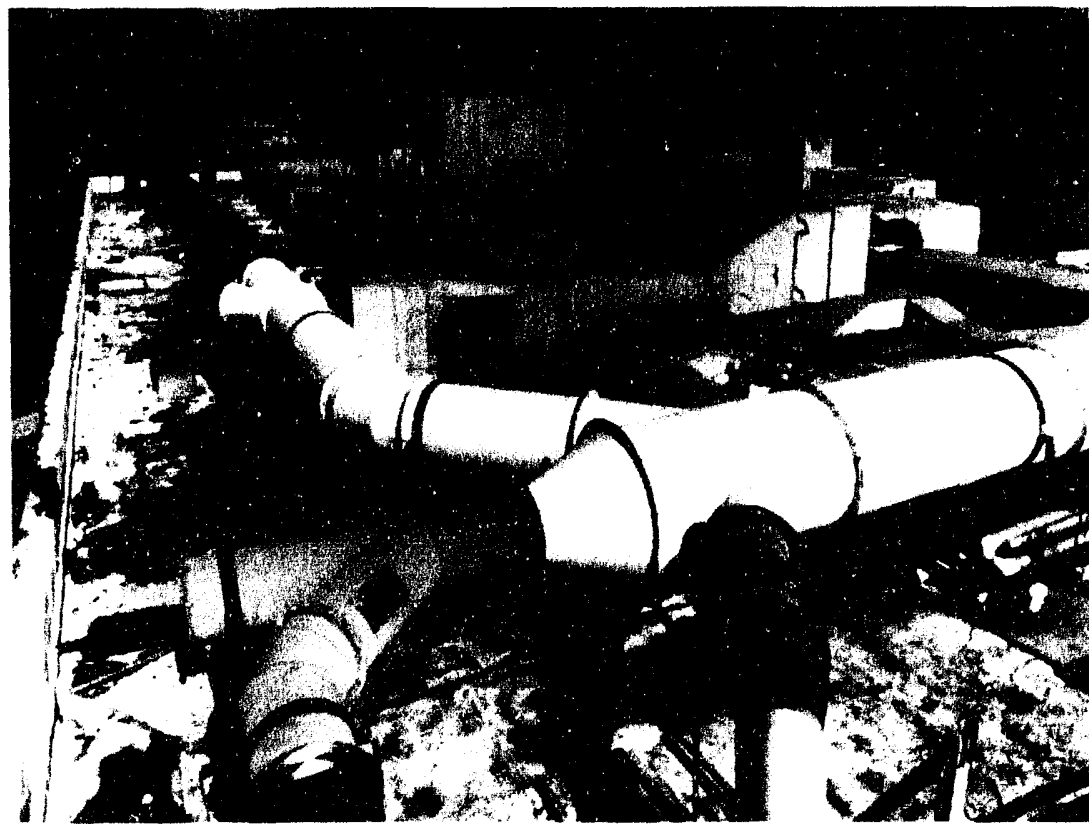

The Chemistry Laboratory Building at Lawrence Livermore has a badly deteriorating roof that leaks profusely. nium compounds. (See Vulnerability CSVR-LLNL-FM-01 in Appendix D.) The degree to which hazardous chemical residues exist throughout the facility has not been established. The roof of this facility has deteriorated badly and leaks profusely, necessitating frequent repairs by maintenance personnel. During these repairs, the ventilation systems serving chemical laboratories and chemical fume hoods are shut down. Strict implementation of complex administrative controls must be enforced to prevent potential worker exposure to hazardous chemicals. The facility is still in use as a chemical laboratory, but once turned over for D\&D, uncharacterized chemical residues throughout the building will be susceptible to dispersion and migration.

The roof of the Explosives Development Processing Facility at Los Alamos also shows evidence of cracks and leaks. (See Vulnerability CSVRLANL-FM-02 in Appendix K.) As a result, chemical residues (uncharacterized high-explosive materials such as RDX) from processing explosive materials could be spread by drains that flow through old collection basins before entering an outfall. This situation may be exacerbated in the near future when processing activities are transferred to the facility from another DOE site because of the DOE weapons reconfiguration initiative.

At Sandia, an analytical chemistry laboratory complex is housed in aging facilities (Buildings 805, 806, and 807) that are being serviced by support equipment near the end of its expected life cycle. (See Vulnerability CSVR-SNL/NM-FM-03 in Appendix L.) 
Inadequate configuration management of these facilities has resulted in the gradual degradation of essential utilities and ventilation systems. These systems protect workers from toxic materials, carcinogens, and low levels of radionuclides handled in the laboratory complex. The affected systems include (1) the makeup air unit that provides heating and cooling for Building 805 (the unit must operate at full load because of the large amount of air exhausted through chemical fume hoods and localized chemical equipment ventilation systems); (2) water chillers in Buildings 805,806 , and 807 ; (3) chilled-water circulation pumps in Buildings 805,806 , and 807 ; and (4) several fume hood exhaust systems serving two or more laboratory rooms. Operations and maintenance personnel for these facilities reported that the systems in question were operating at, or slightly beyond, maximum design capacities; experiencing a higher than normal breakdown incidence rate; and contributing to suspect indoor air quality.

At Rocky Flats, more than 2,400 preventive maintenance items are delinquent by more than a month. (See Vulnerability CSVRRFP-000-04 in Appendix 1.) Many of these items involve important safety systems that include exhaust fans; pressure relief devices; filter systems; chemical containment systems; and

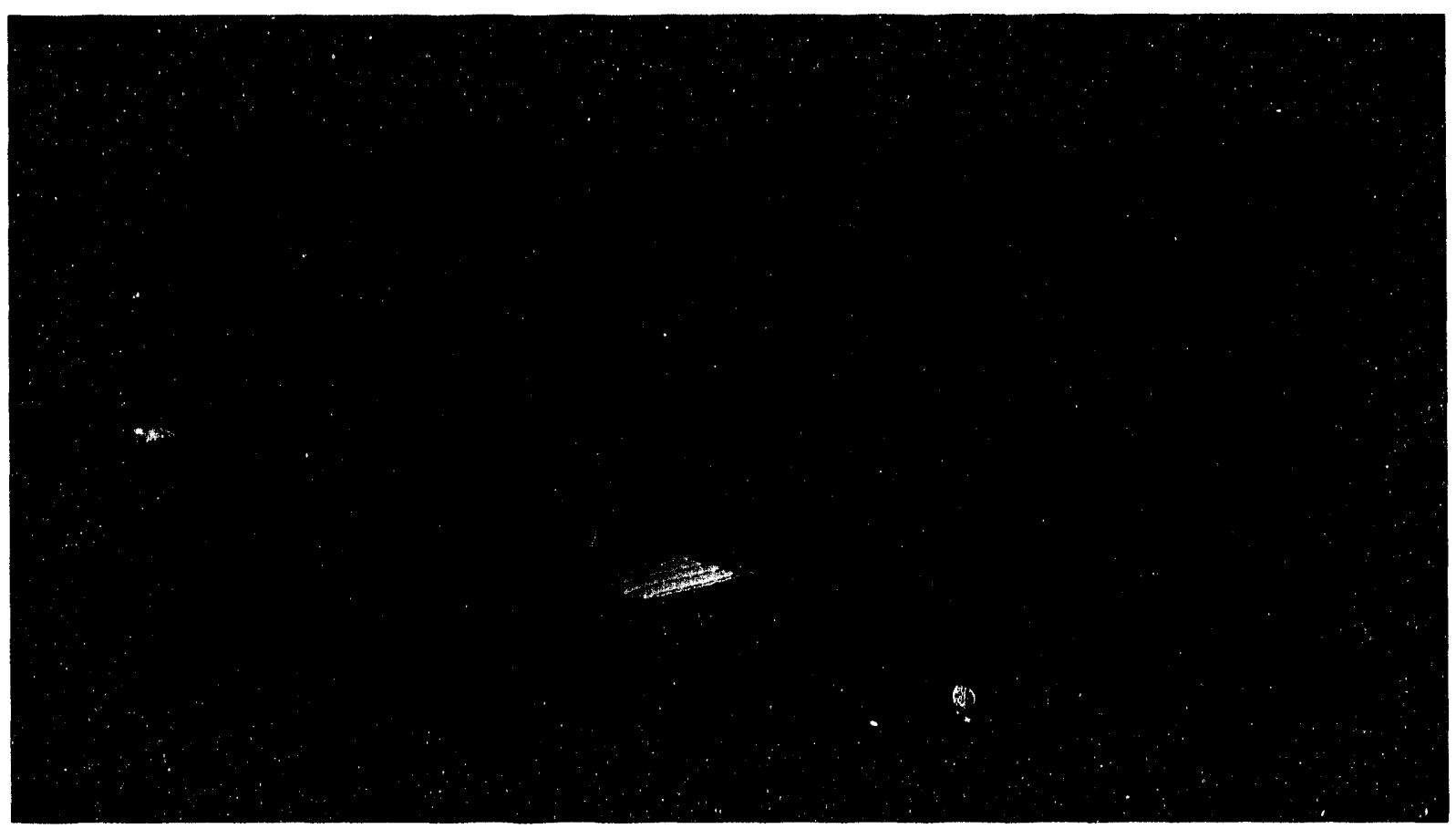

More than 2,400 preventive maintenance items are delinquent at Rocky Flats. 
various analyzers, detectors, and alarms. Many of these systems are intended to protect workers and the environment from chemical hazards. When such systems are not properly maintained, the likelihood of exposure to chemical hazards increases. Maintenance of important safety system equipment has been an issue at Rocky Flats for many years. When the field verification team visited Building 371 , electric motors serving two of the three major ventilation fans were out-of-service, leaving only one ventilation fan to serve the building. This condition could lead to reduced airflow and, thus, reduce the level of protection to workers from such hazardous chemicals as nitric acid and plutonium nitrate. Further, the capacity of the feedwater pump for the cooling tower that serves the central storage vault in Building 371 had dropped from a 10,000-gallon-per-minute flow rate to 5,000 gallons per minute, which caused the temperature in the vault to rise from an optimum of $70-80^{\circ} \mathrm{F}$ to $100^{\circ} \mathrm{F}$. The chemical storage vault houses reactive chemicals, including special nuclear materials, in an inert atmosphere. Temperature excursions of this type increase the potential for the release of hazardous materials to the surrounding environment.

At Brookhaven, the chlorine leak detector for the chlorine delivery system in the Central Water Treatment Plant was improperly placed. (See Vulnerability CSVR-BNL-000-03 in Appendix J.) Since the device would not immediately detect the flow of leaking chlorine, there is an increased likelihood that workers entering the chlorination room could be exposed. Some minimal safety systems are absent in the Hazardous Waste Management Facility at Brookhaven. (See Vulnerability CSVR-BNL-000-01 in Appendix J.) For example, safety showers at the facility were not maintained to an acceptable level. Functional maintenance testing for another emergency shower has not been conducted since 1991 due to water supply problems. Such testing is necessary to ensure that fully functioning showers will be available in the event of a hazardous materials spill.

A restricted-workday case was recently recorded at Savannah River when a worker received second-degree burns after coming into contact with a 94-percent sulfuric acid solution sprayed from a broken 1 -inch acid line. (See Vulnerability CSVR-SRS-000-01 in Appendix F.) The spray from the acid line reached an employee walkway at a distance of 20-30 feet away from the break. No safety system containment features or barriers were in place to protect employees in the nearby walkway, and no surveillance requirements had been established to monitor for deterioration of the acid line. Had the acid spray reached the worker's eyes, blindness could have resulted. 
At the Oak Ridge K-25 Site, lithium hydroxide from the $Y-12$ Plant is being stored in Building $\mathrm{K}-25$ (in Vaults 7, 7A, and 7B). (See Vulnerability CSVR-OR-ORR-04 in Appendix E.) Although repairs are under way, the fire protection system in this area has deteriorated and the roof is leaking. Such deficiencies have reduced the reliability and effectiveness of vital safety systems, thereby increasing the potential for fire and airborne dispersal of lithium hydroxide.

Commendable practices. The removal of hazards (including

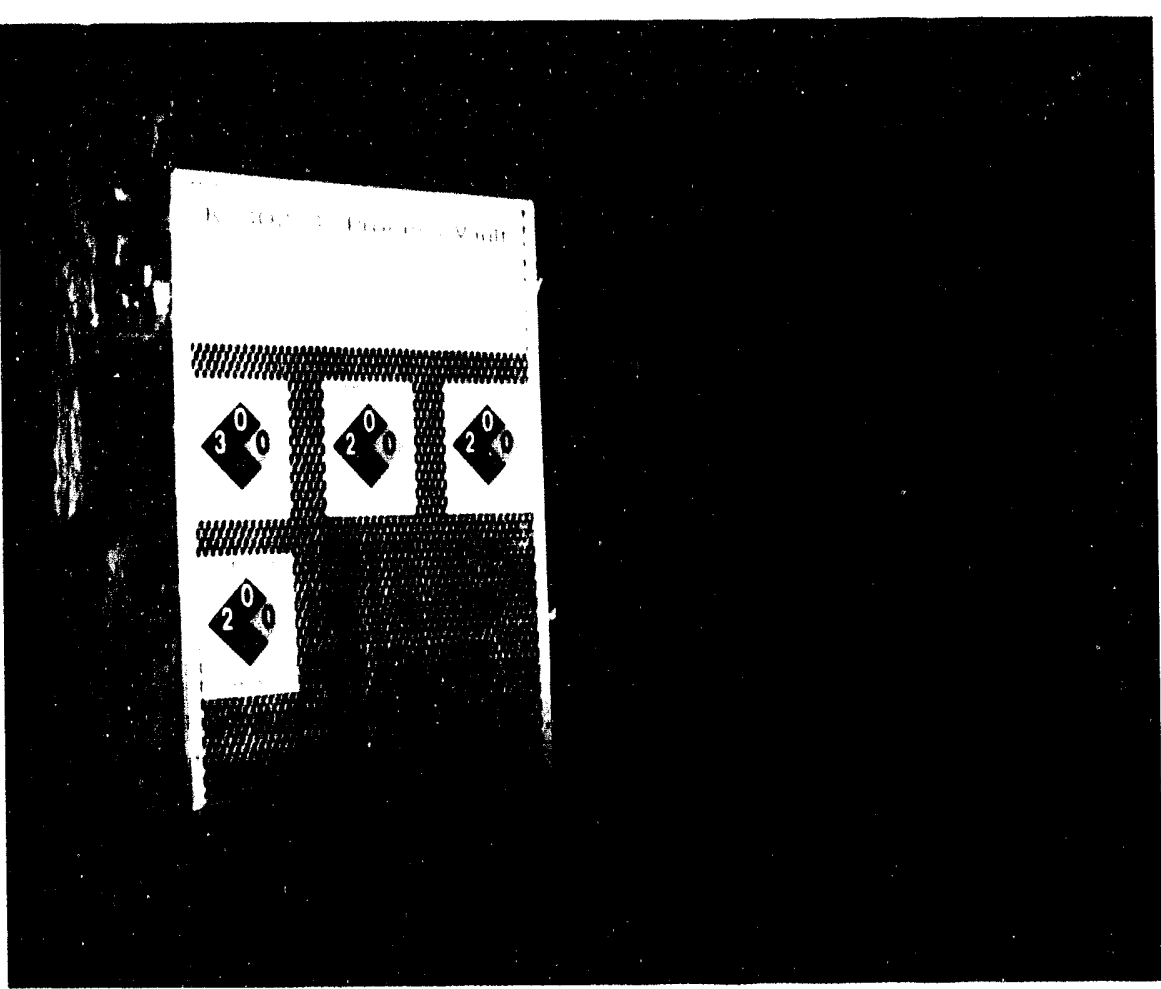

Deteriorating fire protection systems in the vaults used to store chemicals at the Oak Ridge K-25 Building increase the potential for fire and airborne dispersal of hazardous chemicals. chemical hazards) from facilities

and more effective approaches to maintaining facilities have been implemented at some sites. At Sandia, a Facilities Space Management Program has been implemented to ensure that chemical safety hazards are addressed in surplus facilities before they are transferred to another user. This concept is effective for deteriorated facilities that clearly pose hazards to workers or the environment. At Brookhaven, the Maintenance Control Reporting System is being used to develop comprehensive work packages for corrective and preventive maintenance activities. This commendable practice provides a more effective mechanism for maintaining deteriorating facilities.

\section{Abandoned and Residual Chemicals}

Description of Vulnerability. Chemicals and chemical residues have often been abandoned in equipment or facilities that are no longer needed. This conclusion is based on observations at several DOE sites, indicating that sitewide requirements do not exist, or are not enforced, for characterizing and removing chemicals and chemical residues from surplus equipment or facilities. Few plans have been developed to dispose of such substances from aging or surplus facilities. These circumstances have contributed to potential vulnerabilities affecting workers, the public, and the environment through (1) workers inadvertently coming into contact with hazardous chemicals or chemical residues, particularly during D\&D operations; (2) increased public access to areas and facilities containing
Chemicals and chemical residues have often been abandoned in equipment or facilities. 
chemical hazards; and (3) environmental release of hazardous chemicals or chemical residues due to degradation of abandoned facilities or equipment.

Although the abandonment of chemicals and chemical residues in facilities and equipment does not appear to be widespread at all DOE sites, the examples found during field verification visits indicate serious vulnerabilities in this area that could result in worker exposures and environmental releases. The examples that follow describe those vulnerabilities and, in one case, discuss their actual

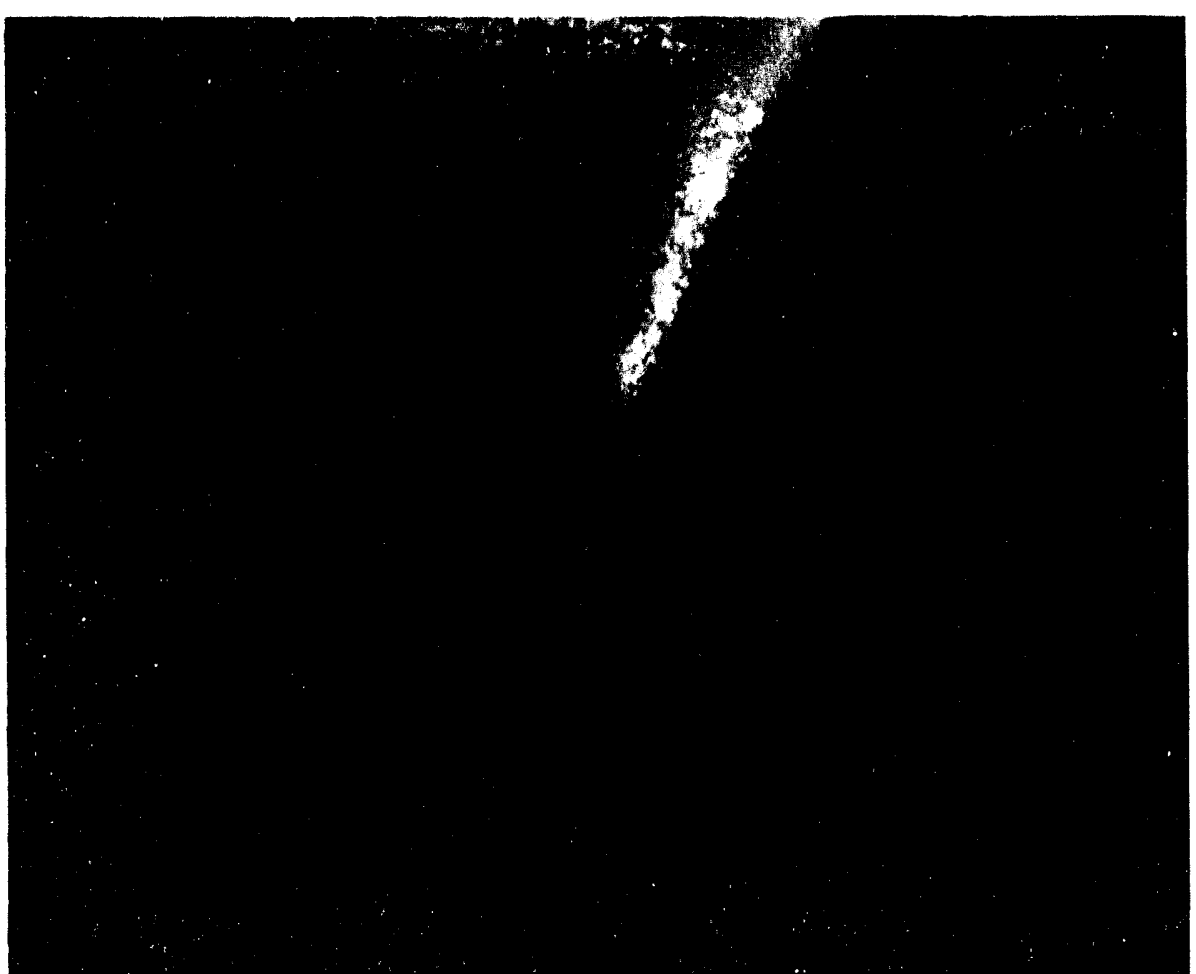

This uncharacterized chemical residue was found in one of the towers of Savannah River's abandoned Heavy Water Extraction Facility. consequences for worker safety. In many instances, contractor management has not established sitewide requirements for characterizing and removing chemicals and chemical residues from abandoned facilities and equipment. This situation does not appear to be improving. Until DOE fully implements a consistent set of requirements for characterizing and removing chemicals and residues from abandoned facilities and equipment, these vulnerabilities will persist.

Examples. Some facilities at Savannah River have been abandoned with chemical residues left in place. (See Vulnerability CSVR-SRS-000-02 in Appendix F.) The 412-D Heavy Water Extraction Facility, for example, was abandoned with uncharacterized chemical residues left inside piping and tanks.

The tank residue was an oily substance with a $\mathrm{pH}$ of about 3.3; the pipe residue was a yellow, unanalyzed solid; and both may have contained sulfur. While D\&D operations were being carried out at this facility, a worker apparently inhaled noxious gases after a pipe containing uncharacterized chemical residues had been cut with a torch. In another case at the abandoned 184-P Power House, the field verification team observed uncharacterized chemical residues near the cleanout door at the base of the smokestack, a location that was readily accessible by workers. (See Characterization of Chemicals, p. 19.) 
At Rocky Flats, the plutonium aqueous recovery system located in Building 371 was shut down in 1984. (See Vulnerability CSVRRFP-000-03 in Appendix I.) Large quantities of plutonium nitrate were left behind in the facility's tanks and ancillary piping. Some of the piping has no secondary containment, and the piping is not constructed of material that is chemically suitable for the long-term storage of corrosives such as nitric acid. In the event of a leak, these circumstances create a potential for serious injury to workers conducting routine inspections of the piping.

Several Oak Ridge facilities have been placed in caretaker status without proper cleanup of chemicals or chemical residues. (See Vulnerability CSVR-OR-ORR-03 in Appendix E.) For example, Building K-725 at the K-25 Site was used from 1946 to 1952 to support the Nuclear Energy for Propulsion of Aircraft Project and was abandoned without cleanup. The building and ductwork are known to be contaminated with hazardous materials, possibly including beryllium, mercury, and uranium. The shielded-cell facility in Building 3047 at the Oak Ridge National Laboratory houses a sump known to contain uncharacterized radioactive chemical residues left behind when chemical processing was discontinued. In Building K-25, chemical residues such as Freon, lubricating oils, and uranium hexafluoride were left in place, along with substantial amounts of uranium. In the event of their release, these abandoned chemicals and chemical residues could present hazards to workers and the environment.

At Lawrence Livermore, only limited strategic planning has been conducted for the disposition of aging or inactive facilities that may contain hazardous or mixed waste. (See Vulnerability CSVR-LLNLFM-01 in Appendix D.) The Chemistry Laboratory (Building 222) is about 40 years old and contains a variety of hazardous and toxic chemicals, including nitric acid, sulfuric acid, various uranium and thorium compounds, and mixed waste residues. Characterization of chemical residues has not been completed for the facility, and plans have not been finalized for their removal before $D \& D$ begins. Because many of these residues may be susceptible to migration or dispersion, they represent a potential vulnerability to workers, the public, and the environment.

Commendable Practices. During field verification visits, commendable practices involving the removal of chemical residues in process equipment were observed at some sites. At the Idaho National Engineering Laboratory, chemical storage and processing systems in the Fluorinel Dissolution Process and Fuel Storage Facility 
were properly flushed and cleaned of chemical residues. The processes used for these operations were documented. A similar process was used at Sandia for the Light Initiated High Explosive Facility, which was thoroughly cleaned of chemical residues before it was placed in safe standby.

\section{Inventory Control and Tracking}

\section{Accurate inventory information is a crucial aspect of chemical safety.}

Description of Vulnerability. Most DOE sites have established systems to record and monitor chemical inventories. However, such systems do not always provide up-to-date information about the quantity and location of these chemicals, nor do they provide information on all chemicals in use at a particular site. DOE guidance on what constitutes an acceptable chemical inventory system is limited. Systems currently in place have been developed and implemented to meet criteria established by the implementing site. As a result, there is considerable disparity in the quality and effectiveness of these systems at different sites. Accurate inventory information is a crucial aspect of chemical safety because it enables implementation of systems to control and minimize the onsite quantities of hazardous chemicals and it provides emergency responders (such as firefighters) with the information they need to respond to emergencies in areas where hazardous chemicals are stored. Hence, the absence of accurate information on chemical inventory increases the possibility that workers and the public will be exposed to hazardous chemicals or that chemicals will be released to the environment.

Management at virtually all DOE sites has recognized the need for chemical inventory control to protect workers, the public, and the environment from damaging incidents involving hazardous chemicals. The inventory control system at some facilities is used primarily to fulfill the reporting requirements of Title III (Emergency Planning and Community Right-to-Know) of the Superfund Amendments and Reauthorization Act. Other facilities also use their systems as realtime or near-real-time monitors of the onsite inventory of chemicals. More sophisticated systems under development (see Commendable Practices in this subsection) will be able to provide information on both the quantity and the location of hazardous chemicals. However, as illustrated by the examples below, the urgency for committing the effort necessary for achieving effective chemical inventory control in an acceptable period of time will require greater emphasis and attention by local DOE and contractor organizations. 
Examples. The Chemical Control System at Rocky Flats was designed solely to track chemicals regulated under Title III of the Superfund Amendments and Reauthorization Act. (See Vulnerability CSVR-RFP-000-01 in Appendix I.) As a result, plant management cannot provide accurate and complete inventories of hazardous chemicals for all facilities on a real-time or near-real-time basis. The inability to provide accurate and complete inventory information on a real-time basis affects the safe management of hazardous chemicals by limiting custodial responsibility to the managers of those few buildings (e.g., Building 559) in which systems have been implemented to track all chemicals. It also limits the ability of site manag-

ers to control building modifications and other changes that could support new missions or transition to D\&D. Accurate information about current chemical inventories for each area is required for the effective management of these changes. The range of hazardous materials in various buildings at Rocky Flats includes organic solvents, organic and inorganic acids and bases, lead-based paint, carcin-ogens, heavy metals, and hazardous and mixed wastes. The absence of effective inventory controls creates the potential for exposure

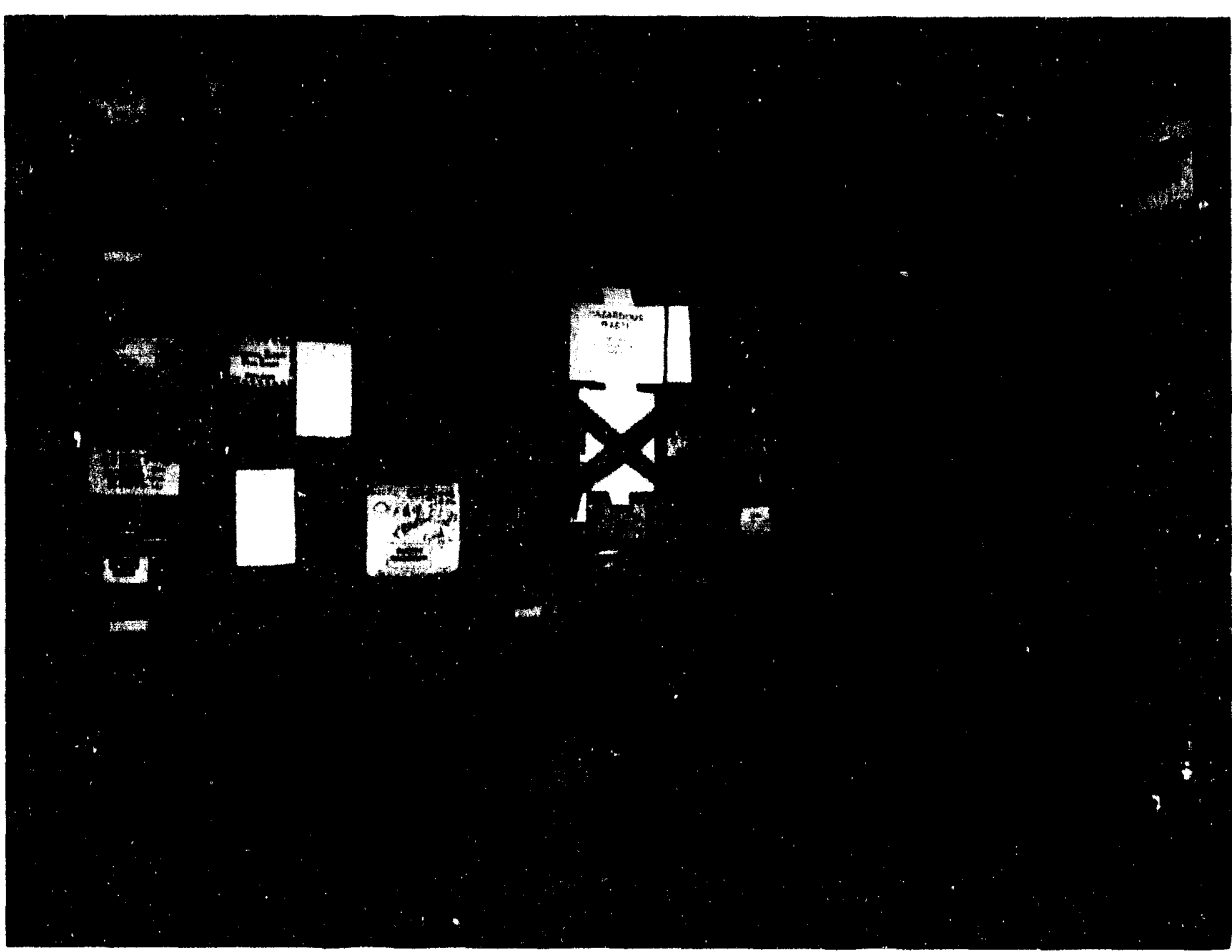

Ineffective inventory and tracking systems could lead to co-locating incompatible chemicals, as shown here in a Building 551 storage room at Rocky Flats. of workers and the public to hazardous chemicals or for fires and explosions caused by the proximity of incompatible chemicals. Building 881 at Rocky Flats may be used as a pilot for a plant-wide project to address these weaknesses.

At Savannah River, a system has not been established to manage chemicals from their procurement through final disposition. (See Vulnerability CSVR-SRS-000-03 in Appendix F.) Furthermore, there 
is no system for tracking hazardous chemicals after they are delivered to the site. Savannah River management has recognized this weakness and is establishing a Chemical Commodities Management Group, which will be functional by the end of 1994 .

Management at Sandia has developed and is using a data base (i.e., ChemMaster) to maintain an official chemical inventory record. However, the system has serious deficiencies. First, it does not actually track hazardous chemicals; rather, it indicates the maximum quantities that could be in inventory. Second. the chemical inventories of some organizations are not updated promptly.

Although Brookhaven maintains chemical inventory systems, containers of a hazardous chemical (ethyl ether) that were found in a Brookhaven laboratory fume hood were not included on the chemical inventory lists. (See Vulnerability CSVR-BNI-000-01 in Appendix J.) Ethyl ether is a highly volatile, flammable liquid that, if undetected, could adversely affect worker performance or contribute to the potential for fires or explosions. Other hazardous chemicals at Brookhaven may have been omitted from formal site inventories because procedures for compiling such inventories are lacking. Clear definition is not provided for what materials should be tracked, and no mechanism has been established for identifying holdings of hazardous chemicals that may have existed before the current systems were implemented. Thus, the potential exists for accumulating hazardous chemicals in operations areas. In general, the lack of specificity in the information provided by chemical inventories contributes to the potential for exposing workers to hazardous chemicals. Both Sandia and Brookhaven plan to implement new systems that will correct these deficiencies; however, for the present, the chemical inventory control systems are flawed and weaknesses based on inaccurate or incomplete information persist.

Commendable Practices. Field verification teams observed commendable inventory control and tracking practices at a number of sites. Pacific Northwest Laboratory at Hanford has implemented the computer-based Chemical Management System, which serves as a model for other sites and is being adapted for use at Brookhaven, Lawrence Berkeley National Laboratory, and Argonne National Laboratory-West. The Facility Information Management System under development at Lawrence Livermore could ultimately have the potential to access chemical inventory information from any site location. Los Alamos and other sites have developed methods to use bar-coded labels on containers of 
hazardous chemicals and waste to facilitate tracking. Several sites have reduced the use of chlorine gas and instituted more stringent administrative controls over its use. Savannah River has replaced chlorine gas with the much-less-hazardous sodium hypochlorite for use in its primary domestic water treatment plant.

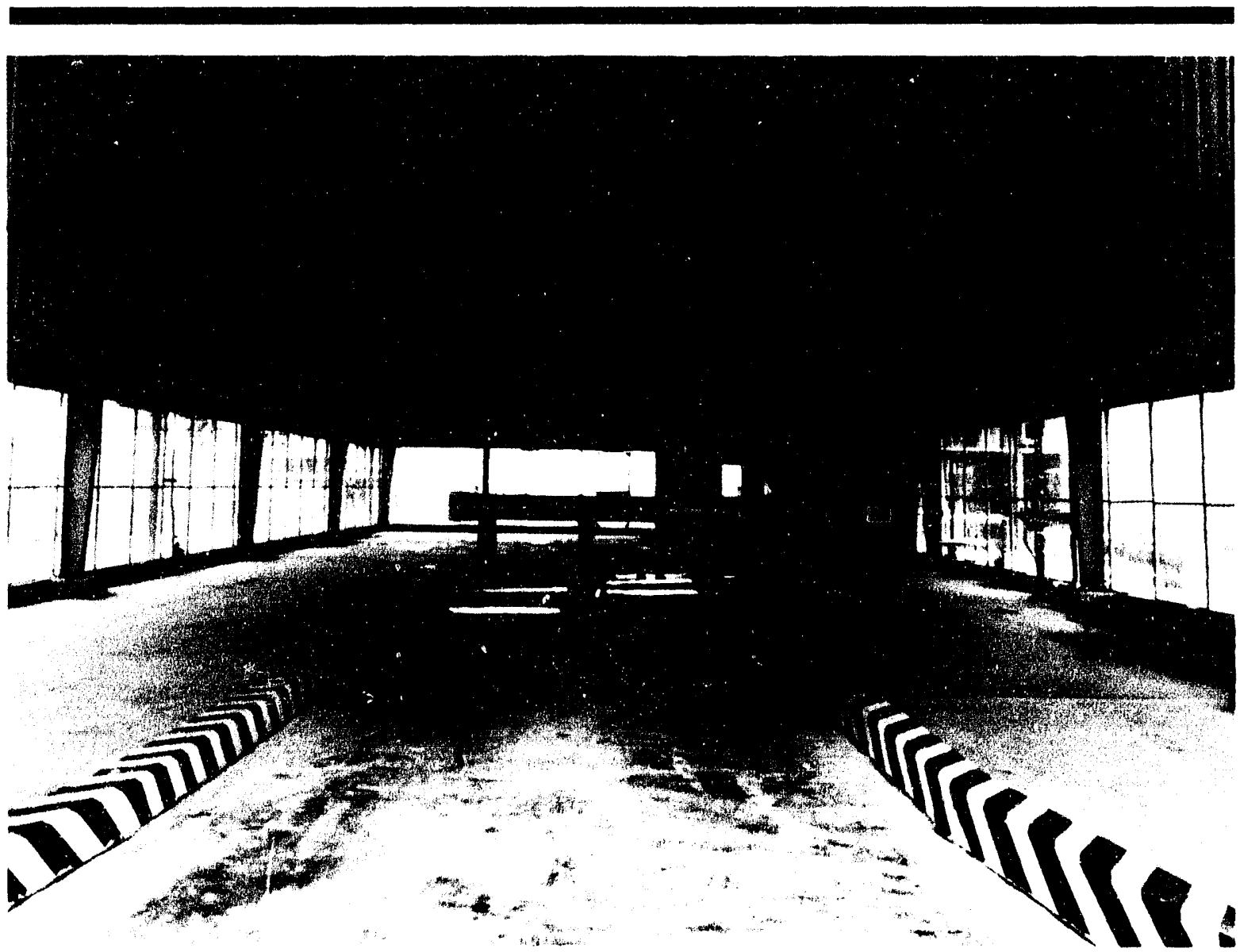

This water treatment facility at Savannah River held as many as 70 1-ton cylinders of chlorine gas before the site began to use sodium hypochlorite in its water treatment process. 


\section{Management System Weaknesses}

\begin{abstract}
A
\end{abstract} nalysis of facility-specific, site-specific, and generic vulnerabilities identified during this review indicates several weaknesses in DOE's overall approach to chemical safety or to particular management systems that contribute to the perpetuation of these vulnerabilities. Management systems provide the structure to facilitate the development, implementation, and oversight of effective chemical safety programs. In practice, these systems consist of policies, programs, and procedures used with such functions as planning, human resources management, training, oversight, information management, scheduling and budgeting, communications, risk management, quality assurance, and project management. If the vulnerabilities and management system weaknesses discussed in this report do not receive prompt and sustained management attention, they could lead to serious chemical safety incidents as the DOE complex continues to age and as cleanup, restoration, and D\&D activities increase. Mitigation of the consequences of facility-specific, site-specific, and generic vulnerabilities and prevention of their recurrence will require effective implementation of management response plans and dedicated efforts to improve the efficiency of these management systems.

Emphasis on, Commitment to, and Implementation of Chemical Safety Programs

Programmatic Weaknesses. Many physical deficiencies and programmatic weaknesses result in part from an overall lack of management emphasis on, commitment to, and strategic planning for chemical safety. This is evidenced by the priority accorded to chemical safety issues, by the diffuse nature of documented requirements and the inadequate nature of guidance provided, and by inadequate consideration of chemical safety in strategic and program planning.

Priority Accorded to Chemical Safety. The most serious concern arising from inadequate management attention to chemical safety is the relatively low priority assigned to chemical hazards 
Four Major Management Weaknesses

relative to other hazards of comparable consequence (e.g., nuclear hazards). DOE Headquarters has not issued an official policy statement on its commitment to chemical safety. At most sites, neither DOE nor contractor management has undertaken the necessary initiatives to develop, implement, and promote well-defined and readily understandable programs for chemical safety that raise the rigor and emphasis of chemical safety programs to the level required for nuclear safety.
- Inadequate emphasis, commitment, and implementation

- Poor management of aging facilities

- Gaps in transition process

- Inadequate budget decision making for chemical safety

The Office of Environment, Safety and Health has established a program to address DOE facilities with large chemical inventories (i.e., exceeding defined threshold quantities) that are regulated by OSHA under 29 CFR 1910.119, "Process Safety Management of Highly Hazardous Chemicals." DOE has developed standards and training based on the requirements of this regulation. Figure 5 describes the process for implementing a process safety management program. However, facilities not covered (i.e., those using less than threshold, but nonetheless significant, quantities of chemicals) require further direction, guidance, and assistance from DOE Headquarters. Overall, the existing DOE Headquarters program is not well coordinated with other related DOE safety programs and initiatives. At present, the program represents a staff commitment of less than one full-time equivalent per year.

Requirements and Guidance. Departmental requirements for chemical safety are scattered throughout a number of DOE Orders and Federal regulations, and no "roadmap" of chemical safety requirements is available to facilitate their application to site activities. (See Figure 6 for a list of requirements and guidance documents.) Consequently, different elements of contractor organizations are managing various components of chemical safety, resulting in fragmented chemical safety programs-particularly at large DOE sites. In general, the lack of clearly articulated chemical safety policy, requirements, and guidance from DOE Headquarters has contributed to the $a b$ sence of comprehensive chemical safety programs at DOE sites.

Strategic and Program Planning. Strategic goals related to improvements in chemical safety are not readily apparent in DOE-wide strategic planning documents. In addition, most 


\begin{tabular}{|c|c|}
\hline PROCESS SAFETY INFORMATION & $\begin{array}{l}\text { Maintain complete and accurate information on the } \\
\text { process technology, process equipment, and hazardous } \\
\text { characteristics and physical properties of all chemicals } \\
\text { and intermediates for all covered processes. }\end{array}$ \\
\hline PROCESS HAZARD ANALYSIS & $\begin{array}{l}\text { Perform Process Hazard Analyses to identify and } \\
\text { assess process hazards for each covered process. }\end{array}$ \\
\hline PRE-STARTUP SAFETY REVIEW & $\begin{array}{l}\text { Establish a procedure and perform pre-startup safety } \\
\text { reviews for new facilities and for modified facilities } \\
\text { when the modification is significant enough to require } \\
\text { a change in the process safety information }\end{array}$ \\
\hline MECHANICAL INTEGRITY & $\begin{array}{l}\text { Ensure the integrity and safe operation of process } \\
\text { equipment through inspection, testing, preventive } \\
\text { maintenance, and quality assurance. }\end{array}$ \\
\hline TRADE SECRETS & $\begin{array}{l}\text { Ensure all information is available to support the Process } \\
\text { Safety Management (PSM) Rule. When necessary, } \\
\text { confidentiality or nondisclosure agreements may be used. }\end{array}$ \\
\hline EMPLOYEE PARTICIPATION & $\begin{array}{l}\text { Ensure that workers are consulted and have access to } \\
\text { information regarding all elements of the PSM } \\
\text { program. }\end{array}$ \\
\hline SUBTIER CONTRACTOR SAFETY & $\begin{array}{l}\text { Ensure that the level of safety is not compromised by } \\
\text { subtier contractor operations on or in the vicinity of a } \\
\text { process using highly hazardous chemicals. }\end{array}$ \\
\hline TRAINING & $\begin{array}{l}\text { Establish and implement a training program for all } \\
\text { employees involved in operating a covered process. The } \\
\text { program must include both initial and refresher training } \\
\text { and provide a means of determining successful completion. }\end{array}$ \\
\hline MANAGEMENT OF CHANGE & $\begin{array}{l}\text { Establish and implement written procedures to manage } \\
\text { changes (except for "replacements in kind") to process } \\
\text { chemicals, technology, equipment, and procedures and } \\
\text { to manage changes to facilities that affect a covered process. }\end{array}$ \\
\hline OPERATING PROCEDURES & $\begin{array}{l}\text { Develop and implement written operating procedures } \\
\text { that provide clear instructions for safely conducting } \\
\text { activities involved in each covered process. Procedures } \\
\text { should address operating limits, safety and health } \\
\text { considerations, safety systems, and their functions. }\end{array}$ \\
\hline NONROUTINE WORK AUTHORIZATIONS & $\begin{array}{l}\text { Ensure that appropriate measures are taken any time } \\
\text { nonroutine operations are performed on or near covered } \\
\text { process areas that might initiate or promote a release. }\end{array}$ \\
\hline COMPLIANCE AUDITS & $\begin{array}{l}\text { Ensure that the PSM program is operating in an integrated } \\
\text { and effective manner in compliance with PSM requirements. }\end{array}$ \\
\hline $\begin{array}{l}\text { EMERGENCY PLANNING RESPONSE } \\
\text { PLANNING }\end{array}$ & $\begin{array}{l}\text { Establish and implement an emergency action plan for the entire } \\
\text { plant that is in compliance with } 29 \text { CFR 1910.38(a) and that } \\
\text { also addresses small releases. }\end{array}$ \\
\hline INCIDENT INVESTIGATION & $\begin{array}{l}\text { Establish a written incident investigation procedure that requires } \\
\text { a team investigation of any incident that results in, or could } \\
\text { reasonably result in, a catastrophic release of a highly hazardous } \\
\text { chemical. The procedure must require a written report and } \\
\text { establish a system to promptly address and resolve any report } \\
\text { findings and recommendations. }\end{array}$ \\
\hline
\end{tabular}

Figure 5. Overview of Process Safety Management Elements 


\section{FEDERAL REGULATIONS}

29 CFR 1910.119

29 CFR 1910.120

29 CFR 1910.1200

29 CFR 1910.1450

40 CFR 68

40 CFR 260-265

40 CFR 355

40 CFR 700-799

DOE 5400.1

DOE 5480.10

DOE $\mathbf{5 4 8 0 . 3}$

DOE 5480.4

DOE 5480.19

DOE 5480.23

DOE 5481.1B
Process Safety Management of Highly Hazardous Chemicals

Hazardous Waste Operations and Emergency Response

Hazard Communication

Occupational Exposure to Hazardous Chemicals in. Laboratories

Risk Management Programs for Chemical Accidental Release Prevention (Proposed Rule)

Resource Conservation and Recovery Act

Emergency Planning and Notification

Toxic Substances Control Act

\section{DOE GUIDANCE}

General Environmental Protection Program

Contractor Industrial Hygiene Program

Safety Requirements for Packaging and Transportation of Hazardous Materials, Hazardous Substances, and Hazardous Wastes

Environmental Protection, Safety, and Health Protection Standards

Conduct of Operations Requirements for DOE Facilities

Nuclear Safety Analysis Reports

Safety Analysis and Review System

Figure 6. Requirements Governing Chemicals and Chemical Wastes at DOE Facilities 
site-specific strategic and program planning efforts do not adequately address long-term goals for programmatic improvements and reduction in chemical inventory and usage.

Implementation Weaknesses. As a result of these weaknesses, chemical safety programs are often poorly articulated or defined, have not been integrated with other safety functions, and are neither fully implemented nor consistently applied across DOE sites.

These weaknesses indicate a general lack of emphasis on and attention to the dangers posed by hazardous chemicals and chemical wastes at DOE sites.
Program Definition. Chemical safety is not addressed as a separate, identifiable element of ES\&H programs at DOE sites. At most sites, there is no clearly articulated policy or direction for chemical safety, and as a result, chemical safety is not uniformly identified as a priority function. This weakness contributes to the absence of implementing criteria or standards for handling hazardous chemicals; lack of requirements, guidance, or management expectations regarding handling, storage, and disposition of hazardous chemicals; lack of consistency for handling and storing hazardous materials at facilities within the same site; and lack of consistent development and implementation of site chemical safety program elements. Collectively, these weaknesses indicate a general lack of emphasis on and attention to the dangers posed by hazardous chemicals and chemical wastes at DOE sites.

Program Integration. At many DOE sites, chemical safety programs are not integrated effectively with other safety programs such as hazards analysis, emergency management, waste management and regulatory compliance, work control, and configuration management. Lack of integration between programs related to chemical safety and those for other safety issues at DOE sites can be attributed to several factors. DOE priorities (and their implied impact on resource allocation) emphasize analysis of nuclear hazards over chemical hazards-even when chemical hazards present comparable potential consequences. Further, the defined scope of required hazards analyses in DOE Orders has been incorrectly interpreted to preclude many chemical operations in nonnuclear systems, and the widespread inappropriate use of the "graded approach" to identify systems receiving funds for safety. analyses does little to encourage the mitigation of hazards associated with chemical systems. 
Hazards analyses (i.e., the evaluation of operational risks associated with processes, equipment, and measures to control such risks) are not applied consistently to chemical systems, particularly when chemicals are introduced or proposed for new uses. Many DOE sites and facilities assessed for this review do not have adequate management systems to analyze processes or equipment for chemical hazards or to prepare and issue formal hazards analyses (e.g., Savannah River, Hanford, Sandia, and Brookhaven). Requirements for formal risk-based hazards analyses for purely chemical operations are not always clearly defined by DOE and implemented by site contractors. When hazards analyses are performed for chemical operations, these efforts often lack sufficient rigor and formality or indicate that personnel assigned to prepare and review hazards analyses are not adequately trained. (See Unanalyzed Hazards, p. 20.)

Emergency management functions are not consistently coupled with chemical safety activities. At some sites (e.g., Idaho National Engineering Laboratory and Lawrence Livermore), analyses to determine emergency astion levels, which are used to establish the extent and scope of emergency planning and preparedness activities, are missing. Facility-specific emergency response plans are not always coordinated with planned responses to sitewide emergency situations, and planned responses to similar emergencies often vary among contractors at the same site. (See Unanalyzed Hazards, p. 20.)

Waste management activities tend to emphasize functions supporting compliance with RCRA requirements without according sufficient consideration to chemical safety concerns. DOE field and contractor management attention and focus on requirements carrying financial penalties for nonresponse may not be sufficient to provide effective integration of activities associated with protecting worker health and safety from chemical hazards. For example, at Rocky Flats the plutonium aqueous recovery system located in Building 371 was shut down in 1984 , but recoverable plutonium (as plutonium nitrate) was left behind in tanks and ancillary piping. These recoverable products were declared by court order to be RCRA-regulated waste. RCRA requires daily inspections of tanks and ancillary piping in which hazardous waste residues are not provided with secondary containment. The Plant Operation Safety Program requires preparation of operational safety analyses for all work activities (whether RCRA related or non-RCRA related) in which a potential for exposure to toxic chemicals exists. A strategy that
When hazards analyses are performed for chemical operations, these efforts often lack sufficient rigor and formality. 


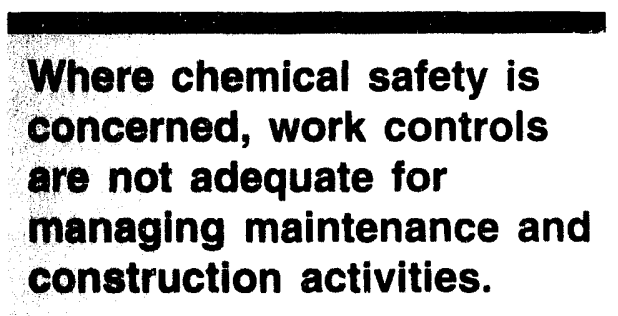

Where chemical safety is concerned, work controls are not adequate for managing maintenance
construction activities. meets RCRA requirements while minimizing worker exposures to chemical and radiological risks has not been implemented. (See Abandoned and Residual Chemicals, p. 41.)

Where chemical safety is concerned, work controls are not adequate for managing maintenance and construction activities. For example, in multiuser laboratory facilities at Sandia, the presence of several operations, maintenance, or construction organizations-all of which function independently-leads to confusion over responsibilities. As a result, workers are not always aware of chemical hazards associated with adjacent operations. In the event of a process upset, equipment failure, or inadvertent hazardous chemical release, personnel may not be properly protected or may be unable to respond properly.

In aging DOE facilities or laboratories, poor configuration management practices in the past have resulted in less-thanadequate documentation of chemical residues. The absence of full-system engineering evaluations during design modifications has led to an elevated incidence rate of breakdowns for support systems. For example, a number of small-scale ventilation modifications have been made over the past several years to support the needs of the multiuser laboratory complex at Sandia. These modifications have expended available excess capacity of ventilation systems, which in turn has resulted in excessive exhaust flow rates and significant air imbalances in the laboratories. If essential ventilation and other support equipment fails in service, there is a potential for exposure of laboratory personnel to hazardous chemicals. Previous exhaust system failures have resulted in pressure reversals, causing not only the loss of chemical vapor control, but the distribution of chemical vapors to other parts of the laboratory complex. At Savannah River, poor configuration management practices in the past have contributed to a lack of knowledge regarding chemical residues in the 412-D Heavy Water Extraction Facility and the 184-P Power House. (See Abandoned and Residual Chemicals, p. 40.)

Program Implementation. Incomplete and inconsistent implementation of chemical safety programs is manifested in a number of areas, including hazards communications, planning, training, timing of program implementation, and latitude in interpretation of guidance. The principal weaknesses in the area of hazards communications involve the limited availability of material safety data sheets and inaccurate or out-of-date labeling for 
some hazardous chemicals at some sites. Planning weaknesses include limited consideration of chemical safety issues when facilities are being designed and constructed, as well as lack of a strategic perspective for the use of hazardous chemicals. Employee training is either not consistently provided or is not verified as complete before allowing employees to enter work areas containing hazardous chemicals. Moreover, not all hazardous work environments have been evaluated to determine whether facility-specific chemical hazards training is required. Some crucial program documents have not been prepared in a timely manner (e.g., a chemical hygiene plan) and other documents do not exist at some DOE sites (e.g., a chemical process safety management plan), further enhancing the likelihood that an overall chemical safety program has not been consistently implemented. Where site policy and standards exist, they may be applied as standards or as discretionary guidance. In the final analysis, DOE field and contractor management's tolerance for the flexible interpretation of policies and standards governing chemical safety practices and programs precipitates a variety of actions that are sometimes contradictory.

\section{Management of Aging Facilities}

DOE has a significant number of aging operational facilities involved in storing or processing chemicals. (See Table 4 for a listing of the average age and relative size of various categories of DOE facilities.)

Many aging facilities represent chemical safety vulnerabilities for one or more of the following reasons:

- $\quad$ physical structures, support systems, and equipmeni have deteriorated rapidly because of their insufficient maintenance priority;

- aging facilities and equipment are sometimes being used for purposes for which they were not designed or equipped; and

- chemical handling practices currently in use do not meet regulatory and departmental requirements. 


\section{Table 4. Summary of Age and Square Footage of Selected Types of DOE Facilities}

\begin{tabular}{|c|c|c|c|c|}
\hline Use & $\begin{array}{c}\text { Number } \\
\text { of } \\
\text { Buildings }\end{array}$ & $\begin{array}{c}\text { Weighted } \\
\text { Average } \\
\text { Age }\end{array}$ & $\begin{array}{c}\text { Gross } \\
\text { Square } \\
\text { Feet }\end{array}$ & $\begin{array}{c}\text { Net } \\
\text { Occupiable } \\
\text { Square } \\
\text { Feet }\end{array}$ \\
\hline Hazardous/Flammable Storage & 200 & 23 & 435,365 & 381,275 \\
\hline Production/Manufacturing Bldgs & 139 & 28 & $2,295,267$ & $1,755,256$ \\
\hline Production/Manufacturing Bldgs (Nuclear) & 18 & 42 & 484,224 & 407,227 \\
\hline Hazardous Production/Manufacturing Bldgs & 7 & 19 & 36,891 & 26,941 \\
\hline Fabrication Facilities & 73 & 42 & $4,216,090$ & $3,497,697$ \\
\hline Fabrication Facilities (Nuclear) & 5 & 35 & 566,809 & 337,600 \\
\hline Assembly Facilities & 55 & 26 & $1,192,408$ & $1,049,410$ \\
\hline Assembly Facilities (Nuclear) & 13 & 7 & 224,570 & 182,765 \\
\hline Manufacturing/Production-Related Labs & 70 & 36 & $1,214,654$ & 944,124 \\
\hline Materials Handling or Process Facilities & 85 & 32 & 550,830 & 439,242 \\
\hline Nuclear Chemical Process Facilities & 70 & 29 & $2,443,929$ & $1,492,280$ \\
\hline Nuclear Waste Process and/or Handling Bldgs & 66 & 31 & 660,757 & 474,285 \\
\hline Other Industrial Facilities & 136 & 38 & 960,447 & 744,082 \\
\hline Maintenance Shops, General & 312 & 32 & $4,415,176$ & $3,848,187$ \\
\hline Paint Shops & 21 & 22 & 61,634 & 54,338 \\
\hline Machine Shops & 103 & 38 & $2,947,922$ & $2,266,013$ \\
\hline Work in Process/Ready Bldgs & 8 & 31 & 48,254 & 42,253 \\
\hline Chemistry Laboratories (Nonnuclear) & 42 & 36 & 853,181 & 532,900 \\
\hline Chemical Laboratories (Nuclear) & 25 & 31 & $1,201,415$ & 847.986 \\
\hline Other Chemistry Laboratories & 18 & 36 & 270,117 & 205,043 \\
\hline Hot Cells & 18 & 35 & 553,531 & 377,549 \\
\hline Laboratories, General (Nonnuclear) & 68 & 26 & $1,346,349$ & $1,016,808$ \\
\hline Laboratories, General (Nuclear) & 42 & 29 & $1,061,063$ & 789,460 \\
\hline Multifunction Research/Lab Bldgs & 54 & 32 & $3,490,871$ & $2,183,664$ \\
\hline
\end{tabular}

NOTE: The weighted average age for all DOE facilities is 31 years. 
These weaknesses, if not addressed, could result in an increased risk to workers, the public, and the environment as the condition of aging facilities continues to deteriorate. In addition, similar consequences can be expected in newer DOE facilities as funding for their missions is reduced or eliminated.

Maintenance Priority. Many aging facilities have not received sufficient maintenance because effective systems to ensure that they are minimally maintained are lacking and because maintenance budgets are declining. Predictive, preventive, and corrective maintenance programs are not fully implemented and, thus, have not been effective in minimizing or eliminating the deterioration of facility physical structures or support systems and in decreasing overall maintenance backlogs. There has been an increased reliance on administrative controls, rather than on well-maintained engineered systems, to prevent or mitigate conditions involving chemical hazards. For example, the Building 222 Chemistry Laboratory at Lawrence Livermore has a roof system and mechanical equipment that are deteriorating. Repair activities for the roof system and the mechanical roof-mounted equipment are frequent and extensive. Maintenance personnel can perform necessary modifications as long as strict administrative controls are followed to prevent researchers from venting noxious gases from individual laboratory fume hoods.

DOE has not effectively addressed management of its facilities throughout their life cycle-from design, construction, and operation through transition to D\&D. Having completed their missions, these facilities are not funded at safe maintenance levels or for safe standby while they await new missions or D\&D. The physical structures of many such facilities have deteriorated significantly. Use of poorly maintained, aging facilities in this manner could decrease the margin of protection provided to workers and the environment from chemical hazards.

Design and Equipment. At some aging facilities, hazardous chemical wastes are being housed in structures not designed or equipped for that purpose. This practice has created an increased potential for worker exposures and environmental releases of hazardous materials and creates an overreliance on administrative controls rather than placing emphasis on engineered systems. (See Maintenance Priority above.) At Brookhaven, the Hazardous Waste Management Facility lacks appropriate engineering controls for repackaging hazardous materials. Repackaging is often performed by operators who
Facilities are not funded at safe maintenance levels or for safe standby while they await new missions or D\&D. 
have to wear personal protective equipment because of the lack of engineering controls. At the Oak Ridge K-25 Site, drums of lithium hydroxide were stored in the lower level of the K-25 Process Building without proper temperature or humidity controls.

Chemical Handling Practices. Chemical handling practices at many aging facilities have not kept pace with changing regulatory requirements. (See Condition of Facilities and Safety Systems, p. 35.) As observed by the field verification team visiting Brookhaven, personnel showers in use in the Hazardous Waste Management Facility did not meet current regulatory requirements. At the Oak Ridge K-25 Site, eyewash stations and safety showers had not been installed for hazardous chemical storage facilities, and the fire protection system in Building $\mathrm{K}$ 25 was not properly maintained. At Los Alamos, several hundred gallons of acids and bases were stored without secondary containment at the Chemistry and Metallurgy Research Facility. At Hanford, 40-year-old stainless steel tanks containing nitric acid and aluminum nitrate were not routinely inspected for corrosion. Although these tanks are located in diked areas, release of their contents could injure workers, damage the environment, or both.

\section{Transition of Facilities From Active Status to New Missions or to Decontamination and Decommissioning}

\section{About 1,200 DOE facilities are either awaiting or undergoing transition to deactivation.}

About 1,200 DOE facilities are either awaiting or undergoing transition to deactivation and, ultimately, to new missions or D\&D. Although the Department has committed to clean up and restore or dismantle these facilities, this process will probably take many years to complete. (See Figure 7 for a depiction of surplus facilities awaiting transition and the proposed transition rates for the next several years.) This transition process will include deactivation, multiple surveys, and prolonged periods of surveillance before D\&D is begun. Many facilities also contain chemical inventories or house structures and equipment that are chemically contaminated, radiologically contaminated, or both. Weaknesses in the current transition process include lack of clearly understood and accepted facility ownership responsibilities, the absence of a requirement to remove chemical residues, lack of a process to retain corporate knowledge related to facility operating histories, and inadequate configuration management. These weaknesses result in an 


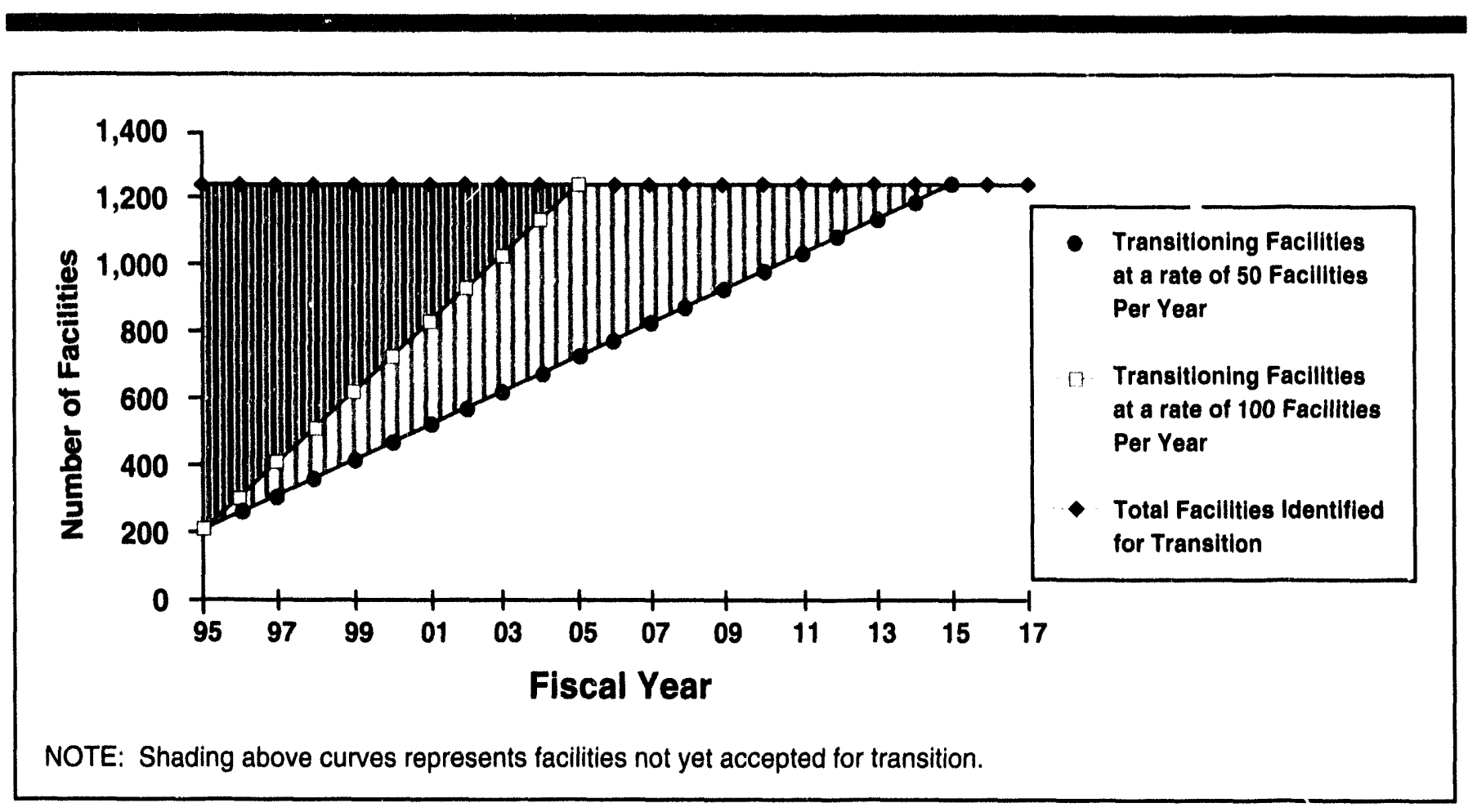

Figure 7. Transition of Facilities to the Office of Environmental Management

increased potential for exposure of workers to chemical hazards during D\&D operations or while performing routine work.

Facility Ownership Responsibility. Responsibility for the cleanup and surveillance and maintenance of facilities that are no longer in use and have not been identified for transition is not clearly understood or accepted. The Office of Environmental Management (EM) recently implemented the DOE-wide Surplus Facility Inventory and Assessment Project to provide a better understanding of the scope and complexity of this transition. Through this initiative, facilities specifically accepted for D\&D have been identified and prioritized for transition to EM for deactivation and cleanup on the basis of their perceived levels of chemical and radiological contamination. This effort will provide a more complete understanding of the number and type of facilities involved in the EM cleanup program and is providing the basis for a more orderly transition of facilities to EM. However, near-term responsibility for funding deactivation operations, surveillance and maintenance activities, characterization of contamination, and cleanup of the facilities that have not been specifically identified for transition is not clearly understood or accepted. 


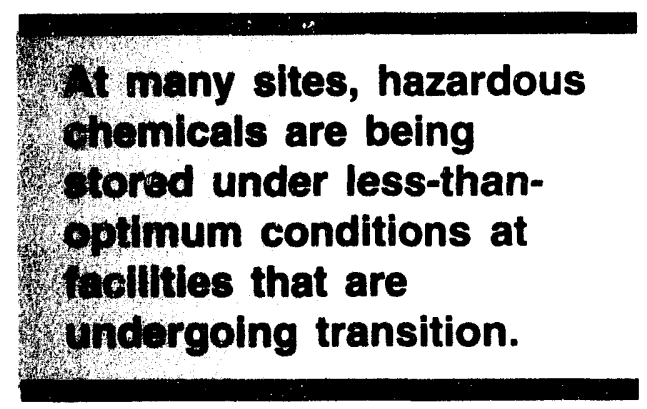

Presence of Chemical Residues. Many facilities either have been or will be placed in caretaker or standby status while awaiting transition to new missions or D\&D, but there is no DOE or other Federal requirement to remove chemical residues from these facilities. Hazardous chemical residues have been left in the process equipment and piping of numerous facilities at Oak Ridge (e.g., Building K-25 at the K-25 Site, the 9201-4 Production Building at the $\mathrm{Y}-12$ Plant, and the Radiochemical Development Laboratory at Oak Ridge National Laboratory). The protracted decision-making and regulatory processes for facilities in transition have also contributed to a delay in remediation of hazardous chemical residues. The inability to dispose of mixed wastes expeditiously has resulted in the retention of large quantities of hazardous materials in facilities undergoing transition. For example, a slightly contaminated solvent at Hanford could not be transported to and processed at the Idaho National Engineering Laboratory because of inconsistencies in regulatory requirements between the two States involved. At many sites, hazardous chemicals are being stored under less-than-optimum conditions at facilities that are undergoing transition. Consequently, chemical residues may exist in these structures for prolonged periods, creating an increased potential for worker exposure or environmental releases.

Corporate Knowledge. The loss of corporate knowledge with respect to the operating histories of facilities awaiting or undergoing transition could have a potentially detrimental impact on successful D\&D activities. Many experienced personnel, particularly operators and "hands-on" engineers, have either transferred to other activities or retired, thereby creating information voids with respect to facility process history, presence of chemical residues, and operation of facility equipment. In most instances, no significant efforts have been made to capture this information. This situation, in turn, extends the time required for facility transition and could lead to an increased potential for exposure of workers and the environment to hazardous chemicals.

Configuration Management. Configuration management systems at many facilities have been nonexistent or have been inconsistently and incompletely implemented. Lack of effective configuration management increases the uncertainty associated with the transition process-particularly with respect to the configuration of chemically contaminated facility systems and equipment. These issues take on added significance when it is 
recognized that the aging facilities most likely to be deactivated in the near future have not had effective configuration management systems and that little or no as-built information is available. For some chemical laboratories nearing the end of their operating lives, sufficient and accurate information required to effect safe facility transition is not available.

\section{Budget Decision Making for Chemical Safety}

DOE budget decision making does not provide consistent and effective budgeting and allocation of resources to support chemical safety programs. This weakness is a result of several factors. Current funding approaches used by sites make it difficult to establish comprehensive chemical safety programs; guidance and requirements for budgeting chemical safety activities are not well defined; many resource allocation decisions do not adequately consider chemical risk; and funding for maintenance of aging facilities and for facility deactivation does not receive adequate priority.

Funding Approaches. The budget approaches for chemical safety used by most field organizations do not always ensure that resources needed to implement effective chemical safety programs are identified and supported. ES\&H budget allocations that provide funding for chemical safety are determined through such mechanisms as operating overhead funds to support ES\&H, direct chargeback for ES\&H tasks, and direct funding for special ES\&H-related tasks.

Chemical safety budgets established on the basis of overhead funds are often governed more by the percentage allocation allowed and budget ceiling established than by specific chemical safety needs. Chemical safety budgets developed through this means are also subject to programmatic fluctuations unrelated to ES\&H considerations. This situation is further exacerbated by the fact that the existing ES\&H budgeting structure does not necessarily provide for allocation of resources to specific chemical safety initiatives, but rather allocates resources to ES\&H functions that may include chemical safety. Chemical safety budgets derived from the direct chargeback for ES\&H tasks are necessarily reactive to the needs of the requesting organization. Requests for support (or projections of requests
Many resource allocation decisions do not adequately consider chemical risk. 
for support) are often made by personnel who are not ES\&H professionals or do not have sufficient expertise to evaluate the priority of chemical safety needs versus other ES\&H needs within the context of overall programmatic requirements.

Since chemical safety is not a separately funded program at DOE sites, the extent to which chemical safety initiatives are recognized and funded is often limited. This situation supports the conclusion that chemical safety initiatives do not receive adequate attention or priority from management. (See Emphasis on, Commitment to, and Implementation of Chemical Safety Programs, p. 46.)

Budget Development Guidance. Limited guidance is provided by DOE Headquarters to assist local DOE and contractor management in budgeting for chemical safety or to establish its basic budgetary elements. As a result, budget allocations for chemical safety are generally not clearly defined, which limits the effectiveness of those resources available. DOE has not developed a complete and consistent set of requirements for its chemical safety program. Although DOE has begun to address this issue through development of two proposed DOE standards (DOE-STD-XXXX-YR, "Process Safety Management for Highly Hazardous Chemicals," and DOE-STD-XXXX-YR, "Analysis of Chemical Process Hazards," both dated March 1994), comprehensive chemical safety program requirements, such as those specified by DOE in manuals for radiological control, electrical safety, and hoisting and rigging, do not exist. The absence of such requirements and other regulatory drivers has led to confusion and uncertainty about the level and type of resources to be incorporated in and allocated to chemical safety.

Resource Allocation Process. At most sites, the ES\&H planning and budgeting process currently in place uses risk considerations to allocate or integrate its ES\&H resources. However, chemical safety programs often do not receive adequate attention commensurate with their risks, particularly when compared with those for nuclear and radiological 
programs. The DOE ES\&H management planning process is the first comprehensive effort to assemble DOE-wide ES\&H budget and planning data in a single document. The ES\&H Management Plan could be instrumental as a management tool ensuring that adequate funds are available to address chemical safety. By providing a means to raise identified high-risk chemical safety issues to management's attention, this system is a positive step toward improving the utilization of ES\&H resources. However, evaluating relative risks and identifying priorities occur at the field level and, hence, are subject to the individual perceptions and value judgments of facility managers, who may have biases toward other safety needs. In addition, constrained budgets often result in other chemical safety needs with lower risks being left without funding, generally without consideration of partial funding options to mitigate risks.

Maintenance Funding. Funding for maintenance activities at aging facilities and for facility deactivation functions that are related to chemical safety has not been effectively addressed by DOE. Maintenance funding is hindered by the absence of a traceable,

Current and future maintenance budgets for many aging facilities are declining.

systematic, and defensible planning and budgeting system similar to that used in developing the ES\&H Management Plan. Current and future maintenance budgets for many aging facilities are declining, and future budget projections indicate a continuation of this trend, suggesting that sufficient funds will not be available in the future to prevent further deterioration of these facilities. (See Management of Aging Facilities, p. 53.) In some instances, these deteriorating conditions are exacerbated by the lack of effective systems to allocate limited maintenance resources. Resources are often allocated on a perceived-risk basis and at the discretion of individual managers, rather than on the basis of actual risk. In the current constrained budget environment, support for activities that are not perceived as addressing immediate and crucial needs is difficult to obtain. The changing DOE mission has resulted in a number of facilities being placed in a caretaker status while awaiting transition to D\&D; however, there is no requirement, and often no funding, to remove chemical residuals from these facilities. This problem is compounded by the fact that when a facility's mission is terminated, operating funds diminish; therefore, funds are not available to complete necessary cleanup functions before the facility is transitioned to D\&D. 


\section{Commendable Practices}

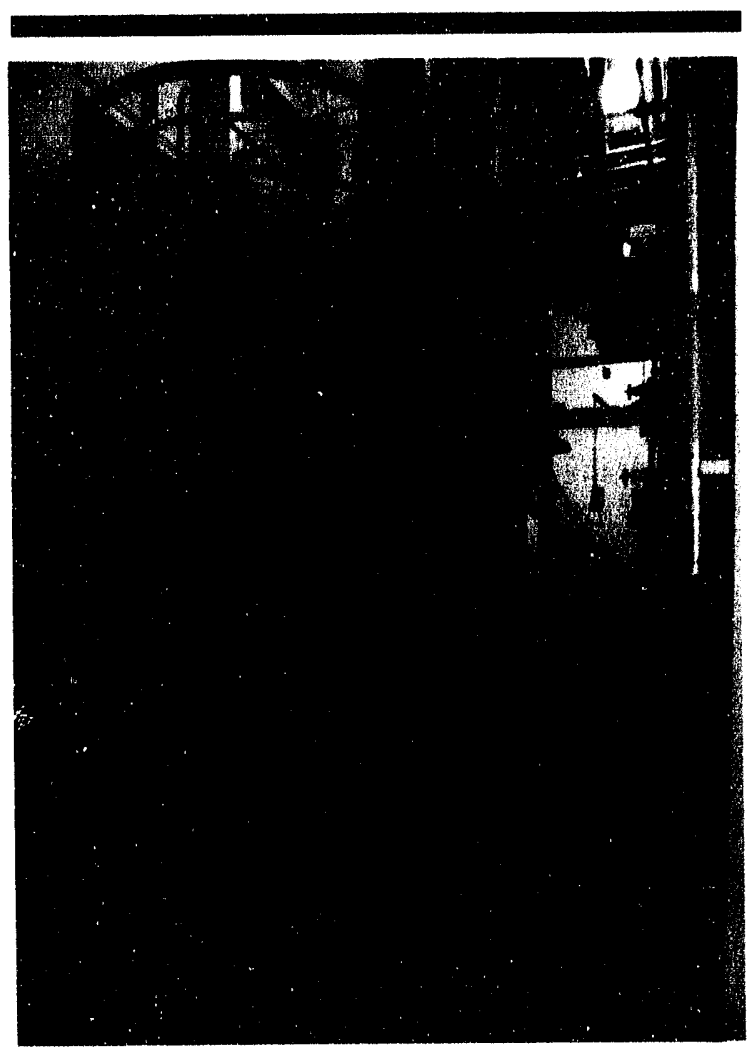

The Idaho National Engineering Laboratory has done a commendable job of flushing and cleaning out chemical residues in the Fluorinel Dissolution Process and Fuel Storage Facility.
D uring the course of this review, a number of commendable practices were observed at DOE sites, including innovative activities, programs, or management systems that can provide lessons learned related to chemical safety. Such practices represent "pockets of innovation and excellence," and their visibility and application should and will be encouraged throughout the Department. Descriptions of specific commendable practices and the names of site contacts who can provide further information are provided in Appendix $O$.

Of the commendable practices listed in Table 5, administrative controls and other management systems developed and implemented to reduce hazardous chemical inventories at DOE sites are particularly notable. Some sites visited had expended significant effort to identify surplus hazardous chemicals and to reuse, dispose of, or sell these materials. Some sites have also adopted "just-in-time" procurement practices to maintain chemical inventories at minimum levels. For example, the Chemical Management System implemented by Pacific Northwest Laboratory at Hanford Site is a model chemical inventory control program. This computer-based chemical inventory system is used to inventory chemicals, provide hazard information about individual chemicals, and minimize chemical waste. The Chemical Management System has been in use since November 1991 and was designated as an outstanding model by the Office of Environment, Safety and Health. Pacific Northwest Laboratory is working with Brookhaven to establish a comparable system; the National Renewable Energy Laboratory and Lawrence Berkeley Laboratory have requested assistance in developing similar programs; and Argonne National Laboratory-West has adapted basic concepts from the Chemical Management System to improve its use of material safety data sheets.

The maturation and effectiveness of industrial hygiene programs addressing operations and nonroutine work controls for hazardous chemicals were also notable. For example, Argonne-West has an exemplary chemical hygiene program that meets and exceeds the requirements of the OSHA Laboratory Standard (29 CFR 1910.1450), the OSHA Hazard Communication (HAZCOM) Standard (29 CFR 1910.1200), and DOE 5480.10, "Contractor Industrial Hygiene Program." Chemical hygiene personnel have taken a proactive approach for implementing this program. The storage, labeling, and administrative 


\section{Table 5. Commendable Practices Addressing Elements of Generic Vulnerabilities}

\begin{tabular}{|c|c|}
\hline GENERIC VULNERABILITY & COMMENDABLE PRACTICE \\
\hline CHARACTERIZATION OF CHEMICALS & - Facilities Space Management Program (Sandia) \\
\hline UNANALYZED HAZARDS & $\begin{array}{l}\text { - Evaluating and Reducing Hazards During Life Cycle of } \\
\text { Operations (Oak Ridge) } \\
\text { - Applying Graded Approach to Hazards Analysis (Brookhaven) } \\
\text { - Emergency Response Nomograph for Toxic Chemical Spills } \\
\text { (Idaho National Engineering Laboratory) } \\
\text { - Dispersion Model to Calculate and Display Plume Dispersions } \\
\text { (Los Alamos) }\end{array}$ \\
\hline PAST CHEMICAL SPILLS & $\begin{array}{l}\text { - Documentation of Facility Dismantling (Sandia) } \\
\text { - Hazardous Material (Hazmat) Response Team Preparedness for } \\
\text { Chemical Spills (Los Alamos) }\end{array}$ \\
\hline $\begin{array}{l}\text { PLANNING FOR DISPOSITION OF } \\
\text { CHEMICALS }\end{array}$ & $\begin{array}{l}\text { - Chemical Salvage Program (Savannah River, Lawrence } \\
\text { Livermore, Idaho National Engineering Laboratory) } \\
\text { - Sitewide Wastewater Discharge Minimization Program } \\
\text { (Hanford) }\end{array}$ \\
\hline CHEMICAL STORAGE PRACTICES & $\begin{array}{l}\text { - Chemical Storage at Analytical Laboratory (Argonne National } \\
\text { Laboratory - West) }\end{array}$ \\
\hline $\begin{array}{l}\text { CONDITION OF FACILITIES AND } \\
\text { SAFETY SYSTEMS }\end{array}$ & $\begin{array}{l}\text { - Facilities Space Management Program (Sandia) } \\
\text { - Computer-Based Maintenance Control Reporting System } \\
\text { (Brookhaven) } \\
\text { - Work Control Program for Engineering and Maintenance } \\
\text { (Idaho National Engineering Laboratory) }\end{array}$ \\
\hline $\begin{array}{l}\text { ABANDONED AND RESIDUAL } \\
\text { CHEMICALS }\end{array}$ & $\begin{array}{l}\text { - Removing Residual Chemicals From Unused Chemical Process } \\
\text { Equipment (Idaho National Engineering Laboratory) } \\
\text { - Facilities Space Management Program (Sandia) } \\
\text { - Documentation of Facility Dismantling (Sandia) }\end{array}$ \\
\hline $\begin{array}{l}\text { INVENTORY CONTROL AND } \\
\text { TRACKING }\end{array}$ & $\begin{array}{l}\text { - Chemical Management Systems (Hanford, Rocky Flats, } \\
\text { Lawrence Livermore, Argonne National Laboratory - West) } \\
\text { - Hazardous Waste Labeling System (Los Alamos) } \\
\text { - Chlorine and Toxic Gas Control Program (Los Alamos, K-25 Site, } \\
\text { Rocky Flats, Sandia) } \\
\text { - Elimination of chlorine gas in water treatment operations } \\
\text { (Savannah River) }\end{array}$ \\
\hline MANAGEMENT SYSTEM DEFICIENCIES & $\begin{array}{l}\text { - Sharing Chemical Safety Program Information (Savannah River) } \\
\text { - Participation, Coordination and Cooperation with State } \\
\text { Regulatory Agencies (Sandia) } \\
\text { - Work Control Program for Engineering and Maintenance (Idaho } \\
\text { National Engineering Laboratory) } \\
\text { - ES\&H Management Assurance Notebooks (Sandia) } \\
\text { - Contract Initiative to Ensure Adequate Hazards Communications } \\
\text { (Brookhaven) }\end{array}$ \\
\hline
\end{tabular}

NOTE: In most cases, the commendable practices listed above address only part of the corresponding generic vulnerability. Some commendable practices have application for more than one generic vulnerability. See Appendix O for detailed descriptions of these practices. 
controls for chemicals are excellent. In particular, the methodology for segregating laboratory chemicals, carcinogens, organics, and other materials is commendable. Using this approach, chemical hygiene personnel at Argonne-West have reduced the inventory of high-risk chemicals such as ethers, benzene, and other organics.

Other commendable practices included efforts to identify and mitigate environmental releases of hazardous chemicals (e.g., the nomograph for toxic chemical spills developed by Westinghouse Idaho Nuclear Company and the chemical plume dispersion model used at Los Alamos).

The implementation of engineered safeguards and controls on chlorine and other toxic gas systems was noted at four locations (Los Alamos, Oak Ridge K-25 Site, Rocky Flats, and Sandia), whereas substituting the use of less haz-

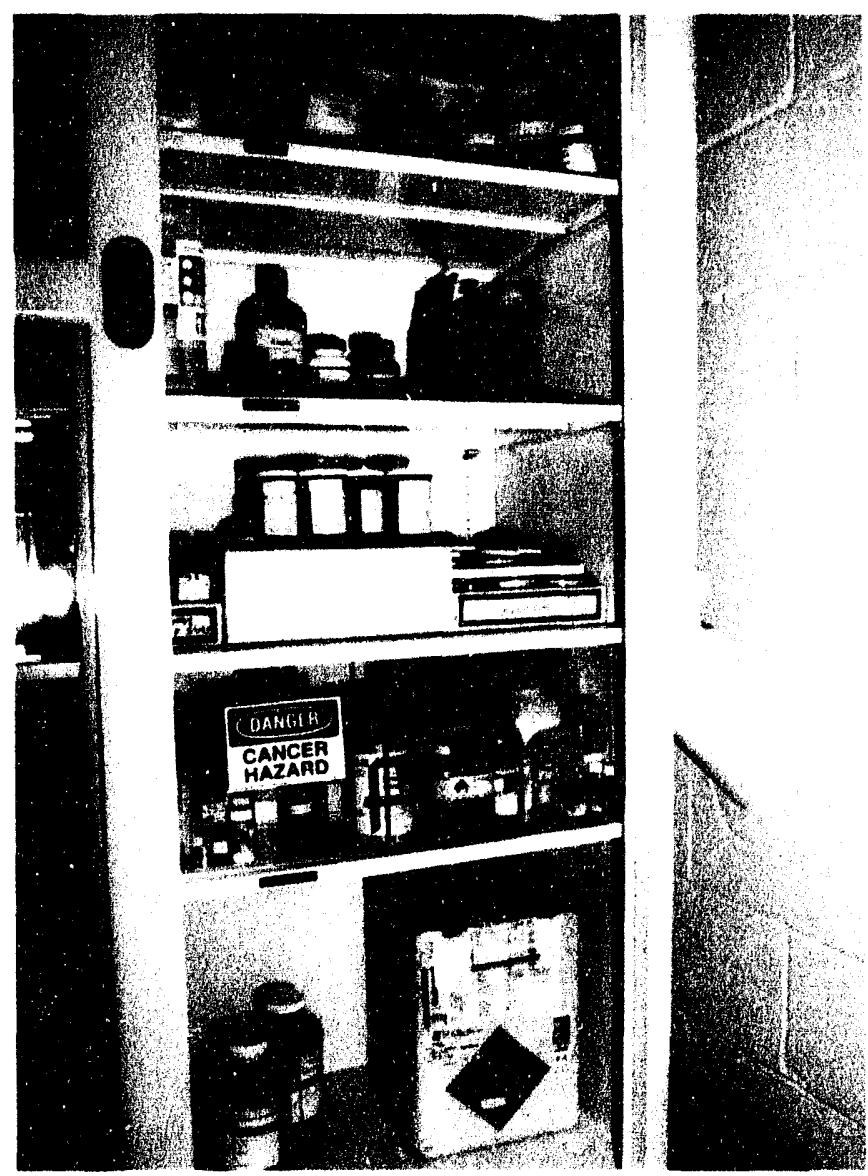

A model chemical hygiene program was observed at the Argonne-West Analytical Laboratory. ardous chemicals for that of more hazardous chemicals was particularly successful in eliminating chlorine gas from water treatment operations at Savannah River.

Finally, the space management program developed at Sandia demonstrates the effectiveness of financial incentives (i.e., space charges) in resolving problems associated with hazardous chemical residues. To effect a facility transfer, thereby avoiding space charges, the current user organization must work through the Facilities Center to have the facility evaluated for residual hazards. If hazards are detected, the current user must take remedial action before the Facilities Center will accept the facility. By performing such evaluations before space ownership is transferred, Sandia seeks to avoid the potential exposure of employees moving to new work areas, to decrease physical hazards in the workplace, to expedite remediation of contaminated areas, and to track the presence of chemical and/or radiological residues. 


\section{Summary of Management Response Plan}

$\mathbf{T}$ o ensure timely action by DOE for addressing the generic chemical safety vulnerabilities identified during this review, the Chemical Safety Vulnerability Working Group has developed the "Manage-

The Working Group's goals for the response plan were twofold: to correct existing chemical problems within the DOE complex and to prevent the recurrence of similar problems. ment Response Plan for the Chemical Safety Vulnerability Review," dated August 1994, which is being issued separately from this report. In developing this plan, the Working Group considered the recommendations and suggestions provided in the management response plans developed by the field for facility- and site-specific vulnerabilities identified during the self-evaluation and field verification phases of the review. Input was also provided by program and field offices, as well as by management and operating contractors, during and after the June 7-8, 1994, Working Group meeting. The Working Group's goals for the response plan were twofold: to correct existing chemical problems within the DOE complex and to prevent the recurrence of similar problems. The response plan has been developed as a "living document" that will be modified and updated, as appropriate.

The management response plan is organized into sections that generally correspond to the programmatic deficiencies identified by the Working Group. The tasks and subtasks outlined in these sections are intended to produce practical, concrete results in a timely and cost-effective manner. To accomplish these goals, the plan calls for the formation of an Action Team for Chemical Safety chaired by a representative of the Office of Environment, Safety and Health and composed of DOE Headquarters and field personnel. The Action Team will coordinate and monitor implementation of the response plan's proposed actions and will assist the sites in program improvement efforts.

The response plan's proposed actions, which will emphasize the use of established practices in an innovative manner, reflect several departmental objectives. Specifically, these objectives stress providing assistance through the Office of Environment, Safety and Health for workshops, management tools, model program development, and the use of commercial chemical industry programs and practices. Commendable programs and practices (e.g., inventory control programs similar to the Chemical Management System used by Pacific Northwest Laboratory) that exist at various DOE sites will be identified and used, where appropriate, and successes will be shared by organizations at the same site and across sites. Actions to 
resolve identified deficiencies will be supported by existing resources through team approaches, matrix support, and sharing resources to develop methods for the mutual benefit of multiple organizations. Similarly, existing programs and practices (e.g., the EH Chemical Safety Program; initiatives developed by the Offices of Field Management, Environmental Management, and Defense Programs for aging facilities, facilities in transition, and chemical inventory reduction) will be emphasized to increase the effectiveness of committed resources. Finally, ongoing corrective actions for facility- and site-specific vulnerabilities will be recognized, and management response plans developed by individual sites will be upgraded to include programs that will resolve the generic vulnerabilities identified by the Working Group. 


\title{
Conclusions
}

\author{
$M$ \\ any significant vulnerabilities \\ and underlying management \\ weaknesses were identified by \\ the Chemical Safety Vulnerability \\ Working Group. Collectively, these \\ managers. \\ vulnerabilities and weaknesses in- \\ dicate that chemical safety has not received the priority and at- \\ tention it deserves from DOE and contractor managers. \\ Chemicals are pervasive throughout the DOE complex; the \\ types and quantities of chemicals found vary widely, as do the \\ processes and operations in which they are used. In manv \\ cases, chemicals are not well characterized or controlled. His- \\ torically, chemicals have been perceived to be less hazardous \\ to workers than were radiation hazards. As a result, chemical \\ hazards are frequently less well recognized and analyzed.
} Chemical safety has not received the priority and attention it deserves from DOE and contractor

There is no uniform understanding within DOE about what constitutes an effective chemical safety program. Expectations have not been clearly articulated, and budget processes have hindered the development of effective programs. As a result, chemical safety programs at DOE sites are typically fragmented or not fully implemented.

Improving DOE's performance with respect to chemical safety will require an immediate and sustained effort by DOE and contractor management. DOE should look within itself as well as toward the private sector for innovative and effective solutions. The best performers in the private sector have long recognized the need to eliminate or mitigate risks associated with hazardous chemicals. DOE must learn from these examples and must also apply its own commendable practices more widely to reduce or remove chemical safety vulnerabilities. 
Glossary of Chemical Terms

\section{CHEMICAL \\ OR TERM \\ CHARACTERISTICS AND USES \\ POTENTIAL HAZARDS}

acetone

adhesive

aluminum nitrate

americlum

argon

arsine

asbestos

base
Colorless, volatile liquid; sweetish odor; miscible with water, alcohol, ether, chloroform, and most oils. Used in preparation of chemicals or as a solvent.

Large class of chemical substances whose water solutions can react with and dissolve certain metals to form salts and with bases or alkalies to form salts. Common inorganic acids are sulfuric, nitric, and phosphoric.

Any substance (organic or inorganic, natural or synthotic) that is capable of bonding other substances together by surface attachment. Adhesives are used for metal/metal and glass/metal seals, miscellaneous packaging applications, and various repair and maintenance purposes.

White crystals that are soluble in cold water and decompose in hot water. Soluble in alcohol and acetone. Used in nucleonics and the manufacture of incandescent filaments; serves as an anticorrosion agent.

A synthetic radioactive element (atomic number 95); member of the actinide series. Alpha and gamma emitter; forms compounds with oxygen, halides, lithium, etc. Metallic americium is silver-white, crystalline. Half-life of americium-241 is 458 years. Used in gamma radiography, radiochemical research, diagnosis, and in electronic devices.

A nonmetallic element (atomic number 18). Colorless, odorless, tasteless, monatomic gas not known to combine chemically with any element. Uses include inert-gas shield in arc welding, furnace brazing, plasma jet torches, electric and specialized light bulbs; titanium and zirconium refinishing; flushing molten metals to remove dissolved gases; in Geiger-counter tubes; lasers; and inert gas or atmosphere in miscible applications.

Colorless gas, soluble in water, slightly soluble in alcohol alkalies. Used in organic synthesis and as an agent for solid-state electronic components.

Impure magnesium silicate occurring in fibrous form. Noncombustible. Fireproof fabrics can be found in brake lining, gaskets, roofing compositions, electrical and heat insulation, paint filler, and chemical filters. Reinforcing agent in rubber and plastics.

Any of a large class of compounds that can react with (neutralize) acids to form salts. Includes hydroxides and oxides of metals. Common strong bases (alkalies) include sodium and potassium hydroxides, ammonium hydroxide, etc.
Flammable, dangerous fire risk. Acts as narcotic in high concentrations. Moderately toxic by ingestion and inhalation.

Highly irritating and corrosive to human tissue.

Adhesives containing organic solvents are flammable.

Strong oxidizing agent that cannot be stored near combustible materials.

Radioactive poison.

Noncombustible; an asphyxiant gas.

Highly poisonous by inhalation.

Highly toxic by inhalation of dust particles. An active carcinogen.

Caustic and corrosive to skin eyes, and mucous membranes. 


\section{CHEMICAL}

OR TERM

\section{CHARACTERISTICS AND USES}

beryllium

beryllium hydride

carbon disulfide

carbon tetrachloride

carbonyl sulfide

carcinogen

caustic

chemical waste

chlorine
Metallic element (atomic number 4). A hard, brittle, graywhite metal; soluble in acids (except nitric) and alkalies. Resistant to oxidation at ordinary temperatures. It is the lightest structural metal known; can be fabricated by rolling, forging, and machining. Joining is chiefly by shrink-fitting; brazing and welding are difficult. Highly permeable to $x$-rays. Structural material in space technology; moderator and reflector of neutrons in nuclear reactors; source of neutrons; special windows for x-ray tubes; in gyroscopes, computer parts, inertial guidance systems; additive in solid-propellant rocket fuels; berylliumcopper alloys.

White solid. Reacts with water, dilute acids, and methanol to liberate hydrogen. Liberates hydrogen rapidly when heated to $220{ }^{\circ} \mathrm{C}$. Can be used in rocket fuels.

Clear, colorless, or faintly yellow liquid with strong disagreeable odor. Soluble in alcohol, benzene, and ether; slightly soluble in water. Classed as an inorganic compound. Used as a solvent.

A chlorinated hydrocarbon. Colorless liquid with sweetish distinctive odor. Miscible with alcohol, ether, chloroform, benzene, solvent naphtha, and most of the fixed and volatile oils; insoluble in water. Noncombustible. Uses include refrigerants and propellants, metal degreasing, chlorinating organic compounds, production of semiconductors.

Colorless gas with typical sulfide odor. Soluble in water and alcohol. Used in the synthesis of organic compounds.

Any substance that causes the development of cancerous growths in living tissue.

Usually refers to caustic soda (sodium hydroxide). Any strongly alkaline material that has a corrosive or irritating effect on living tissue.

Unusable byproduct from several chemical and metalprocessing operations. Often contains toxic or polluting materials that become environmental threats when disposed of improperly.

Nonmetallic halogen element (atomic number 17); a dense, greenish-yellow, diatomic gas. Noncombustible, but supports combustion; pungent irritating odor. Soluble in chlorides and alcohols. Extremely strong oxidizing agent. Slightly soluble in cold water. Used in manufacture of chemicals, water purification, flameretardant compounds, and special batteries (with lithium or zinc).
A carcinogen. Very high toxicity, especially by inhalation of dust.

Fire risk when exposed to water, organic materials, and heat. Highly toxic.

Highly flammable; dangerous fire and explosion risk; can be ignited by friction. A poison. Toxic by skin absorption.

Highly toxic by ingestion inhalation, and skin absorption. Narcotic. A suspect carcinogen that decomposes to phosgene at high temperatures.

Flammable; highly toxic; acts as narcotic in high concentrations.

Cancer risk.

Corrosive to tissue in presence of moisture; strong irritant to tissue (eyes, skin, mucous membranes).

Poses a wide variety of hazards.

Toxic as irritant and by inhalation. Moderate fire risk in contact with turpentine, ether, ammonia, hydrocarbons, hydrogen, powdered metals, and other reducing materials. 


\section{CHEMICAL OR TERM \\ CHARACTERISTICS AND USES \\ POTENTIAL HAZARDS}

combustible material

corrosive material

cyanogen

ethyl ether

explosive

flammable material

Freon
Any substance that will burn, regardless of its autoignition temperature or whether it is solid, liquid, or gas. As usually defined, refers to solids that are relatively difficult to ignite and that burn relatively slowly, and to liquids having a flash point higher than $100^{\circ} \mathrm{F}$.

Any solid, liquid, or gaseous substance that burns, irritates, or destructively attacks organic tissues, particularly the skin or, when ingested, the lungs and stomach. Includes hydrochloric acid, hydrofluoric acid, nitric acid, sodium hydroxide, and sulfuric acid.

Colorless gas, pungent penetrating odor, burns with a purple-tinged flame. Soluble in water, alcohol, and ether. Uses include organic synthesis, welding and cutting metals, fumigant, and rocket propellant.

Colorless, volatile, mobile liquid; hygroscopic; aromatic odor; burning and sweet taste. Soluble in alcohol, chloroform, benzene, solvent naphtha, and oils; slightly soluble in water. Used in organic synthesis, as an industrial solvent, in analytical chemistry, or as in anesthetic or extractant.

A chemical compound that detonates as a result of shock or heat.

Any solid, liquid, vapor, or gas that will ignite easily and burn rapidly. Flammable solids are of several types:

(1) dusts or fine powders; (2) solids that ignite spontaneously at low temperatures; (3) solids in which internal heat is built up by microbial or other degradation activity; (4) films, fibers, and fabrics of low-ignition-point materials. The most common flammable gases are hydrogen, carbon monoxide, acetylene, and other hydrocarbon gases.

Trademark (DuPont) for series of fluorocarbon products used in refrigeration and air-conditioning equipment, including blowing agents, fire-extinguishing agents, and cleaning fluids and solvents. Clear, water-white liquids. Vapors have a mild, somewhat ethereal odor aniu are not irritating; essentlally stable and inert.
Fire hazard.

Burns, irritates, or destructively attacks organic tissues.

Flammable. Should be stored away from light and heat. $A$ very toxic material.

Extremely flammable, severe fire and explosion hazard when exposed to heat or flame. Forms explosive peroxides. Central-nervoussystem depressant via inhalation and skin absorption.

Detonation or deflagration.

Fire hazard. Flammable gases are extremely dangerous fire hazards and require precisely regulated storage conditions.

Flammable liquids and solids are defined by a flash point (temperature at which a liquid or volatile solid gives off a vapor sufficient to form an ignitable mixture with the air near its surface).

Environmental hazard. Nonflammable, nonexplosive, and noncorrosive. 


\section{CHEMICAL OR TERM

fuel

gas

hazardous material

hazardous waste

heavy metal

hexone

hydrocarbon
Any substance involving energy in a controlled chemical reaction. The most common type of chemical reaction is combustion, the type of oxidation occurring with petroleum products, natural gas, coal, and wood. More rapid oxidation takes place in rocket fuels (hydrogen, hydrogen peroxide, hydrazine) and approaches the rate of an explosion.

A state of matter characterized by very low density and viscosity (relative to liquids and solids); comparatively great expansion and contraction with changes in pressure and temperature; ability to diffuse readily into other gases; ability to occupy the whole of any container with almost complete uniformity. Gases may be either elemental (argon) or compounds (carbon dioxide); elemental gases may be monatomic (helium), diatomic (chlorine), or triatomic (ozone).

Any material or substance that, in normal use, can be damaging to human health and well-being. Such materials cover a broad range of types, which may be classified as follows: (1) poisons or toxic agents that are in any way harmful, ranging from poisons to skin irritants and allergens; (2) corrosive chemicals that destroy or otherwise damage the skin and mucous membranes on external contact or inhalation; (3) flammable materials, including (a) organic solvents, (b) finely divided metals or powders, (c) some classes of fibers, textiles, or plastics, and (d) chemicals that either evolve or absorb oxygen during storage, thus constituting a fire risk in contact with organic materials; (4) explosives and strong oxidizing agents; (5) materials in which dangerous heat buildup occurs on storage, either by oxidation or microbiological action; and (6) radioactive chemicals that emit ionizing radiation.

See chemical waste, radioactive waste.

A metal of atomic weight greater than sodium (e.g., aluminum, lead, cobalt).

See methyl isobutyl ketone.
Fire, explosion.

Gases are readily inhaled and are available for absorption through exposed skin.

Wide range of hazards as noted under Characteristics and Uses.
Various hazards depending on substances involved.

Most heavy metals are toxic.

Flammable; dangerous fire risk. Avoid ingestion and inhalation. Can be absorbed by skin.

Most are flammable/explosive. Some are carcinogenic or toxic.
An organic compound consisting exclusively of carbon and hydrogen. Derived principally from petroleum, coal tar, and vegetable sources. 


\section{CHEMICAL OR TERM \\ CHARACTERISTICS AND USES \\ POTENTIAL HAZARDS}

\section{hydrochloric acid}

hydrofluoric acid

hydrogen

hydrogen chloride

hydrogen fluoride

inorganic

isobutane
Hydrogen chloride in aqueous solution; colorless or slightly yellow, fuming, pungent liquid. Hydrochloric acid is a strong, highly corrosive acid. Soluble in water, alcohol, and benzene. Noncombustible. Uses include acidizing (activation) of petroleum wells, boiler scale removal, chemical intermediate, ore reduction, pickling and metal cleaning, industrial acidizing, general cleaning, alcohol denaturant, and laboratory reagent.

Hydrogen fluoride in aqueous solution. Colorless, fuming, mobile liquid; will attack glass and any silicon-containing material. Used in aluminum production, fluorocarbons, pickling stainless steel, etching glass, acidizing oil wells, fluorides, processing uranium.

Nonmetallic element (atomic number 1). A diatomic gas; very slightly soluble in water, alcohol, and ether. Noncorrosive. Uses include chemical production, reducing atmosphere to prevent oxidation, oxyhydrogen flame for high temperatures, atomic-hydrogen welding, instrumentcarrying balloons, production of high-purity metals, cryogenic research.

Colorless, fuming gas, with a suffocating odor, very soluble in water, soluble in alcohol and ether. Used in hydrochlorination, polymerization, isomerization, alkylation, and nitration reactions.

Colorless, fuming gas or liquid; very soluble in water. Uses include catalyst in alkylation, isomerization, condensation, dehydration, and polymerization reactions; fluorinating agent in organic and inorganic reactions; production of fluorine and aluminum fluoride; additive in liquid rocket propellants; refining of uranium.

Any chemical compound that does not contain the element carbon, with the exception of the oxides of carbon; compounds containing a carbonate group such as calcium carbonate, carbon disulfide, phosgene, carbonyl sulfide, and metallic carbonyl.

A liquefied petroleum gas. Colorless gas with slight odor; stable, does not react with water; has no corrosive action on metals. Soluble in water, slightly soluble in alcohol, and soluble in ether. Uses include organic synthesis, refrigerant, fuel, aerosol propellant, and instrument calibration fluid.
Highly toxic by ingestion and inhalation; strong irritant to eyes and skin.
Toxic by ingestion and inhalation; highly corrosive to skin and mucous membranes.

Highly flammable and explosive. Dangerous when exposed to heat or flame. Classed as an asphyxiant.

Nonflammable. Toxic by inhalation, strong irritant to eyes and skin.

Nonflammable. Toxic by ingestion and inhalation, strong irritant to eyes, skin, and mucous membranes.

Inorganic compounds range from those that are almost wholly inert (sand, clay, limestone) to highly active and corrosive materials (hydrofluoric acid).

Highly flammatle. Dangerous fire and explosion risk. 


\section{CHEMICAL OR TERM

lead

lithium

lithium beryllium
hydride

lithium carbonate

lithium chloride

lithium hydride

lithium hydroxide
Metallic element (atomic number 82). Heavy, ductile, soft, gray solid. Soluble in dilute nitric acid; insoluble in water, but dissolves slowly in water containing a weak acid; resists corrosion; relatively impenetrable to radiation. Poor electrical conductor; good sound and vibration absorber. Noncombustible. Used in storage batteries, process equipment, radiation shielding, cable covering, sheet and pipe, solder and fusible alloys, type metal, vibration damping in heavy construction, and foil.

Metallic element (atomic number 3). It is the lightest and least reactive of the alkali metals and the lightest solid element. Very soft silvery metal. Reacts exothermally with nitrogen in moist air at high temperatures. High electrical conductivity. Soluble in liquid ammonia. Used in production of tritium, scavenger and degasifier for stainless and mild steels in molten state, modular iron, soaps and greases; used as deoxidizer in copper and copper alloys. Catalyst and heat-transfer liquid.

Component in storage batteries (with sulfur, selenium, tellurium, and chlorine), rocket propellants, silver solders, and nuclear reactor coolant.

White crystalline mixed salt. Used for energy and nuclear studies.

White powder; slightly soluble in water and insoluble in alcohol; soluble in dilute acid. Uses include ceramics and porcelain glazes; pharmaceuticals; catalyst; other lithium compounds; coating of arc-welding electrodes; nucleonics; luminescent paints, varnishes, and dyes; glass ceramics; aluminum production.

White deliquescent crystals; very soluble in water, alcohols, ether, pyridine, and nitrobenzene. One of the most hygroscopic salts known. Uses include air conditioning, welding and soldering flux, dry batteries, heat-exchange media, salt baths, desiccant, production of lithium metals.

White, translucent, crystalline mass or powder. Decomposed by water, forming hydrogen and lithium hydroxide; insoluble in benzene and toluene; soluble in ether. Uses include desiccant, source of hydrogen, condensing agent in organic synthesis, preparation of lithium amide and double hydrides, nuclear shielding material.

Colorless crystals that are slightly soluble in alcohol; soluble in water; absorbs carbon dioxide and water from air. Uses include storage battery electrolyte, lubricating greases, and ceramics.
Toxic by ingestion or inhalation of dust or fumes. A cumulative poison.
Ignites in air near its melting point $\left(179^{\circ} \mathrm{C}\right)$. Dangerous fire and explosion risk when exposed to water, acids, or oxidizing agents. Lithium in solution is toxic to the central nervous system.
Fire risk when exposed to water, organic materials, and heat. Highly toxic.

Strong irritant in water solution.

Low toxicity; should not be ingested.

Flammable, dangerous fire risk; ignites spontaneously in moist air. Toxic.

Strong irritant in water solutions. 


\section{CHEMICAL OR TERM

lubricating oll

mercury

metal

methane

methyl isobutyl ketone (hexone)

nitric acid
A selected fraction of refined mineral oil used for lubrication of moving surfaces, usually metallic, ranging from small precision machinery (watches) to heavy equipment. Consistency ranges from thin liquids to grease-like substances. In contrast to lubricating greases, lubricating oils do not contain solids or fibrous materials.

Metallic element (atomic number 80 ). Silvery, extremely heavy liquid. Insoluble in hydrochloric acid; soluble in sulfuric acid upon boiling; readily soluble in nitric acid. Insoluble in water, alcohol, and ether. Uses include amalgams, catalysts, electrical apparatus, instruments (thermometers, barometers, etc.), mildew-proofing preparations, mercury vapor lamps, extractive metallurgy, arc lamps, coolant, and neutron absorber in nuclear power plants.

An element that forms positive ions when its compounds are in solution; metallic oxides from hydroxides rather than acids with water. About $75 \%$ of the elements are metals. Most are crystalline solids with metallic luster, conductors of electricity, and have rather high chemical reactivity; many are hard and strong. Most readily form solutions (alloys) with other metals. Geologically, metals usually occur in the form of compounds that must be physically or chemically processed to yield the pure metal.

Colorless, odorless, tasteless gas; lighter than air; practically inert toward sulfuric acid, nitric acid, alkalies, and salts; reacts with chlorine and bromine in light (explosive in direct sunlight). Soluble in alcohol and ether; slightly soluble in water. Used in the synthesis of chemicals; used as a fuel in the form of natural gas.

Colorless, stable liquid; pleasant odor. Slightly soluble in water; miscible with most organic solvents. Uses include solvent for paints, varnishes, nitrocellulose lacquers; manufacture of methyl amyl alcohol; extraction processes, including extraction of uranium from fission products; organic synthesis; denaturant for alcohol.

Transparent, colorless or yellowish, fuming, suffocating, hygroscopic, corrosive liquid. Will attack almost all metals. The yellow color is due to release of nitrogen dioxide on exposure to light. Strong oxidizing agent. Miscible with water; decomnoses in alcohol. Uses include manufacture of ammoniurr trate for explosives, organic synthesis (dyes, drugs, exp -ives, cellulose nitrate, nitrate salts), metallurgy, photoeny ing, etching steel, ore flotation, reagent, reprocessing $s_{r}$ it nuclear fuel.
Flammable/explosive in air at high temperatures.

Metallic mercury is highly toxic by skin absorption and inhalation of fumes or vapors; absorbed by respiratory and intestinal tract. All inorganic compounds of mercury are highly toxic by ingestion, inhalation, and skin absorption. Most organic compounds of mercury are highly toxic. Spillage may be a toxic hazard because of droplet proliferation. Cleanup requires special care.

Includes carcinogens (e.g. beryllium), toxics (e.g., heavy metals), and flammables (e.g., alkali metals).

Severe fire explosion hazard; forms explosive mixtures with air. Methane is an asphyxiant gas.

Flammable; dangerous fire risk. Avoid ingestion and inhalation. Can be absorbed by skin.

Dangerous fire risk in contact with organic materials. Highly toxic by inhalation. Corrosive to skin and mucous membranes. 


\section{CHEMICAL OR TERM

nitric oxide

nitrogen

oil

organic compound

oxidizing material

paint

pH
Colorless gas (readily reacts with oxygen at room temperature to form nitrogen dioxide, a reddish-brown gas), slightly soluble in water. Used as an intermediate in production of chemicals.

Gaseous element (atomic number 7). Colorless, odorless, tasteless, diatomic gas constituting approximately $80 \%$ of the air; colorless liquid, chemically unreactive; slightly soluble in water; slightly soluble in alcohol. Used in the production of chemicals; manufacture of explosives; inert gas for purging, blanketing, and electronic industries; pressurizing liquid propellants; cryogenic preservation; and source of pressure in oil wells.

Allied to a wide range of substances that are chemically different. Oils derived from animals or from plant seeds or nuts are chemically identical with fats. Petroleum (rock oil) is a hydrocarbon mixture comprising hundreds of chemical compounds. Petroleum-derived oils are used as lubricants (e.g., engine oil, machine oil, cutting oil).

Any substance that contains the element carbon, except carbon oxides and various carbonates. Some 700,000 organic substances have been identified.

Any compound that spontaneously evolves oxygen either at room temperature or under slight heating. Includes such chemicals as peroxides, chlorates, perchlorates, nitrates, and permanganates.

A uniformly dispersed mixture having a viscosity ranging from a thin liquid to a semisolid paste and consisting of a drying oil, synthetic resin, or other film-forming component, called the binder; a solvent or thinner; and an organic or inorganic pigment. Paints are used to protect a surface from corrosion, oxidation, or other type of deterioration, and to provide decorative effects.

$\mathrm{pH}$ is a value taken to represent the acidity or alkalinity of an aqueous solution. Pure water is the standard used in arriving at this value and has a $\mathrm{pH}$ of 7 (representing neutrality) on a scale of 0 to 14. As values decrease below 7 , they represent increasing acidity, and as values increase above 7 , they represent increasing alkalinity.
Supports combustion. Toxic by inhalation, strong irritant to skin and mucous membranes.

Noncombustible, an asphyxiant gas.

Petroleum and petroleumderived oils are flammable/ explosive in air at higher temperatures.

Organic compounds are typically combustible or flammable. Variety of hazards to living tissue depending on substarices involved.

Vigorous reactions at ambient temperatures when stored near or in contact with reducing materiais such as cellulosic and other organic compounds. Storage areas should be well ventilated and kept as cool as possible.

Flammable, dangerous fire risk (except for water-based paints). Toxic if vapors are inhaled over a long period.

Chemicals/compounds with $\mathrm{pH}$ values on extremes of scale are highly reactive/ corrosive. 


\section{CHEMICAL OR TERM

phosgene

phosphine

plutonium

poison

polychlorinated biphenyl (PCB)

potassium dichromate

propylene

pyrophoric
Liquid or easily liquefied gas; colorless of light yellow; odor varies from strong and stifling when concentrated to haylike in dilute form; slightly soluble in water and slowly hydrolyzed by it; soluble in benzene and toluene. Used in organic synthesis, pesticides, and herbicides.

Colorless gas, disagreeable, garlic-like odor. Soluble in alcohol, ether, and cuprous chloride solution; slightly soluble in cold water; insoluble in hot water. Uses include organic preparations, phosphonium halides, doping agent for n-type semiconductors, polymerization initiator, condensation catalyst.

Synthetic radioactive metallic element (atomic number 94). Plutonium is readily fissionable with both slow and fast neutrons and can be used for either nuclear weapons or electric power production.

Any substance that is harmful to living tissues when applied in relatively small doses. Effective dosage depends on (1) quantity or concentration, (2) duration of exposure, (3) particle size or physical state of the substance, (4) affinity for living tissue, (5) solubility in tissue fluids, and (6) sensitivity of the tissues or organs.

One of several aromatic compounds containing two benzene nuclei with two or more substituent chlorine atoms. Colorless liquid. Chief use is in heat-exchange and insulating fluids in closed systems.

Bright, yellowish-red, transparent crystals; bitter, metallic taste. Soluble in water; insoluble in alcohol. Used as oxidizing agent (chemicals, dyes, intermediates) and analytical reagent. Also used for brass pickling compositions, electroplating, explosives, pyrotechnics, safety matches, textiles, dyeing and printing, glass, chrome glues and adhesives, process engraving and lithography, alloys, ceramic products, depolarizer in dry cell batteries.

Colorless gas; soluble in alcohol and ether; slightly soluble in water. Used in chemical synthesis.

Any liquid or solid that will ignite in air at about $130^{\circ} \mathrm{F}$. Sodium and lithium hydride are spontaneously flammable in moist air because they react exothermically with water. Must be stored in an atmosphere of inert gas or under kerosene.
Very toxic via inhalation, strong irritant to eyes.

Spontaneously flammable. Toxic by inhalation, strong irritant.

The most radiotoxic of the elements and one of the most toxic substances known. Dangerous ionizing radiation persists indefinitely. A powerful carcinogen. Must be handled by remote control and with adequate shielding.

Poisons can be dangerous to life or strongly irritating. Hazardous either by contact with the body (skin absorption) or by ingestion.

Highly toxic. Persistent ecological hazard. (Because of persistence, toxicity, and ecological damage via water pollution, the manufacture of PCBs was discontinued in the United States in 1976.)

Toxic by ingestion and inhalation. Dangerous fire risk in contact with organic materials. Strong oxidizing agent.

Highly flammable. Dangerous fire risk. An asphyxiant gas.

Dangerous fire risk near combustible materials. 


\section{CHEMICAL OR TERM

radioactive waste

sodium hydroxide

(caustic soda)

sodium hypochlorite

sodium-potassium alloy (NaK)

solvent

sulfur

sulfur dioxide
Waste containing radioisotopes and spent nuclear reactor fuel. Such wastes may remain radioactive for thousands of years and can constitute a long-term hazard. Safe disposal techniques are being studied intensively.

White deliquescent solid; occurs chiefly in form of beads or pellets, or as $50 \%$ and $73 \%$ aqueous solutions. Absorbs water and carbon dioxide from the air. Soluble in water, alcohol, and glycerol. Uses include chemical manufacturing, regenerating ion exchange resins, organic fusions, laboratory reagent, etching, and electroplating.

Strong oxidizing agent, usually stored and used in solution; disagreeable, sweetish odor and pale greenish color. Soluble in cold water; decomposed by hot water. Uses include water purification, intermediate, organic chemicals, medicine, fungicides, swimming pools, household bleach, laundering, and reagent.

Soft, silvery solid or liquid; must be kept away from air and moisture. The liquid forms come under the class name potassium or sodium; metallic liquid alloy. Uses include heat exchange fluid, electric conductor, organic synthesis, and catalysis. Legal label name for NaK.

A substance capable of dissolving another substance (solute) to form a uniformly dispersed mixture (solution). Water is the most common of all solvents. Aromatic hydrocarbons have higher solvent power than aliphatics (alcohols). Other organic solvent groups are esters, ethers, ketones, amines, and nitrated and chlorinated hydrocarbons. Uses include coatings (paints, varnishes, and lacquers), industrial cleaners, printing inks, extractive processes, and pharmaceuticals.

Nonmetallic element (atomic number 16). Insoluble in water; slightly soluble in alcohol and ether; soluble in carbon disulfide, carbon tetrachloride, and benzene. Used in production of chemicals, explosives, cement sealant, and binder and asphalt extender in road paving.

Colorless gas or liquid with sharp, pungent odor. Soluble in water, alcohol, and ether. An outstanding oxidizing and reducing agent. Noncombustible. Uses include chemicals (sulfuric acid, sulfites, hydrosulfites of potassium and sodium, thiosulfates, alum from shale, and recovery of volatile substances), ore and metal refining, intermediates, solvent extraction of lubricating oils, disinfecting, reducing agent, and antioxidant.
Radiation hazard.

Corrosive to tissue in presence of moisture. Strong irritant to tissue (eyes, skin, mucous membranes).

Fire risk in contact with organic materials. Toxic by ingestion; strong irritant to tissue.

Ignites in air; explodes in presence of moisture, oxygen, halogens, and acids. Store under kerosene.

Many solvents are flammable and toxic to varying degrees. Contribute to air pollution and fire hazards.

Combustible. Fire and explosion risk in finely divided form.

Toxic by inhalation. Strong irritant to eyes and mucous membranes, especially under pressure. Dangerous air contaminant and constituent of smog. 


\section{CHEMICAL OR TERM \\ CHARACTERISTICS AND USES \\ POTENTIAL HAZARDS}

sulfuric acid

thorium

toxicity

toxic substances

tributyl phosphate
Strongly corrosive, dense, oily liquid; colorless to dark brown depending on purity. Miscible with water. Very reactive, dissolves most metals; concentrated acid oxidizes, dehydrates, or sulfonates most organic compounds, often causes charring. Uses include chemicals, dyes and pigments, etchant, alkylation catalyst, electroplating baths, industrial explosives, laboratory reagent, and nonferrous metallurgy.

Metallic element (atomic number 90); a member of the actinide series. Soft metal with bright silvery luster when freshly cut; similar to lead in hardness when pure. Can be cold-rolled, extruded, or drawn and welded. Soluble in acids; insoluble in alkalies and water. Some alloys may ignite spontaneously; not flammable in massive form. Uses include nuclear fuel, sun lamps, photoelectric cells, target in $\mathrm{x}$-ray tubes, and alloys.

The ability of a substance to cause damage to living tissue; impairment of the central nervous system; severe illness or (in extreme cases) death when ingested, inhaled, or absorbed by the skin. Amounts required to produce these results vary widely with the nature of the substances and the time of exposure.

Chemicals that are generally regarded as having toxic properties by either ingestion, inhalation, or absorption via the skin. Considerable variation in the degree of toxicity among these substances, which include individual chemicals such as asbestos (carcinogen); carbon monoxide, chlorine, hydrogen peroxide, hydrogen sulfide, methanol, sulfur dioxide; and groups of chemicals such as aldehydes, alkaloids, arsenic, beryllium, chlorinated hydrocarbons, chromium (hexavalent carcinogenic compounds), corrosive materials, cyanides, fluorine compounds, lead compounds, mercury, radioactive substances, selenium, and thallium.

Stable, colorless, odorless liquid. Miscible with most solvents and diluents. Soluble in water. Uses include heat-exchange; solvent extraction of metal ions from solution of reactor products; solvent for nitrocellulose, cellulose acetate; plasticizer; pigment-grinding assistant; antifoam agent; dielectric.
Highly toxic. Strong irritant to tissue.

Flammable and explosive in powder form. Dusts of thorium have very low ignition points and may ignite at room temperature. Radioactive decay isotopes are dangerous when ingested.

The toxicity hazard of a material depends on its physical state and on its solubility in water and acids. Some metals that are harmless in solid or bulk form are quite toxic as fumes, powder, or dust.

Cause damage to living tissue (see toxicity.)

Combustible. Toxic by ingestion and inhalation. Irritant to skin. 


\section{CHEMICAL OR TERM \\ CHARACTERISTICS AND USES \\ POTENTIAL HAZARDS}

Metallic element (atomic number 92); a member of the actinide series. Dense, silvery solid; strongly electropositive; ductile and malleable; poor conductor of electricity. Forms solid solutions (for nuclear reactors) with molybdenum, niobium, titanium, and zirconium. Reacts with nearly all nonmetals. Attacked by water, acids and peroxides; inert toward alkalies. Green tetravalent uranium and yellow uranyl ion are the only species that are stable in solution. Source of fissionable isotope uranium-235; source of plutonium by neutron capture; electric power generation. Depleted uranium is uranium metal from which most uranium-235 has been removed (below $0.7 \%$ as found in normal uranium).

uranium hexafluoride
Colorless, volatile crystals; sublimes; soluble in liquid bromine, chlorine, symtetrachloroethane, carbon tetrachloride, and fluorocarbons. Reacts vigorously with water, alcohol, ether, and most metals. Vapor behaves as nearly perfect gas. Used in gaseous diffusion process for separating isotopes of uranium.
Powder is a dangerous fire risk; ignites spontaneously in air. Highly toxic radioactive material. Source of ionizing radiation.

Highly corrosive. Radiation risk.

Note: Information provided in Hawley's Condensed Chemical Dictionary (12th ed., 1993), revised by Richard J. Lewis, Sr., was used to prepare this table. 

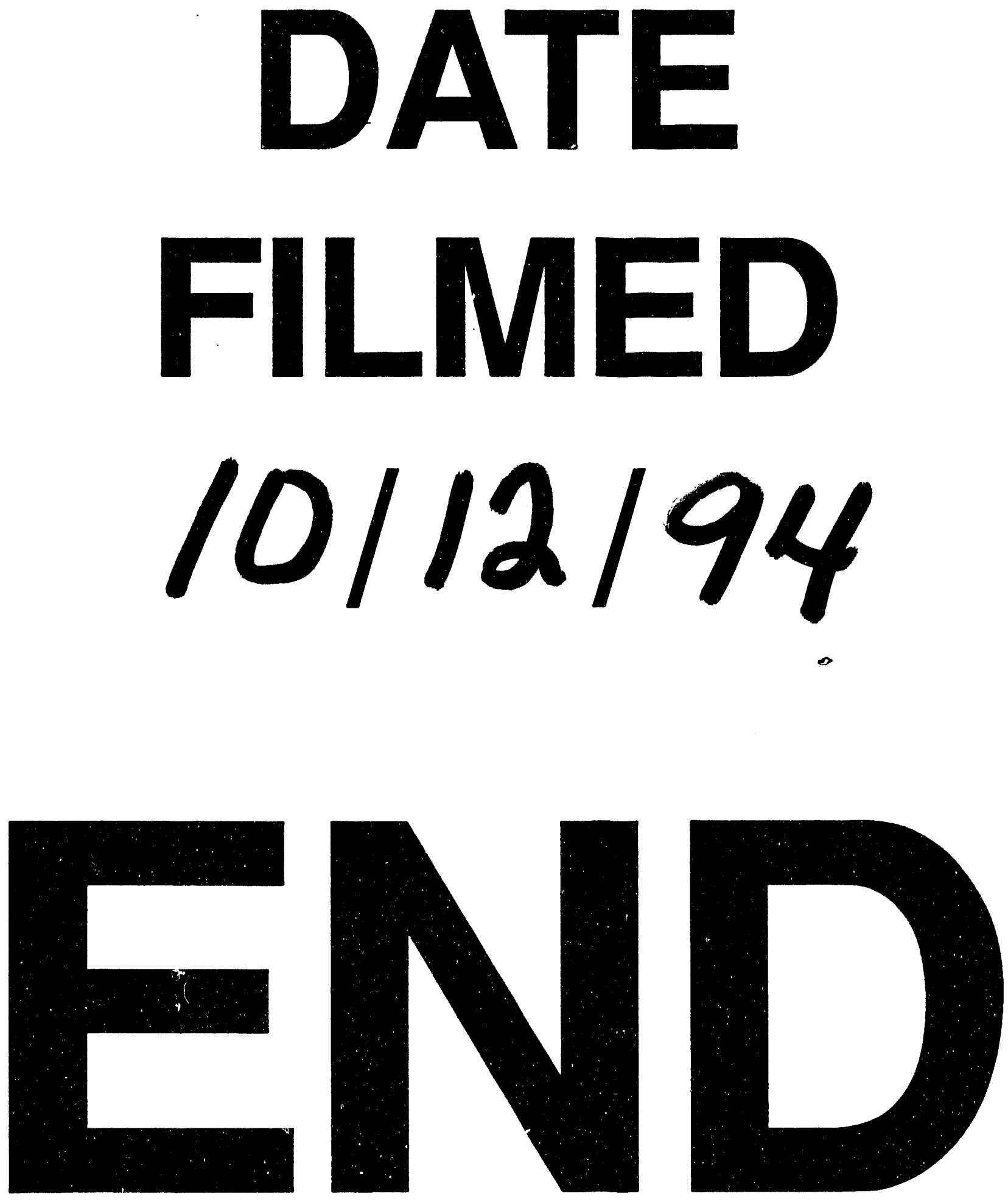
